MIRELLA GUALTIERI

\author{
VISÃO DE CORES E \\ SENSIBILIDADE AO \\ CONTRASTE EM INDIVÍDUOS \\ COM DIABETE MELITO: \\ AVALIAÇÃO PSICOFÍSICA E \\ ELETROFISIOLÓGICA
}

São Paulo

2004 
MIRELLA GUALTIERI

\section{VISÃO DE CORES E SENSIBILIDADE AO CONTRASTE EM INDIVÍDUOS COM \\ DIABETE MELITO: AVALIAÇÃO \\ PSICOFÍSICA E ELETROFISIOLÓGICA}

Dissertação apresentada ao Instituto de Psicologia da Universidade de São Paulo como parte das exigências para a obtenção do título de Mestre em Psicologia. Área de concentração Neurociências e Comportamento.

Orientadora: Profa. Dra. Dora Fix Ventura

São Paulo

2004 
Ficha Catalográfica preparada pelo Serviço de Biblioteca

e Documentação do Instituto de Psicologia da USP

Gualtieri, M.

Visão de cores e sensibilidade ao contraste em indivíduos com diabete melito: avaliação psicofísica e eletrofisiológica./ Mirella Gualtieri. - São Paulo: s.n., 2004. - 153p.

Dissertação (mestrado) - Instituto de Psicologia da Universidade de São Paulo. Núcleo de Pesquisa em Neurociências e Comportamento.

Orientadora: Dora Selma Fix Ventura.

1. Percepção de cor 2. Sensibilidade ao contraste 3. Eletrorretinograma 4. Diabete melito 5. Psicofísica 6. Eletrofisiologia 7. Visão I. Título. 
MIRELLA GUALTIERI

\begin{abstract}
VISAO DE CORES E SENSIBILIDADE AO CONTRASTE EM INDIVÍDUOS COM

DIABETE MELITO: AVALIAÇÃO

PSICOFÍSICA E ELETROFISIOLÓGICA
\end{abstract}

Banca examinadora:

Profa. Dra. Dora Selma Fix Ventura

Prof. Dr. Luiz Carlos de Lima Silveira

Prof. Dr. Marcus Vinícius Chrysóstomo Baldo

Dissertação defendida e aprovada em: 
A minha mãe Lourdes. Meus melhores exemplos de inteligência, honestidade e abnegação. 
A verdade definitiva é o seu compromisso com o conhecimento.

Jules-Henri Poincaré (1854 - 1912). 


\section{AGRADECIMENTOS}

À minha família e especialmente meus pais Chrisósotomo e Lourdes, meu irmão Neto e minha tia Maria, com quem sempre pude contar, feliz e inadvertidamente.

À Dora, por tudo que me ensinou e pela dedicação carinhosa.

Ao professor Luiz Carlos, cuja dedicação à ciência é minha maior inspiração.

Ao professor John Manuel de Souza, por todos os auxílios.

Ao Dr. Mauro Nishi e ao Dr. Marcos Lago, pelo encaminhamento dos pacientes e por todas as discussões.

À professora Adriana Berezovisky pelas sugestões e discussão.

Ao Claudiel pelo auxílio nos momentos críticos.

À amiga Soninha, pelos momentos de confissão e pela companhia, mesmo que remota.

Ao Fernando pelos cafés e pela consultoria de editoração.

A todos do laboratório de São Paulo e de Belém: Daniela, Malu, Cézar, André, Anderson, Ana Luiza, Ana Laura, Claudia, Cristiane, Elaine, Izabel, Marcelo, Sandra e Trulha.

À FAPESP que financiou este trabalho. 


\section{RESUMO}

\section{Gualtieri, M. Visão de cores e sensibilidade ao contraste em indivíduos com diabete melito: avaliação psicofísica e eletrofisiológica. São Paulo, 2004. 141 p. Dissertação (Mestrado). Instituto de Psicologia. Universidade de São Paulo.}

Mesmo antes do estabelecimento de retinopatia detectável no exame clinico, a visão de cores e a sensibilidade ao contraste podem estar afetadas (Dean e cols., 1997; Kurtenbach e cols., 1999). Os déficits sensoriais têm sido atribuídos a alterações vasculares e da função de fotorreceptores (Greenstein e cols., 2000; Lieth e cols., 2000). Contudo, poucas conclusões acerca dos mecanismos fisiopatológicos têm sido obtidas.

Este trabalho teve por objetivo identificar - em pacientes diabéticos tipo 2 com fundo de olho normal - possíveis alterações na visão de cores e sensibilidade ao contraste cromático e acromático e correlacionar os prejuízos sensoriais com a função eletrofisiológica da retina. A avaliação sensorial foi feita utilizando o Teste de Cores de Cambridge e o teste de sensibilidade ao contraste Psycho (Ventura e cols., 2003a, Ventura e cols., no prelo) e a função eletrofisiológica foi avaliada usando o eletrorretinograma de campo total (ERG).

Os resultados dos pacientes diabéticos $(n=40$; idade $=56$ anos \pm 9 e tempo de diabetes $=7$ anos \pm 9 ) foram comparados aos de grupos equiparado por idade.

O limiar de discriminação de cores no eixo protan foi superior ao limite normal em $50 \%$ dos pacientes, no eixo deutan em $37 \%$ e tritan em $28 \%$. A sensibilidade ao contraste cromático nos eixo vermelho/verde e azul/amarelo dos pacientes entre as freqüências espaciais de 0,2 a $2 \mathrm{cpg}$ foi em média $10 \mathrm{~dB}$ menor que a dos pacientes, enquanto que na função de sensibilidade ao contraste acromático entre as freqüências espaciais de 0,3 a $20 \mathrm{cpg}$, a sensibilidade dos pacientes foi apenas $6 \mathrm{~dB}$ menor que a dos controles. No ERG, os componentes mais alterados foram os relacionados à atividade da retina interna. A amplitude da onda-b na resposta de bastonetes e dos potenciais oscilatórios foi inferior aos limites normais para $24 \%$ e $39 \%$ dos pacientes, respectivamente, e as latências correspondentes foram mais lentas em $45 \%$ e $76 \%$ dos pacientes.

A perda da discriminação de cores dos pacientes teve padrão difuso; contrariando relatos anteriores de que a diabete provoca defeito da visão de cores no eixo tritan. Os resultados de sensibilidade ao contraste mostraram que o processamento cromático foi claramente mais afetado que os sistemas relacionados ao processamento acromático. Os dados do ERG indicaram haver alteração da atividade da retina interna. Estes achados confirmam e ampliam dados anteriores e sua aplicação clínica pode mudar o conceito de retinopatia diabética.

Palavras-chave: visão de cores, sensibilidade ao contraste, eletrorretinograma, diabete melito, psicofísica visual, eletrofisiologia. 


\begin{abstract}
Gualtieri, M. Color vision and contrast sensitivity in subjects with diabetes mellitus: psychophysical and electrophysiological evaluation. São Paulo, 2004. 141 p. Master's Dissertation. Instituto de Psicologia. Universidade de São Paulo.
\end{abstract}

Before the establishment of retinopathy detectable in the ophthalmologic examination, color vision and contrast sensitivity may be altered in diabetic patients. (Dean e cols., 1997; Kurtenbach e cols., 1999). The sensory deficits have been attributed to vascular alterations and to (Greenstein e cols., 2000; Lieth e cols., 2000). However, there are no definite conclusions about the pathological mechanisms involved in the vision losses. The objective of this work was to identify in patients with type 2 diabetes and normal fundus, possible alterations in color vision and chromatic and achromatic contrast sensitivity, and to correlate the sensory losses with the electrophysiological function of the retina. The psychophysical evaluation was made using the computerized Cambridge Colour Test and PSYCHO contrast sensitivity test. (Ventura e cols., 2003a, Ventura e cols., in press). Electrophysiological function was assessed using the full field electroretinogram (ERG).

Patient's results $(n=40$; age $=56$ years \pm 9 time of diabetes $=7$ years \pm 9$)$ with results obtained with age-matched controls.

The color discrimination threshold was higher than the normal limit in $50 \%$ of the patients in the protan axis, in $37 \%$ in the deutan axis and in $28 \%$ in the tritan axis. Chromatic contrast sensitivity in both the red/green and the blueyellow axes showed a loss of about $10 \mathrm{~dB}$ in patients as compared to controls throughout the frequencies tested $(0.2$ to $2 \mathrm{cpd})$. In the achromatic contrast sensitivity function the loss found in patients was smaller, of about $6 \mathrm{~dB}$ throughout the frequency range tested (3 to $20 \mathrm{cpd}$ ). In the ERG b-wave and in the oscillatory potentials the amplitudes were smaller, respectively, in $24 \%$ and $39 \%$ of the patients compared to controls. The corresponding latencies were longer in $45 \%$ and $76 \%$ of the patients.

The pattern of color discrimination losses of the patients indicates that there is a diffuse loss of color vision, as opposed to most previous results indicating that tritan losses. The contrast sensitivity results showed that the chromatic pathways were more affected than the achromatic pathways. The alterations found in the full field ERG are suggestive of inner retina losses. The present findings confirm and extend previous reports. Their clinical application may change the concept of diabetic retinopathy.

Key words: color vision, contrast sensitivity, electroretinogram, diabetes mellitus, visual psychophysics, electrophysiology. 


\section{ÍNDICE}

Ficha Catalográfica preparada pelo Serviço de Biblioteca .................................... 3

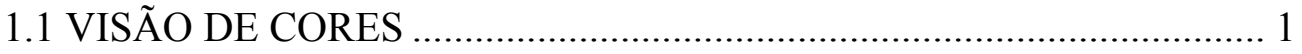

1.1.2. REPRESENTAÇÃO GRÁFICA DAS CORES NO DIAGRAMA DE

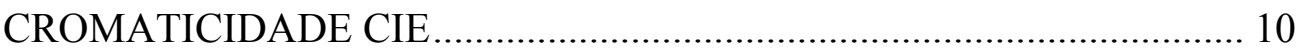

1.1.3. ALTERAÇÕES NA VISÃO DE CORES .......................................... 14

1.1.4. AVALIAÇÃO DA VISÃO DE CORES ............................................ 21

1.1.4.a. Métodos psicofísicos de avaliação da visão de cores................... 22

1.1.4.b. Métodos eletrofisiológicos ....................................................... 28

1.2. SENSIBILIDADE AO CONTRASTE ............................................... 35

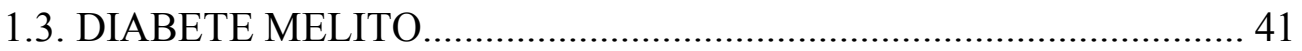

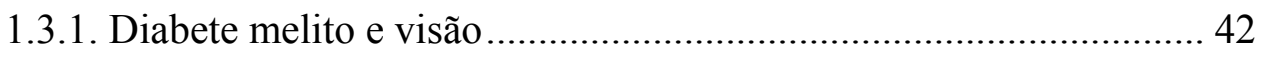

1.3.2 Visão de cores, sensibilidade a contrastes e ERG na presença de

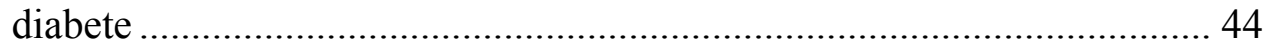

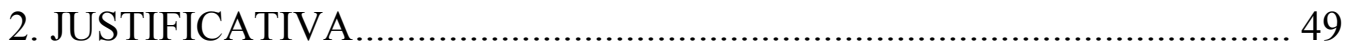

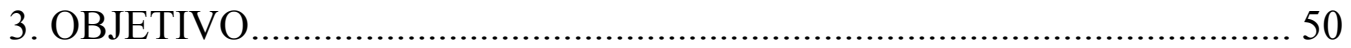

4. METODOLOGIA …............................................................................... 51

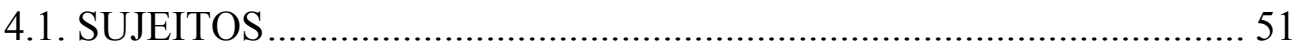

4.2. CAMBRIDGE COLOUR VISION TEST (CCT) …............................ 54

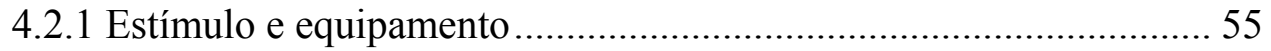

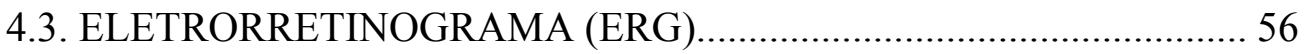

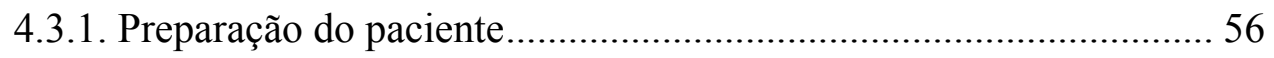

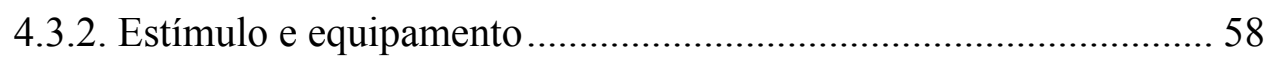

4.3.3. Condições de registro e análise de resultados ................................. 60 
4.4.1. Estímulo 62

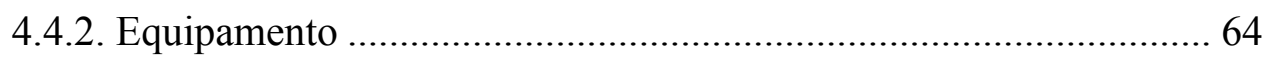

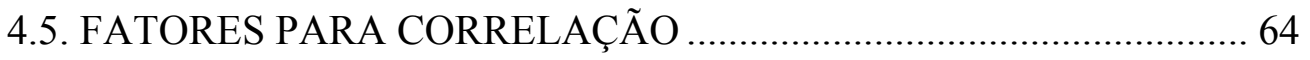

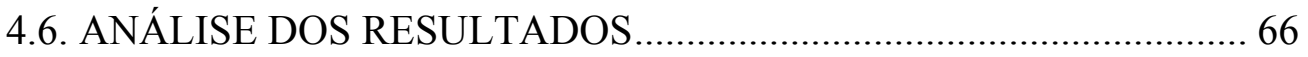

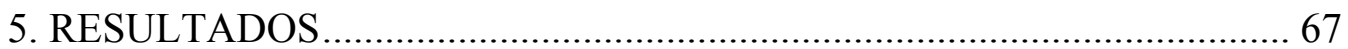

5.1. CAMBRIDGE COLOUR VISION TEST - CCT …............................... 67

5.2. ELETRORRETINOGRAMA - ERG …............................................. 80

5.3. SENSIBILIDADE AO CONTRASTE …............................................ 92

6. DISCUSSÂO …................................................................................. 102

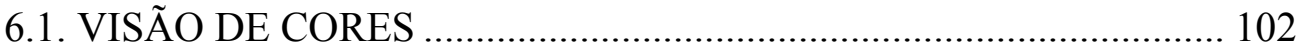

6.2. SENSIBILIDADE AO CONTRASTE ................................................ 104

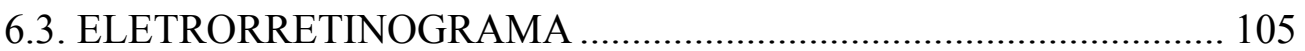

6.4. MECANISMOS ENVOLVIDOS …................................................... 107

6.5. SENSIBILIDADE DOS TESTES …................................................. 110

REFERÊNCIAS BIBLIOGRÁFICAS ........................................................ 114

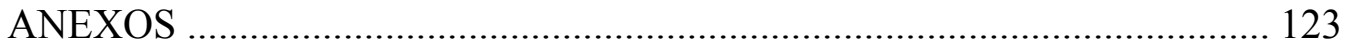




\section{ÍNDICE DE FIGURAS}

Figura 1: Curvas de absorção espectral dos fotopigmentos dos cones S. M e L (curvas azul, verde e vermelha) e de bastonetes (linha pontilhada) medidas eletrofisiológicamente. Dados de Bowmaker e Dartnall, 1980...................... 4

Figura 2: Curvas de sensibilidade espectral dos cones medidas por métodos psicofísicos. Dados de DeMarco e cols., 1992. 5

Figura 3: Exemplo de um campo receptivo de célula ganglionar com oponência cromática. (Figura de Bear, Connors e Paradiso, 2002) .....

Figura 4: Esquema ilustrativo das conexões que dão origem às vias de processamento paralelo. Os fotorreceptores fazem conexões especificas com vários tipos de células bipolares e horizontais. Na retina interna, os sinais das bipolares são transmitidos a diferentes tipos de células ganglionares. (Lee, 2004).

Figura 5: Exemplo de uma função de equiparação de cor (CMF) de um observador padrão.

Figura 6: Diagrama de cromaticidade CIE de 1931 ou CIExy.

Figura 7: Disposição dos eixos de confusão protan dentro do diagrama de cores

CIE xy. (http://webvision.med.utah.edu).

Figura 8: Disposição dos eixos de confusão deutan dentro do diagrama de cores

CIE xy. (http://webvision.med.utah.edu). 16

Figura 9: Disposição dos eixos de confusão tritan dentro do diagrama de cores

CIE xy. (http://webvision.med.utah.edu). 16

Figura 10: Exemplo do estímulo apresentado no teste de discriminação cromática Cambridge Colour Test. 24 
Figura 11: Exemplo da situação inicial do teste, quando vetores partem de um ponto de origem para as diferentes direções do diagrama em que o limiar de discriminação será estabelecido.

Figura 12: Exemplo de uma elipse obtida ao final do teste. A área desta elipse dentro do espaço de cores corresponde às cores que o sujeito não é capaz de discriminar.

Figura 13:Exemplo de um resultado final normal mostrando a disposição de cada elipse dentro do espaço de cores. A área da elipse corresponde às cores que o sujeito não é capaz de discriminar. No diagrama à direita estão as elipses em aumento e os respectivos números usados para a identificação de cada elipse.

Figura 14: Exemplo de um registro da resposta de bastonetes. 30

Figura 15: Exemplo de um registro da resposta escotópica máxima. 31

Figura 16: Exemplo de um registro de potenciais oscilatórios. 32

Figura 17: Exemplo de um registro da resposta de cones. 32

Figura 18: Exemplo de um registro normal de flicker $30 \mathrm{~Hz}$. 33

Figura 19: Freqüência espacial de uma onda senoidal. Figura de Schwartz, 2004.

Figura 20: Nível de contraste de uma onda senoidal determinado pela amplitude da variação de luminäncia. Figura de Schwartz, 2004. 37

Figura 21: Exemplo de uma curva de sensibilidade ao contraste de luminância linha branca tracejada - em função da freqüência espacial do estímulo ilustrada pelas barras verticais ao fundo. 39

Figura 22: Mecanismo de inibição lateral reduzindo a sensibilidade a estímulos com freqüência espacial baixa. Figura de Schwartz, 2004. 40 
Figura 23: Simulação da situação de teste com sujeito posicionado a frente do monitor segurando a caixa de respostas.

Figura 24: Um exemplo do estímulo usado no teste CCT e suas dimensões em graus de ângulo visual.

Figura 25: Posicionamento do eletrodo de registro, à esquerda, e do paciente diante da cúpula de estimulação, à direita. 57

Figura 26: ERG - representação das medidas extraídas de um registro eletrorretinográfico. "a" representa a amplitude da onda $a ; b=$ amplitude da onda $\mathrm{b} ; \mathrm{La}=$ latência da onda $\mathrm{a} \mathrm{e} \mathrm{b}=$ latência da onda $\mathrm{b}$.

Figura 27: Redes senoidais com modulação espacial da luminância para uma onda acromática (acima) e ondas cromáticas no eixo vermelho/verde (abaixo)... 63

Figura 28: Disposição das coordenadas de cromaticidade dos estímulos usados nos testes de sensibilidade ao contraste de cor e de fotometria por flicker heterocromático. 64

Figura 29: CCT - Teste trivector. Limiar de pacientes e controles nos eixos protan, deutan e tritan. 68

Figura 30: CCT-Teste trivector. Resultados individuais de limiar para o grupo de pacientes diabéticos para os eixos protan, deutan e tritan. A faixa na área do gráfico indica o limite de normalidade para este resultado. 70

Figura 31: CCT - Teste das elipses. Média das elipses de discriminação dos pacientes diabéticos dispostas no diagrama de cores CIE u'v'.... 71

Figura 32: CCT - Teste das elipses. Média das elipses de discriminação dos sujeitos controle dispostas no diagrama de cores CIE u'v' 72

Figura 33: CCT - Teste das elipses. Desempenho de pacientes e controles para o parâmetro de área. 74 
Figura 34: CCT -Teste das elipses. Freqüência da distribuição dos ângulos de cada elipse para diabéticos e controles. $\mathrm{Na}$ abscissa de cada gráfico estão os valores de ângulos enquanto na ordenada estão os números de indivíduos.. 77

Figura 35: ERG - Exemplos de resposta de pacientes diabéticos obtidas nos cinco registros do exame. À esquerda estão as respostas normais e à direita, as respostas alteradas. 81

Figura 36: ERG - Resultados de amplitude e latência de pacientes e controles. $\mathrm{Na}$ resposta escotópica máxima está representada a amplitude da relação b/a; nos potenciais oscilatórios a amplitude corresponde à soma dos picos $\mathrm{O} 1$ a $\mathrm{O} 4$; nos demais registros estão representadas as amplitudes pico-a-pico. Os valores de latência são os da onda b de cada registro; para os potenciais oscilatórios foi considerada a latência do $\mathrm{O} 1$ 83

Figura 37: Esquema de representação das respostas do ERG 85

Figura 38: ERG - Resposta de bastonetes. Resultados individuais de amplitude e latência da onda $b$ dos pacientes. As linhas horizontal e vertical indicam, respectivamente, os limites de normalidade para os parâmetros de amplitude e latência. 86

Figura 39: ERG - Resposta escotópica máxima. Resultados individuais de amplitude e latência da onda $b$ dos pacientes. As linhas horizontal e vertical indicam, respectivamente, os limites de normalidade para os parâmetros de amplitude e latência.

Figura 40: ERG - Potenciais Oscilatórios. Resultados individuais para a soma das amplitudes de $\mathrm{O} 1$ a $\mathrm{O} 4$ versus a latência de $\mathrm{O} 1$ dos pacientes. As linhas horizontal e vertical indicam, respectivamente, os limites de normalidade para os parâmetros de amplitude e latência. 88 
Figura 41: ERG - Resposta fotópica de cones.- Resultados individuais de amplitude versus latência da onda $b$ dos pacientes. As linhas horizontal e vertical indicam, respectivamente, os limites de normalidade para amplitude e latência.

Figura 42: ERG - Flicker 30Hz.- Resultados individuais de amplitude versus latência da onda $b$ dos pacientes. As linhas horizontal e vertical indicam, respectivamente, os limites de normalidade para amplitude e latência. 90

Figura 43: Sensibilidade ao contraste vermelho/verde. Curvas determinadas pelos valores médios de pacientes e controles. As barras verticais representam \pm 0 erro padrão da média de cada grupo. 93

Figura 44: Sensibilidade ao contraste amarelo. Curvas determinadas pelos valores médios de pacientes e controles. As barras verticais representam \pm 0 erro padrão da média de cada grupo.

Figura 45: Sensibilidade ao contraste de luminância. Curvas determinadas pelos valores médios de pacientes e controles. As barras verticais representam \pm 0 erro padrão da média de cada grupo. 95

Figura 46: Sensibilidade ao contraste vermelho/verde. Dados individuais do grupo de pacientes. 96

Figura 47: Sensibilidade ao contraste azul/amarelo. Dados individuais do grupo de pacientes 97

Figura 48: Sensibilidade ao contraste azul/amarelo. Dados individuais do grupo de pacientes 98

Figura 49: Sensibilidade ao contraste vermelho/verde. Diferença em dB entre as respostas médias de pacientes e controles. 99 
Figura 50: Sensibilidade ao contraste azul/amarelo. Diferença em dB entre as respostas médias de pacientes e controles.. 100

Figura 51: Sensibilidade ao contraste de luminância. Diferença em dB entre as respostas médias de pacientes e controles. 101

Figura 52: Esquema de algumas possíveis vias envolvidas nos déficit funcional e sensorial. 110

Figura 53: Quantidade de respostas alteradas em cada teste. 111 


\section{ÍNDICE DE TABELAS}

Tabela 1: Causas de discromatopsias adquiridas e o tipo de defeito estabelecido.21

Tabela 2: Valores normais para os registros do ERG de campo total, segundo diferentes autores

Tabela 3: Visão de cores, sensibilidade ao contraste e eletrorretinograma em pacientes diabéticos. Trabalhos relacionados. 46

Tabela 4: Tabela descritiva dos pacientes do grupo experimental 52

Tabela 5: Condições de Estimulação para o ERG de Campo Total segundo protocolo da ISCEV

Tabela 6: Correlação entre os resultados do CCT e o tempo de diagnóstico, a glicose no dia do teste e a $\% \mathrm{HbA}$ 79

Tabela 7: ERG - Resultados da comparação entre diabéticos e controles para os parâmetros de amplitude e latência (valores do nível significância $p$ do teste de hipótese). 84

Tabela 8: Correlação entre os resultados do ERG e o tempo de diagnóstico de diabete, a glicemia no dia do teste e a $\%$ de $\mathrm{HbA}$. 91

Tabela 9: Resultado da comparação entre os testes de sensibilidade ao contrate de pacientes e controles (valores de significância no teste Kruskal-Wallis).... 92 


\section{INTRODUÇÃO}

\subsection{VISÃO DE CORES}

A cor não é uma propriedade inerente aos objetos; é sim o resultado perceptual de um dos efeitos sensoriais da luz sobre o sistema visual.

A função adaptativa da visão de cores para uma grande quantidade de espécies é evidente. Embora não se possa inferir como é a visão de cores em todos os animais, uma vez que os processamentos perceptuais da informação que seu sistema visual é capaz de captar são desconhecidos, existem vários sinais que indicam a existência de algum tipo de discriminação de cores.

A discriminação de cores tem papel fundamental no auxílio para a busca de alimentos - distinção entre frutos verdes e maduros ou folhagens tenras ou secas. A cor também pode funcionar como um sinalizador de perigo. Freqüentemente, animais com venenos poderosos apresentam padrões de cores característicos que são identificados de alguma forma pelos outros animais e “entendidos" como sinal de perigo (Summers, Cronin e Kennedy, 2003).

A função da visão de cores, bem como os processos e estruturas anatômicas envolvidos variam entre as espécies. Sendo assim, as informações a seguir referem-se apenas à visão de cores humana.

A faixa visível do espectro eletromagnético está entre aproximadamente 370 e 740 nanômetros (nm). As cores percebidas nessa faixa variam do violeta na porção de comprimentos de onda curtos até o vermelho na porção com comprimentos de onda longos. 
A absorção de luz pelos fotorreceptores da retina é o passo inicial do processo que leva à percepção visual. Existem dois tipos de fotorreceptores: bastonetes (que respondem pela visão noturna ou escotópica e, portanto, têm pouca participação na discriminação de cores) e cones (ativados por luz com intensidade mais elevada que a faixa que ativa os bastonetes, respondendo, desta forma, pela visão diurna ou fotópica e deles pela visão de cores). Há indícios de que os bastonetes também colaborem, apesar de em menor grau, para a visão de cor (Knight e Buck, 2002; Reitner, Sharpe e Zrenner, 1991).

Na retina humana normal existem três tipos de cones. Os cones são células especializadas, que contém pigmentos fotossensíveis localizados em uma estrutura composta por vários discos membranosos - o segmento externo. Os discos membranosos são preenchidos por moléculas de um pigmento fotossensível genericamente chamado de rodopsina.

A rodopsina é formada por uma molécula de opsina ligada a um cromóforo - dá-se o nome cromóforo a toda estrutura capaz de absorver e reagir à luz. Nos mamíferos, o cromóforo das opsinas visuais é o retinal. No escuro o retinal está na forma de 11-cis. A energia dos fótons absorvidos pelo cromóforo é o substrato para a alteração de sua conformação espacial que passa então para a forma de trans retinal. A mudança do retinal da forma 11-cis para seu isômero trans retinal é chamada fotoisomerização. A fotoisomerização constitui o primeiro passo para que os receptores sinalizem a presença de luz.

Não obstante o comprimento de onda da luz que atinge a retina, a resposta dos fotorreceptores é invariavelmente a mesma: uma hiperpolarização de membrana, no caso de vertebrados, e uma despolarização no caso dos invertebrados, cuja amplitude para um quantum não varia em função do 
comprimento de onda da luz. A forma univariante com que o fotorreceptor responde à luz é sobre o que se refere o Princípio da Univariância proposto por Rushton em 1972.

O Princípio de Univariância mostra que, uma vez absorvido, o efeito de um quantum é sempre o mesmo para qualquer comprimento de onda. O que se altera em função do comprimento de onda é a probabilidade da absorção ocorrer. Esta probabilidade é descrita pela curva de absorção espectral do pigmento segundo uma curva em forma de "U" invertido. As curvas de absorção de diferentes opsinas têm picos em diferentes partes do espectro eletromagnético.

O que determina que a absorção espectral do fotopigmento seja específica e diferente para cada tipo de cone são diferenças na seqüência de aminoácidos de das moléculas das opsinas.

De acordo com a região do espectro em que os fótons têm maior probabilidade de excitar seu fotopigmento, os cones são classificados em:

- Cone $\mathrm{S}$ - cujo pigmento tem maior absorção para comprimentos de onda curtos, com pico em $420 \mathrm{~nm}$;

- Cone $\mathrm{M}$ - cujo pigmento é mais sensível a comprimentos de onda médios, com pico em $534 \mathrm{~nm}$;

- Cone L - cujo pigmento tem sensibilidade espectral maior para comprimentos de onda longos, com pico em $564 \mathrm{~nm}$.

A figuras 1 e 2 mostram como a sensibilidade dos fotorreceptores muda de acordo com o comprimento de onda. Na figura 1 estão representadas as curvas de absorção espectral dos fotopigmentos dos bastonetes e dos cones S, M e L de um sujeito tricromata normal medidas eletrofisiológicamente (Bowmaker e Dartnall, 
1980). Na figura 2 está representada a sensibilidade espectral dos cones medida por métodos psicofísicos (DeMarco, Pokorny e Smith, 1992).

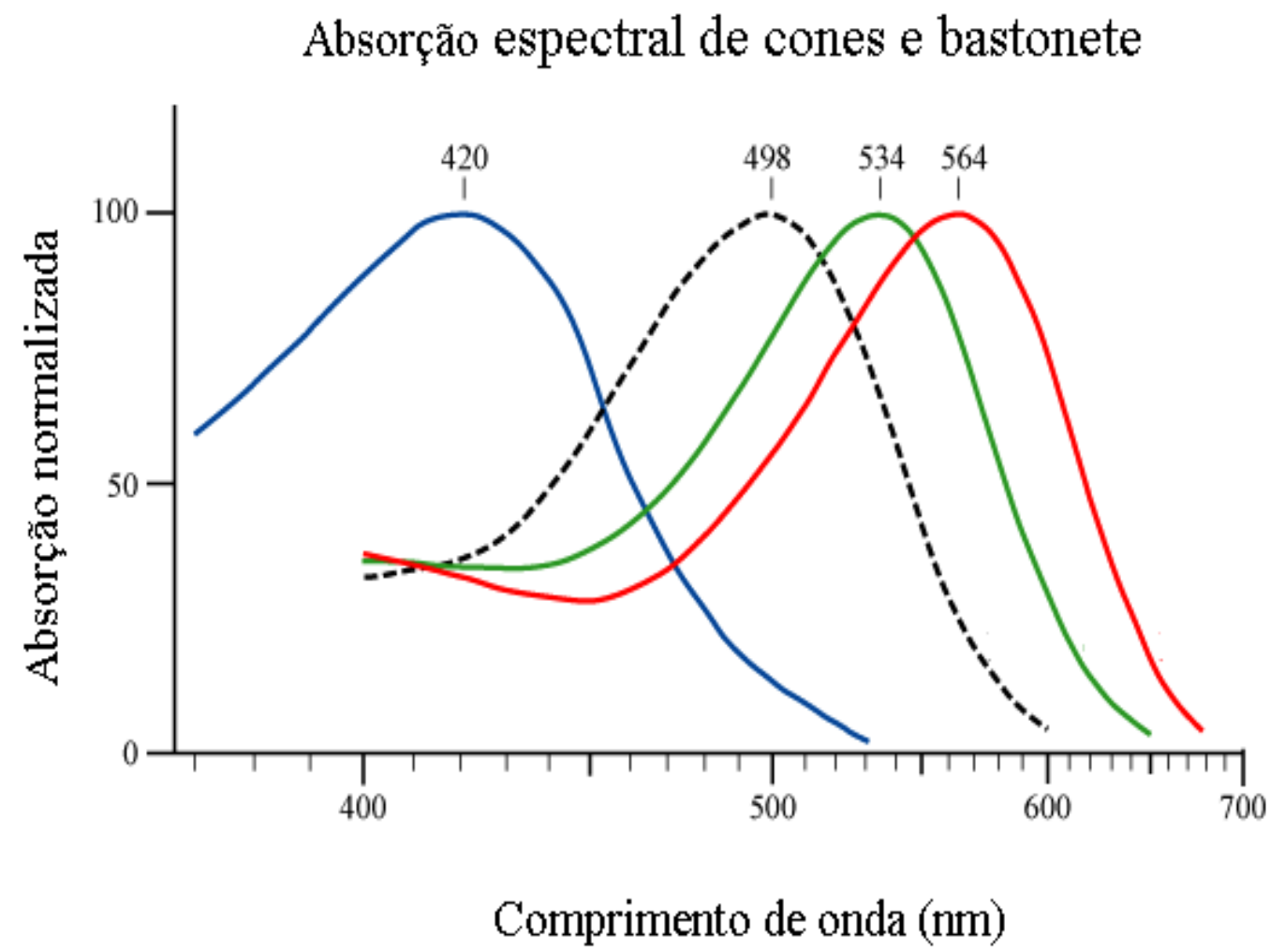

Figura 1: Curvas de absorção espectral dos fotopigmentos dos cones $S$. M e L (curvas azul, verde e vermelha) e de bastonetes (linha pontilhada) medidas eletrofisiológicamente. Dados de Bowmaker e Dartnall, 1980. 
Sensibilidade espectral dos cones

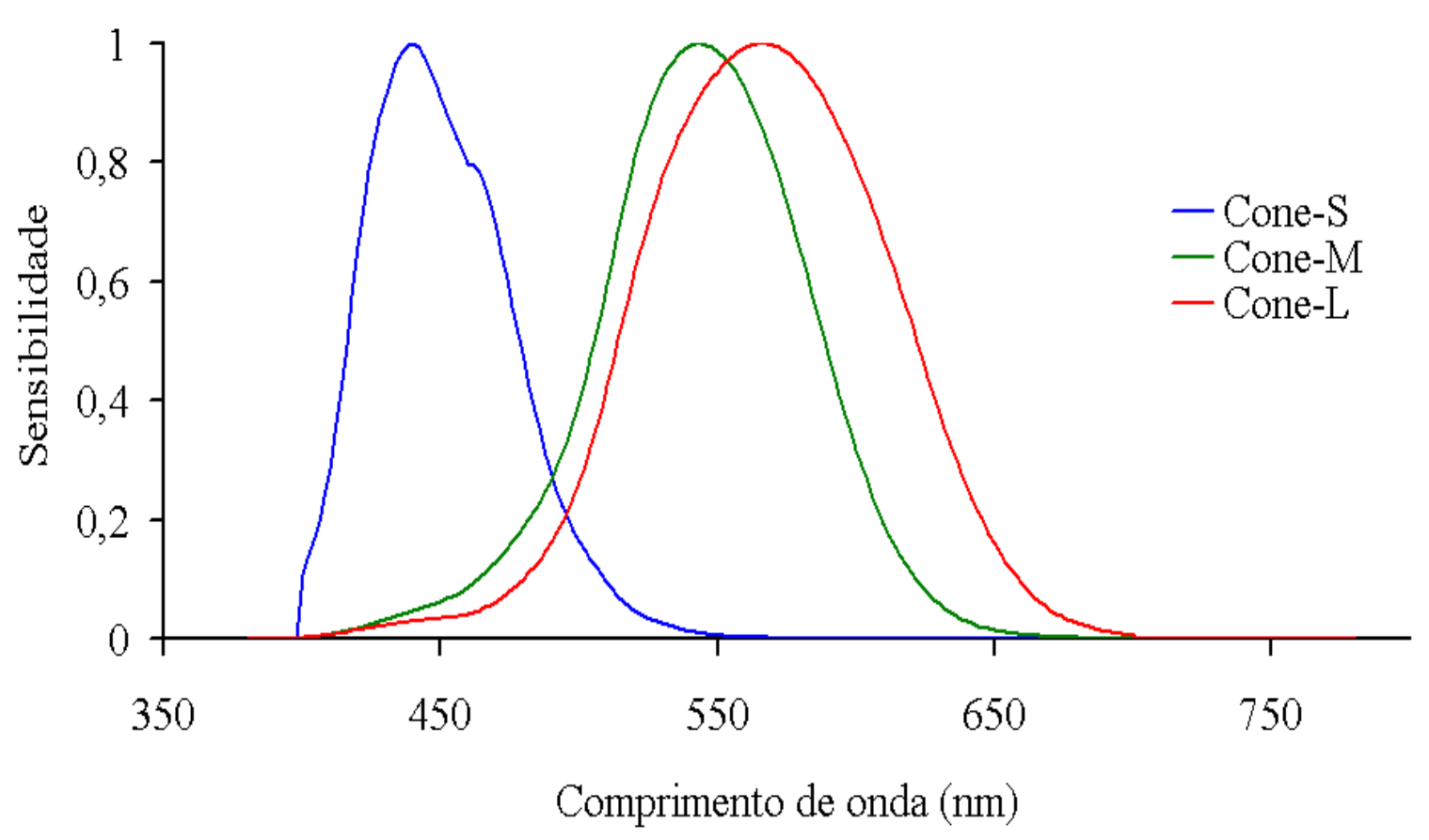

Figura 2: Curvas de sensibilidade espectral dos cones medidas por métodos psicofísicos. Dados de DeMarco e cols., 1992.

Note que nas figuras acima, as curvas estendem-se por uma faixa ampla de comprimentos de onda da luz, admitindo níveis bastante diferentes de sensibilidade do receptor ao longo do espectro. Assim, verifica-se que os fotorreceptores são capazes de responder à luz em uma faixa extensa de comprimentos de onda, no entanto, a probabilidade de que os diferentes pigmentos contidos em cada um dos tipos de cone reajam à luz varia bastante ao longo do espectro.

Considerando as explicações acima, fica evidente que os cones não têm respostas diferentes para cada tipo de comprimento de onda, não se podendo a eles atribuir qualquer tipo de percepção de cor. A designação dos cones como S, 
M e L é apenas um artifício usado para a identificação dos cones e se relaciona com a região espectral em que a sensibilidade do receptor é maior.

A partir dos cones, a informação cromática é recebida pela retina e nos estágios neurais subseqüentes tem início o processamento deste sinal. Este processamento depende da relação entre atividades de excitação e inibição neural, que é a base para a codificação espacial e cromática no sistema visual. Estes mecanismos dão origem a respostas neurais diferenciadas para diferentes regiões do espaço ou para diferentes faixas do espectro visível.

$\mathrm{Na}$ retina de vertebrados inferiores oponência cromática vermelho/verde e azul/amarelo é encontrada no nível das células horizontais, em diferentes tipos celulares (Ventura e cols., 2001). Na retina de primatas não há oponência cromática nas células horizontais, essa oponência se verifica na camada de células ganglionares, cujos campos receptivos se organizam de forma concêntrica, com centro e periferia caracterizados por respostas de sinal inverso excitatório ou inibitório, e havendo também células com oponência cromática (DeValois, 1965; Lee, 2004).

Em 1953, Kuffler (apud Enroth-Cugell,1993, p. 166) disse a respeito de campos receptivos no sistema visual: “... funcionalmente as regiões centrais $e$ periféricas são oponentes, uma tende a suprimir a outra. A célula ganglionar está sujeita a múltiplas influências de seu campo receptivo e sua descarga de disparos expressará a ponderação entre essas influências opostas”.

A figura 3 mostra como a resposta de uma célula ganglionar é modulada pela cor e pela posição do estímulo. 
Campo receptivo com opência cromática

\section{Potenciais registrados}
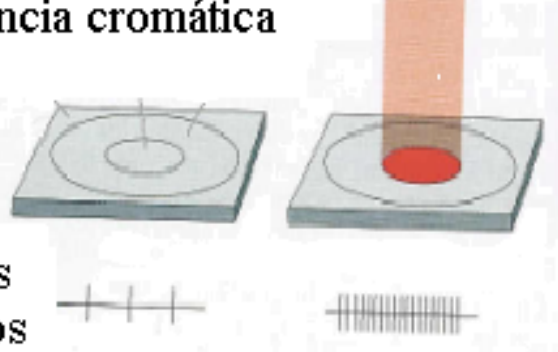
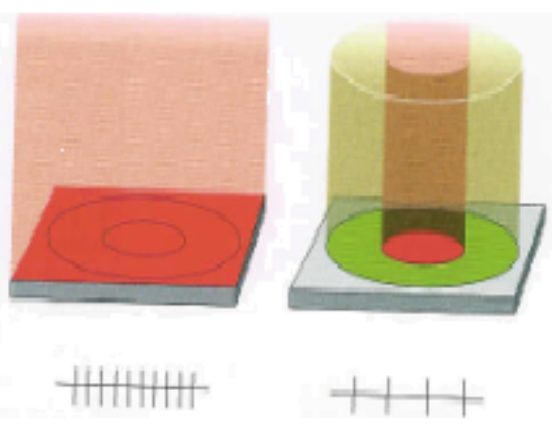

Figura 3: Exemplo de um campo receptivo de célula ganglionar com oponência cromática. (Figura de Bear, Connors e Paradiso, 2002)

A figura acima traz um exemplo de resposta de uma célula ganglionar tipo P com centro tipo vermelho ON (excitado pelo vermelho) e periferia tipo verde OFF (inibido pelo verde). Vê-se que a freqüência de resposta da célula aumenta quando o estímulo está sobre a área em que é ótimo para a célula (na célula da figura, luz vermelha no centro do campo), note que se a área do estímulo excede o tamanho da área central do campo receptivo excitada pelo estímulo em questão a freqüência de respostas diminui. Quando a região periférica do campo receptivo é estimulada por luz de cor oposta (verde), a resposta da célula é oposta àquela dada quando o estímulo estava sobre sua região central, ou seja, a taxa de disparos da célula diminui.

A existência de seletividade na resposta a diferentes comprimentos de onda permite a formação de canais de oponência cromática. A idéia de que esses canais oponentes mediavam a percepção de cores surgiu antes que eles fossem demonstrados pela eletrofisiologia. A teoria de processos oponentes foi estabelecida por Hering em 1878. A teoria de Hering propõe que no sistema visual as informações são organizadas em três canais de processamento oponente: um 
canal vermelho/verde; um canal azul/amarelo e finalmente, um canal acromático ou de luminância.

As informações codificadas por cada canal seguem por trajetórias distintas em direção ao sistema nervoso central, formando vias paralelas de processamento neural.

A maior parte dos axônios de células ganglionares dirige-se ao Núcleo Geniculado Lateral (NGL). Há também uma pequena parte de fibras das células ganglionares, aproximadamente 5\%, que forma projeções direcionadas a diferentes estruturas do encéfalo e cujos sinais relacionam-se com funções como ajuste dos movimentos de fixação do olhar e acompanhamento de objetos em movimento; controle do diâmetro pupilar e sincronização de ritmos biológicos. Os próximos parágrafos descrevem mais detalhadamente as aferências da retina para o NGL por serem estas as de maior interesse para os mecanismos envolvidos na visão de cores.

Os axônios das células ganglionares do tipo P ou anã que recebem sinais dos cones $\mathrm{M}$ e L dirigem-se às camadas parvocelulares do NGL constituindo a via parvocelular de processamento (via $\mathrm{P}$ ) que se caracteriza pela alta seletividade a estímulos cromáticos no sistema vermelho/verde e pela pouca seletividade a estímulos em movimento e/ou com baixo contraste de luminância. As fibras que compõem a via $\mathrm{P}$ dirigem-se para a camada IVC $\beta$ do córtex visual primário.

As fibras das células ganglionares do tipo $\mathrm{M}$ ou parasol recebem sinais gerados pelos cones M e L e partem da retina para as camadas um e 2 do NGL a partir de onde é formada a via magnocelular de processamento (M). Esta via constitui a base para a formação do canal de luminância e está mais relacionada à função de detecção e localização dos objetos e tem como características 
principais: alta sensibilidade a estímulos em movimento e/ou de baixo contraste e baixa sensibilidade a cores. Do NGL as fibras da via M dirigem-se à camada IVC $\alpha$ do córtex visual primário.

Fibras das células ganglionares do tipo bi-estratificada pequena recebe sinais dos cones $\mathrm{S}, \mathrm{M}$ e $\mathrm{L}$ e têm suas projeções direcionadas a estruturas interlaminares do NGL. Estas fibras compõem a via de processamento koniocelular $(\mathrm{K})$ a qual se atribui o processamento das informações cromáticas do canal de oponência azul/amarelo. O destino das projeções das fibras K do NGL para o córtex cerebral ainda não foi bem estabelecido (Lee, 2004).

Deste modo, as informações que partem da retina em direção ao sistema nervoso central são organizadas em vias de processamento paralelo formadas pelos axônios dos diferentes tipos de células ganglionares que formam o nervo óptico. A figura 4 traz um esquema ilustrando as conexões estabelecidas na retina até que as fibras das células ganglionares formem o nervo óptico. 


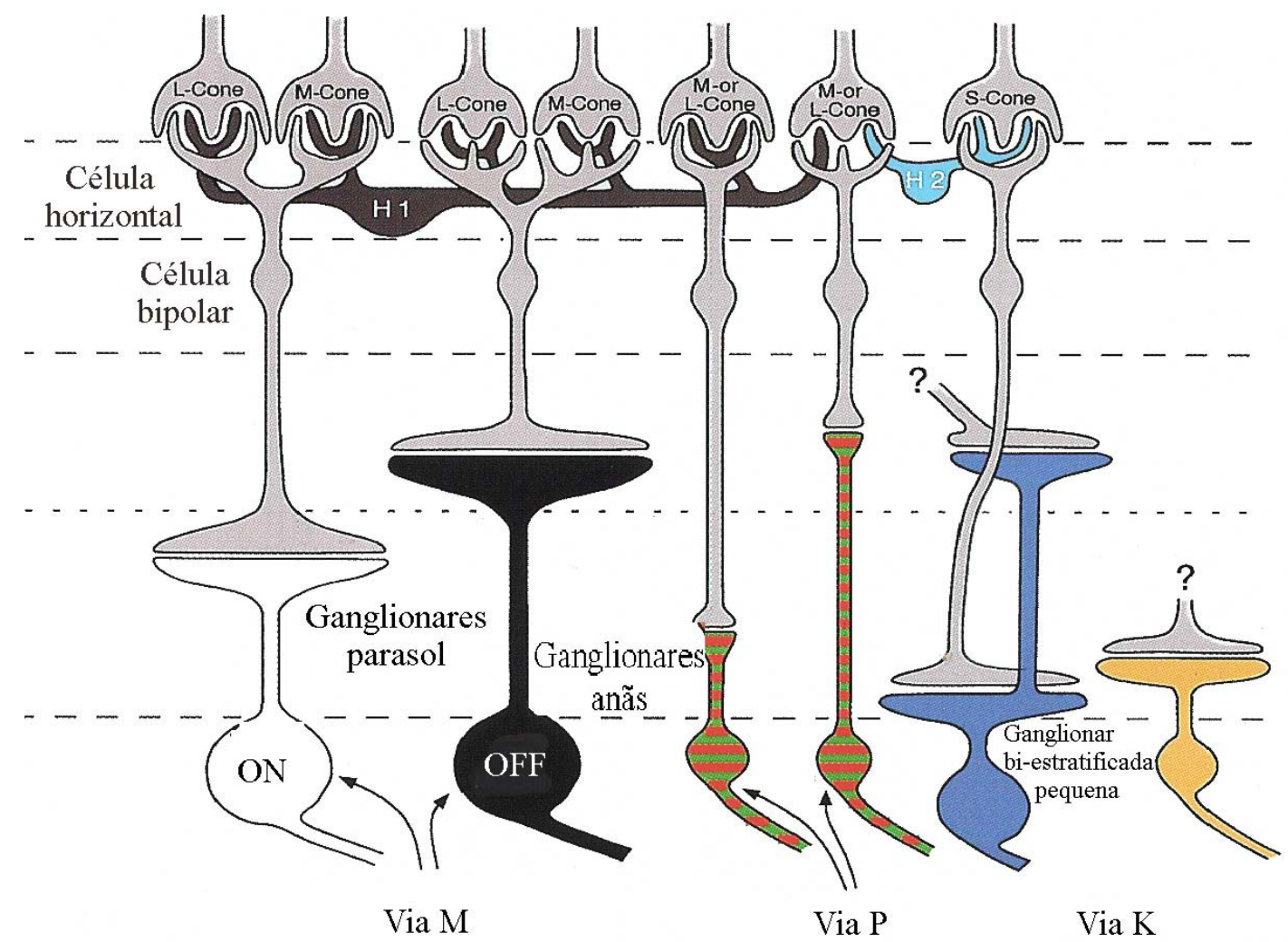

Figura 4: Esquema ilustrativo das conexões que dão origem às vias de processamento paralelo. Os fotorreceptores fazem conexões especificas com vários tipos de células bipolares e horizontais. Na retina interna, os sinais das bipolares são transmitidos a diferentes tipos de células ganglionares. (Lee, 2004).

\subsubsection{REPRESENTAÇÃO GRÁFICA DAS CORES NO DIAGRAMA DE CROMATICIDADE CIE}

Considerando-se o princípio da teoria tricromática de Young e Helmholtz, segundo o qual qualquer cor vista por um tricromata normal é resultado da combinação de três cores primárias, a formação de um modelo espacial para a representação das cores deve ser baseada em expressões da relação entre três informações de entrada, correspondente a cada uma dessas cores primárias. . 
Utilizando esse tipo de representação da cor, a Comissão Internacional de Iluminação (Commission Internationale de l'Eclairage, CIE) elaborou um diagrama em que a determinação das cores é feita relacionando-se proporções de três cores primárias: vermelho, verde e azul necessárias para a composição de qualquer cor. Estas proporções são dadas por funções de equiparação de cores (Color Matching Functions, CMF). Os valores de CMF são obtidos em experimentos psicofísicos de equiparação de cores aplicados a uma população de sujeitos com visão de cores normal (observador padrão).

As primárias utilizadas na construção do diagrama CIE, designadas X, Y e $\mathrm{Z}$ não existem fisicamente; são construtos matemáticos baseados em primárias reais escolhidos de forma a permitir que esta série de primárias transformadas satisfizesse às seguintes condições:

- Sempre produzir conjuntos positivos de valores tri-estímulo;

- Permitir a representação de qualquer cor;

- O branco deve ser produzido por valores iguais de cada primária;

- A luminância deve ser a mesma para todas as cores do diagrama

A figura 5 apresenta as $\mathrm{CMF}$ ajustadas a partir das cores primárias $\mathrm{X}, \mathrm{Y}$ e $\mathrm{Z}$ do diagrama CIE. 


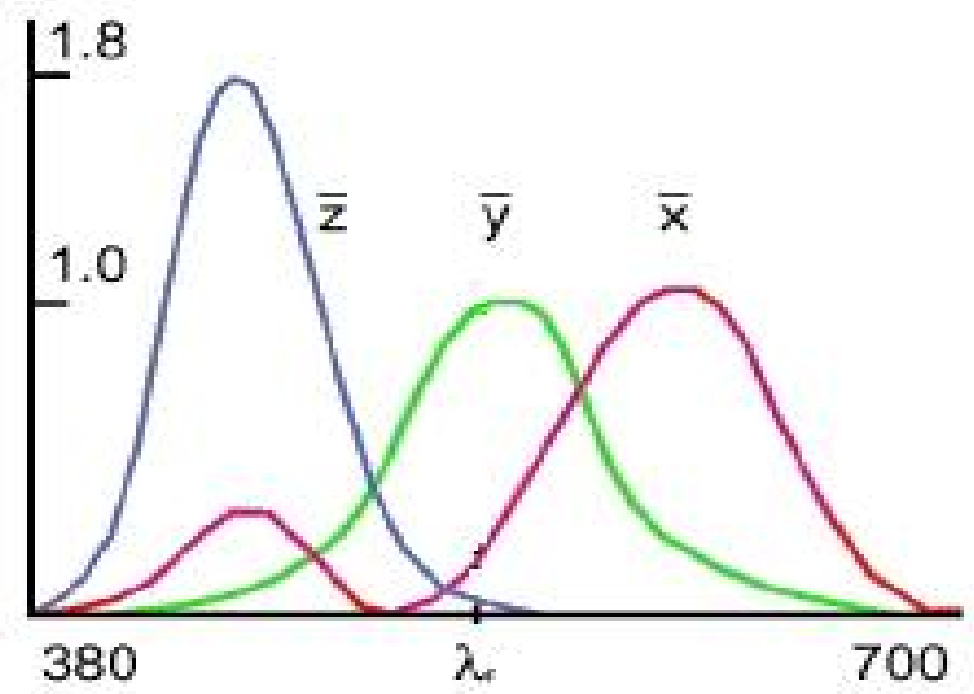

Figura 5: Exemplo de uma função de equiparação de cor (CMF) de um observador padrão.

$\mathrm{Na}$ primeira versão do diagrama CIE, feita em 1931, as cores são determinadas por unidades de $\mathrm{x}, \mathrm{y}$ e $\mathrm{z}$ que representam a proporção de cada uma das cores primárias necessária para a formação de uma cor $\mathrm{x}, \mathrm{y}, \mathrm{z}$ determinada (figura 6). O conjunto de valores $\mathrm{x}, \mathrm{y}, \mathrm{z}$ de uma cor constituem suas coordenadas de cromaticidade. As coordenadas do diagrama CIExy são obtidas através das seguintes fórmulas:

$$
\begin{aligned}
& x=X / X+Y+Z \\
& y=Y / X+Y+Z \\
& z=Z / X+Y+Z
\end{aligned}
$$

Onde: $\mathrm{X}, \mathrm{Y}$ e Z representam as funções de equiparação obtidas com as cores primárias e x, y e z são as coordenadas de cromaticidade. 


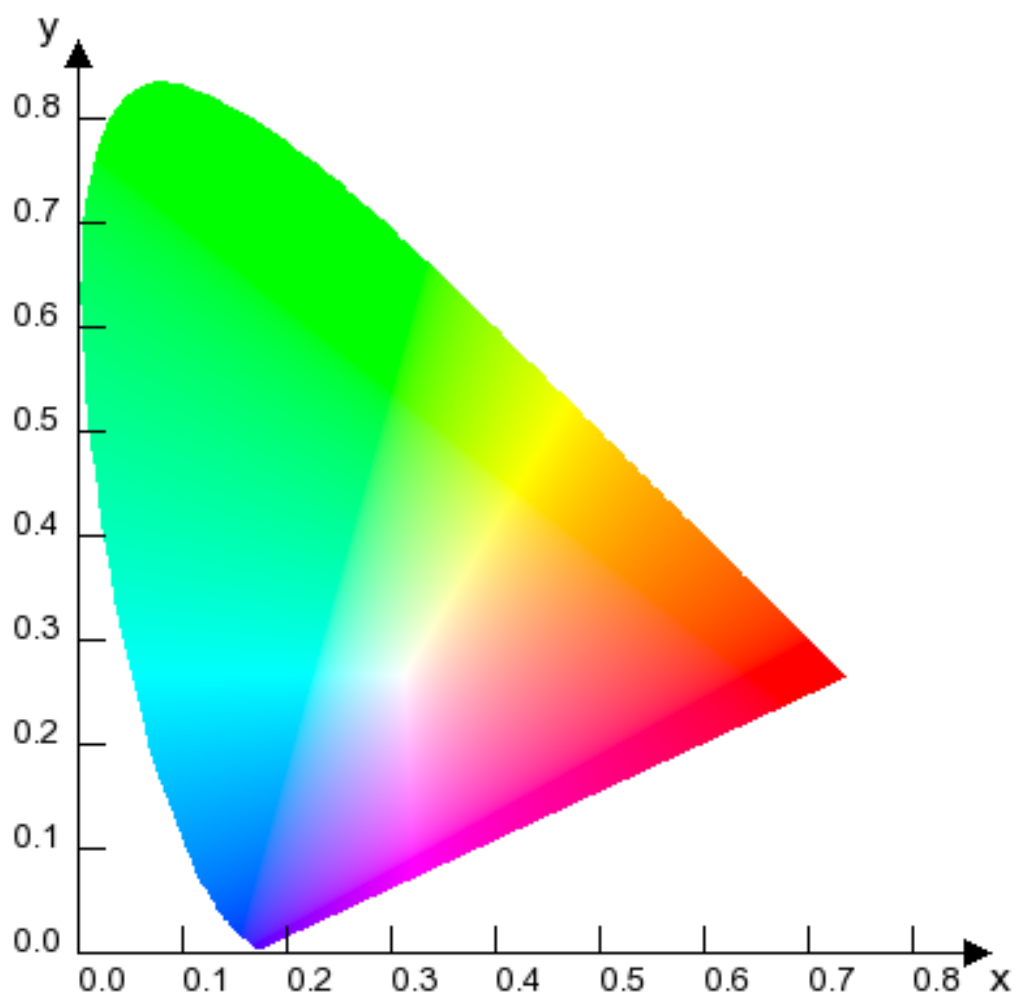

Figura 6: Diagrama de cromaticidade CIE de 1931 ou CIExy.

Ao longo da curva na borda exterior do diagrama estão dispostas as cores espectrais ou matizes. Esta linha é chamada lócus espectral e representa cores com a maior saturação possível (cores espectrais ou puras). $\mathrm{Na}$ área interna do diagrama estão as cores originadas por misturas de vários comprimentos de onda, cujas saturações são menores que as do lócus espectral. No ponto correspondente a valores iguais das três coordenadas, situa-se o branco. Traçando-se uma linha unindo o branco a um ponto que represente uma dada cor no diagrama e a estendermos até o lócus espectral, onde está representada a máxima saturação, a distância em que se situa o ponto representa a proporção de saturação da referida cor. O parâmetro de luminância é o mesmo em todas as coordenadas do diagrama. 
Apesar do uso convencional deste diagrama em trabalhos sobre visão de cores, ele apresenta alguns problemas. Um deles é que as distâncias numéricas entre as cores no diagrama não correspondem a "distâncias" perceptuais iguais. Exemplo disso é a área ocupada pelas cores de matiz verde que contém um número maior de cores do que aquelas distinguidas por um indivíduo com visão de cores normal.

Com a intenção de reduzir os problemas do diagrama CIExy, a comissão de iluminação formulou novos diagramas que são transformadas lineares das coordenadas do diagrama de 1931. Em 1960 foi criado o diagrama CIEuv e em 1976 o diagrama CIEu'v' que tem sido o mais usado atualmente para a representação de cromaticidades.

\subsubsection{ALTERAÇÕES NA VISÃO DE CORES}

Disfunções na percepção das cores, designadas pelo termo discromatopsia, podem ocorrer por um grande número de causas, sejam estas causas congênitas ou adquiridas. A ausência completa de visão de cores é chamada de acromatopsia.

Discromatopsias se refletem na dificuldade ou incapacidade de discriminação de cores em certas regiões espectrais. A classificação dos tipos de discromatopsias é feita utilizando o diagrama de cromaticidade CIE. No diagrama são traçadas linhas unindo os pontos que representam cores não discrimináveis para indivíduos com algum tipo de alteração da visão de cor; essas linhas são chamadas eixos de confusão ou linhas isocromáticas. Para cada tipo de discromatopsia é formado um conjunto de eixos de confusão. 
Os eixos de confusão protan, ilustrados na figura 7 , são os que se encontram no extremo correspondente ao vermelho, chamado ponto copunctal protan. Defeitos no eixo protan resultam de alterações na absorção de comprimentos de onda longos.

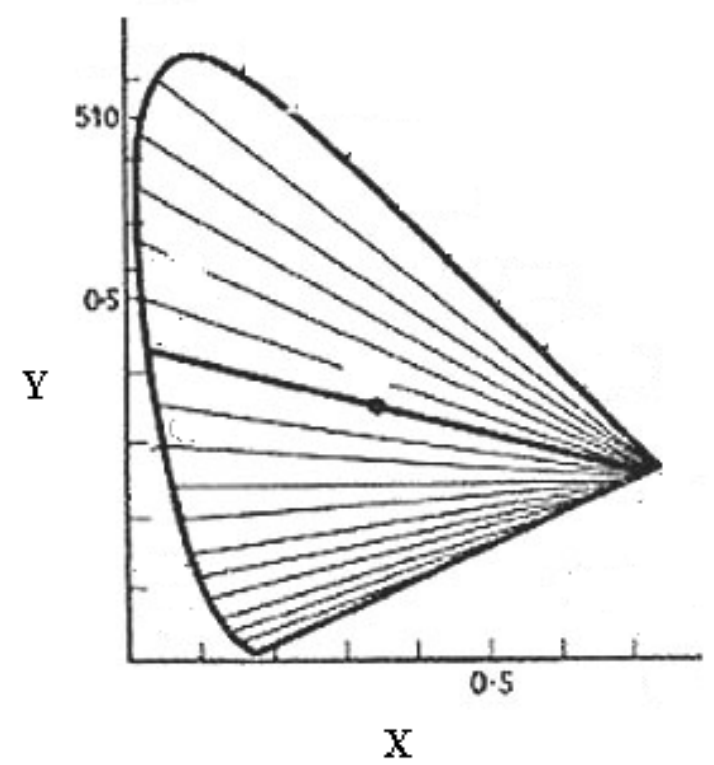

Figura 7: Disposição dos eixos de confusão protan dentro do diagrama de cores CIE xy. (http://webvision.med.utah.edu).

Os eixos de confusão deutan, ilustrados na figura 8 , se encontram num extremo fora do diagrama, o que ocorre provavelmente por falhas da construção geométrica do diagrama CIE. Defeitos deutan resultam de alterações na absorção de comprimentos de onda médios. 


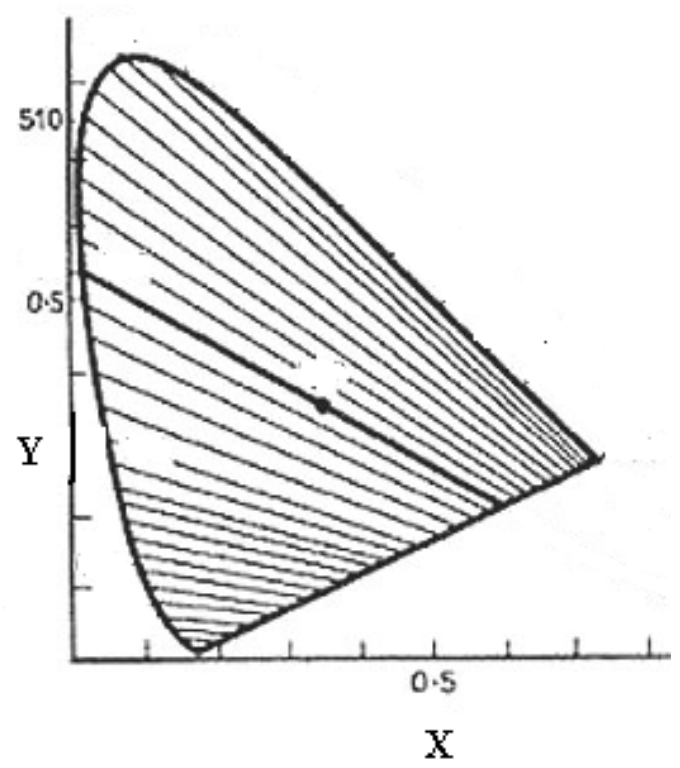

Figura 8: Disposição dos eixos de confusão deutan dentro do diagrama de cores CIE xy. (http://webvision.med.utah.edu).

Os eixos de confusão tritan, ilustrados na figura 9, convergem para o ponto do diagrama de cores correspondente ao azul. Defeitos no eixo tritan resultam de alterações na absorção de comprimentos de onda curtos.

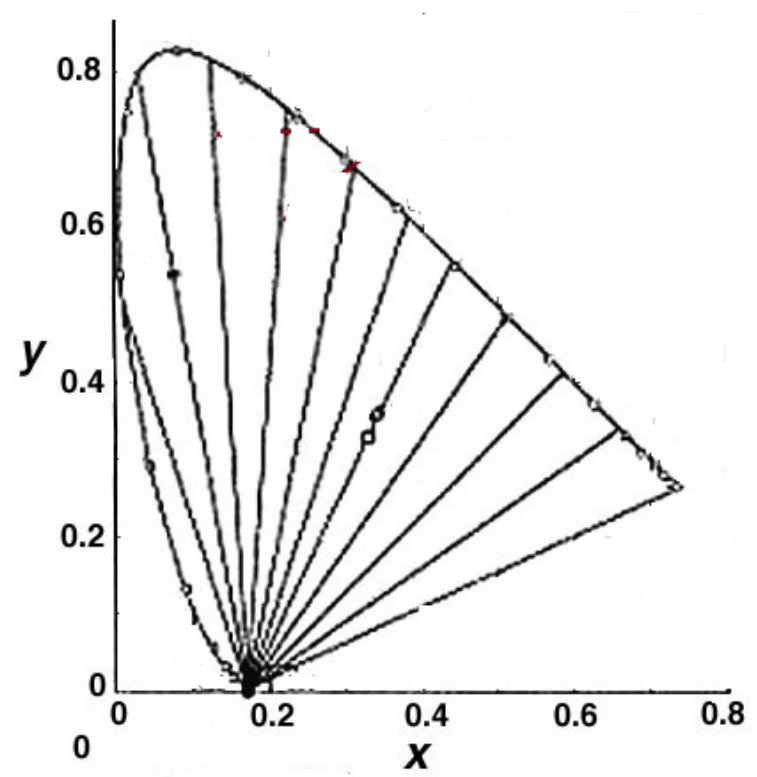

Figura 9: Disposição dos eixos de confusão tritan dentro do diagrama de cores CIE xy. (http://webvision.med.utah.edu). 
A distância existente entre os eixos traçados no diagrama reflete a extensão da faixa de cores indistinguíveis para o sujeito afetado. Desta forma, um maior número de eixos indica uma melhor discriminação; comparando as figuras 7 e 8, por exemplo, pode-se concluir que indivíduos com defeitos deutan discriminam mais cores que aqueles com defeitos protan.

A distinção entre deficiências adquiridas e congênitas é essencial na avaliação clínica da visão de cores.

São características dos defeitos congênitos a inalteração do déficit ao longo do tempo e o comprometimento igual em ambos os olhos. De acordo com a magnitude do defeito e a relação de receptores cujos pigmentos visuais estão ausentes ou com absorção alterada, as discromatopsias congênitas são divididas em tricromatismos anômalos, dicromatismos, acromatismos incompletos ou típicos e acromatismos completos ou atípicos.

Segue uma breve descrição dos tipos as causas e prevalência das discromatopsias congênitas. Neste ponto, cabe ratificar que os números citados referem-se a dados de populações européias já que não há estudos epidemiológicos acerca da prevalência de discromatopsias congênitas, ou daltonismo, no Brasil.

Os tricromatismos anômalos apresentam-se quando o sujeito portador dos três cones tem um deles com uma capacidade de absorção anormal. Nas anomalias congênitas ocorre freqüentemente, em aproximadamente $5 \%$ da população masculina européia, uma alteração nos cones $\mathrm{M}$ que torna sua curva de sensibilidade espectral muito semelhante à faixa dos cones L, provocando assim um tricromatismo deuteranômalo. Em uma pequena parte dos tricromatismos anômalos congênitos, $1 \%$ da população masculina européia, a alteração dos cones 
$\mathrm{L}$ aproxima sua sensibilidade espectral à dos cones $\mathrm{M}$ e neste caso estabelece-se um tricromatismo protanômalo. Nas alterações deste tipo, é grande a variabilidade da extensão do defeito, isto devido a diferenças interpessoais que incluem quantidade de cones com fotopigmento alterado, proporção de cones dos tipos $\mathrm{M}$ e L, ou diferenças no processamento pós-receptores. Assim estes defeitos podem ser classificados em simples ou extremos, de acordo com o desempenho do portador do déficit em exames de avaliação (Swanson, 1989).

Compreendem os dicromatismos aquelas situações em que um dos cones é completamente ausente, ou tem sensibilidade espectral alterada (Swanson, 1989). Um indivíduo dicromata usa diferentes proporções de apenas duas cores primárias para perceber todo o espectro visível, enquanto para o tricromata são necessárias três cores primárias.

$\mathrm{Na}$ maioria dos casos de dicromatismo, os cones inexistentes ou com fotopigmentos anormais são os cones L ou M. Os defeitos resultantes são por isso, defeitos no eixo de confusão vermelho/verde que podem apresentar-se como dicromatismos protanópicos ou deuteranópicos. Grande parte destes defeitos, senão todos, são deficiências congênitas causadas por uma herança genética ligada ao cromossomo $\mathrm{X}$. Por isso, indivíduos de sexo masculino são mais freqüentemente acometidos por defeitos congênitos da visão de cores.

Além dos dicromatismos protanópicos e deuteranópicos há também o dicromatismo tritanópico - um tipo de alteração autossômica dominante extremamente rara $(0,008 \%$ da população européia) na qual os cones-S estão ausentes ou a absorção espectral de seu fotopigmento é anormal provocando déficits de discriminação no eixo de confusão azul/amarelo. 
Os acromatismos são alterações congênitas da visão de cores muito mais severas que os tricromatismos anômalos ou dicromatismos descritos anteriormente, pelo fato de ser comum nos acromatismos uma redução da acuidade visual. Caracteriza-se como acromatismo incompleto o quadro em que os bastonetes e apenas um dos cones têm quantidade e função normais. Este tipo de déficit é essencialmente congênito e pode ser ligado ao cromossomo-X ou autossômico recessivo. Na perda que decorre de mutações ligadas ao cromossomo-X há presença normal dos bastonetes e cones-S, enquanto os cones M e L estão ausentes ou mantém uma atividade alterada e em nível residual (Smith e cols., 1983); seus portadores podem apresentar sinais como nistagmo na infância e alta miopia, além de sintomas como fotofobia e baixa da acuidade visual que tende a valores entre 20/60 e 20/200 Para os defeitos causados por uma herança autossômica recessiva há uma diferença quanto ao cone que se mantém normal em conjunto com os bastonetes, há casos em que este é o cone $\mathrm{M}$, outros o cone L, outros uma combinação de cones $\mathrm{M}$ e $\mathrm{L}$ e ainda pode haver uma combinação de cones-S e L.

Os acromatismos completos são os únicos defeitos que implicam em incapacidade total da percepção de cores. Considera-se que nestes casos haja uma ausência completa de cones normais na retina.

Déficits de visão de cores adquiridos podem ocorrer devido a patologias tais como: degenerações maculares e/ou do pigmento macular, alterações vasculares da retina ou cérebro, uso de drogas farmacológicas ou de abuso e distrofias diversas da retina ou da coróide. Predominantemente, as discromatopsias adquiridas têm magnitude diferente entre os dois olhos e tendem a se modificar ao longo do tempo, já que em muitos casos a severidade da 
discromatopsia reflete a progressão da patologia. Assim, sua avaliação é de grande importante na rotina de avaliação visual.

Os defeitos decorrentes de comprometimentos pós-receptores (da retina interna, nervo óptico, núcleo geniculado lateral e córtex cerebral) normalmente ocorrem no eixo vermelho/verde (Mollon, 1982; Schwartz, 2004; Swanson, 1989).

As alterações das estruturas oculares pré-receptores ou dos receptores comumente provocam defeitos no eixo azul/amarelo (Mollon, 1982; Schwartz, 2004; Swanson, 1989). A causa mais freqüente de discromatopsia adquirida por alteração pré-receptor é o amarelecimento fisiológico do cristalino com o avanço da idade que leva a um aumento na absorção de luzes com comprimento de onda curto (faixa do azul) pelo cristalino e assim, menos luz nesta faixa espectral chega até os cones e por conseqüência há um déficit na discriminação do azul. Por ser este um evento que ocorre para todos os indivíduos, é essencial levá-lo em consideração ao se avaliar a discriminação de cores de sujeitos de idade mais avançada para que este fator não seja um viés nos resultados obtidos.

A tabela 1 (reproduzida de Schwartz, 2004) mostra exemplos de causas de discromatopsias adquiridas e o tipo de defeito estabelecido. 
Tabela 1: Causas de discromatopsias adquiridas e o tipo de defeito estabelecido.

\begin{tabular}{|c|c|c|}
\hline Localização & Tipo de defeito & $\begin{array}{c}\text { Exemplo de } \\
\text { patologias }\end{array}$ \\
\hline $\begin{array}{c}\text { Meios } \\
\text { dióptricos }\end{array}$ & Azul/amarelo & Catarata \\
\hline Retina externa & Azul/amarelo & $\begin{array}{l}\text { Degeneraçâo macula } \\
\text { relacionada à idade / } \\
\text { Retinopatia diabética }\end{array}$ \\
\hline Retina interna & Vermelho/verde & $\begin{array}{l}\text { Atrofia óptica de } \\
\text { Leber / Ambliopia } \\
\text { tóxica }\end{array}$ \\
\hline Via visual & Vermelho/verde & Lesões \\
\hline
\end{tabular}

\subsubsection{AVALIAÇÃO DA VISÃO DE CORES}

Diante da grande quantidade e dos variados graus de discromatopsias que se podem apresentar, a existência de exames que avaliem a integridade da função de discriminação de cores faz-se necessária.

A seguir, a descrição de métodos psicofísicos e eletrofisiológicos usados para o estudo da visão de cores e da função da retina mostra o quanto estas metodologias foram fundamentais para o estabelecimento de conceitos primários a respeito da fisiologia envolvida na percepção de cor e como sua avaliação pode ser feita. 


\subsection{4.a. Métodos psicofísicos de avaliação da visão de cores}

A teoria das medidas internas, desenvolvida por Gustav Theodor Fechner (1801- 1887), no final do século XIX, propõe uma abordagem matemática da relação entre os componentes psicológicos internos da informação sensorial de um indivíduo e os componentes físicos dos estímulos externos. A mensuração das respostas sensoriais provocadas por um estímulo externo constitui a metodologia psicofísica.

Como os testes psicofísicos quantificam a resposta dada pelo sujeito frente a uma pergunta pré-estabelecida e esta resposta, por sua vez, depende do processamento e integração das informações recebidas pelo sujeito - estímulo mais tarefa - fatores cognitivos e emocionais podem influenciar o desempenho no teste. Contudo, o fato de os dados psicofísicos resultarem sempre de um grande número de medidas torna a função estímulo-resposta obtida no final do teste livre desses fatores que podem apenas deslocar minimamente o resultado dentro de uma faixa de variabilidade. Por esse motivo, a determinação de funções psicométricas é um método válido e bastante confiável.

A metodologia psicofísica tem sido usada desde os primeiros trabalhos investigativos acerca dos mecanismos da percepção de cor.

Os diferentes tipos de teste usados na avaliação psicofísica da visão de cores podem ser separados em três classes: testes de pranchas; testes de ordenamento e anomaloscópios (Pokorny e cols., 1979).

Os testes de prancha são amplamente utilizados e têm indicação para as avaliações gerais cuja finalidade é diferenciar portadores de visão de cores 
normais e portadores de defeitos congênitos, visto que estes testes não permitem avaliação quantitativa e nem, portanto, distinção entre os graus de severidade da perda. Os testes de prancha mais difundidos são aqueles que usam o princípio das pranchas pseudoisocromáticas. A idéia básica deste princípio é promover uma discriminação baseada apenas no aspecto cromático da figura - normalmente números, letras ou construções geométricas - eliminando-se qualquer pista de luminância e contorno. Normalmente, a figura e o fundo são constituídos por um padrão de círculos com tamanho e luminosidade variáveis. As cores da figura e do fundo são diferentes de forma que um indivíduo com visão de cor normal as discrimine e aqueles com defeitos da visão de cores, não. Este princípio foi concebido por Stilling, em 1877, e por Chibretem 1887 (apud Mollon e Reffin, 1989).

Com o objetivo de conseguir resultados quantitativos da discriminação de cores foram desenvolvidos os testes de ordenamento. Os testes mais usados clinicamente são:

- Farnsworth-Munsell 100-hue test

- Farnsworth-Munsell Dichotomous Panel D-15 test;

- Lanthony New Color Test;

- Lanthony Desaturated Panel D-15.

Esses testes utilizam séries de peças coloridas que constituem degraus da escala Munsell de cores, que são apresentadas aleatoriamente ao sujeito testado que deve ordená-las segundo critério de semelhança entre o matiz de cada peça, partindo de um ponto fixo com um matiz de referência, ou seja, a partir de um ponto fixo o sujeito deve agrupar em seqüência as peças cujas cores julgar mais semelhantes entre si. 
A discriminação de cores é quantificada com base no número de erros de ordenamento cometidos durante a tarefa de ordenamento realizada pelo sujeito e provê a determinação do eixo de confusão do possível defeito.

Recentemente, foi desenvolvida uma versão atual e computadorizada dos testes de pranchas pseudoisocromáticas: o Cambridge Colour Test (CCT).

O CCT é um teste psicofísico, computadorizado, desenvolvido por Mollon e Regan em 1989 (Mollon e Reffin, 1989). Consiste na apresentação, a intervalos regulares de tempo, de estímulos coloridos na forma do $\mathrm{C}$ de Landolt em um monitor de vídeo. O estímulo (figura 10) é formado por círculos de tamanhos diferentes, distribuídos aleatoriamente e com e com luminância variável. Esta configuração, ruído de luminância mais ruído de forma, impede que o brilho e o contorno sejam usados como dicas para a tarefa de discriminação.

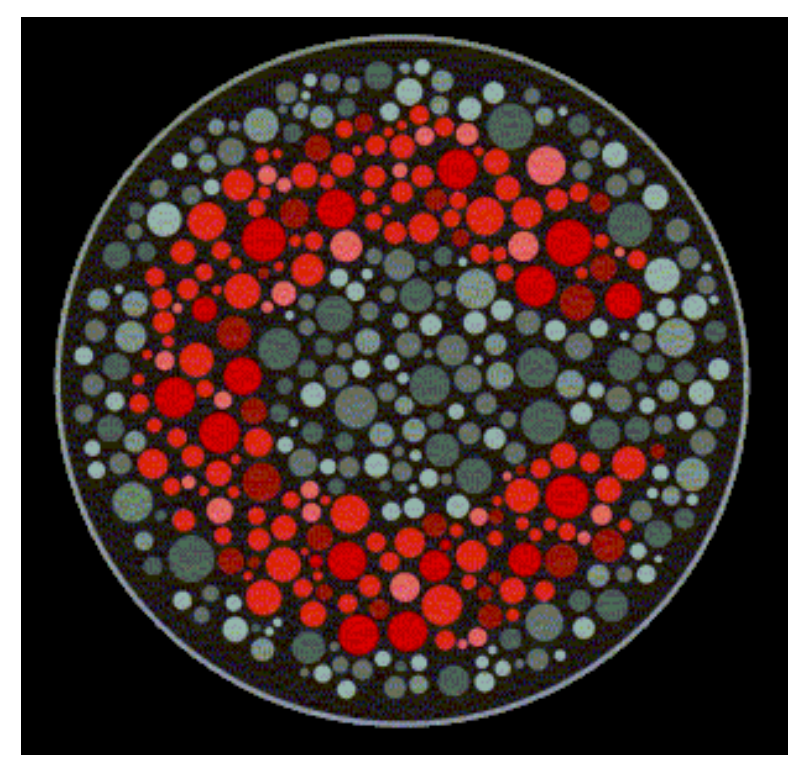

Figura 10: Exemplo do estímulo apresentado no teste de discriminação cromática Cambridge Colour Test. 
A posição do estímulo muda a cada nova apresentação $(\mathrm{C}$ com abertura à direita, esquerda, para cima ou para baixo). $\mathrm{O}$ fato deste teste não utilizar estímulos alfanuméricos, como a maioria dos outros testes, é vantajoso; evita que a resposta seja influenciada por testes anteriores, ou que sua aplicação seja limitada pelo grau de instrução do sujeito.

O teste é composto por duas etapas:

- Teste Trivector - as cores apresentadas nesta etapa estão dispostas sobre três eixos protan deutan e tritan - funciona como triagem para a detecção de defeitos congênitos e como treino para a etapa seguinte;

- Teste das elipses - série mais detalhada, subdividida em 5 fases nas quais cinco pontos do diagrama de cor são tomados como ponto de partida para a determinação de elipses de descriminação.

As coordenadas de cada ponto central representam a cromaticidade de cada fundo a partir do qual partem vetores em várias direções dentro do diagrama. A figura 11 mostra um teste em fase inicial, com dois vetores partindo de um ponto central. 


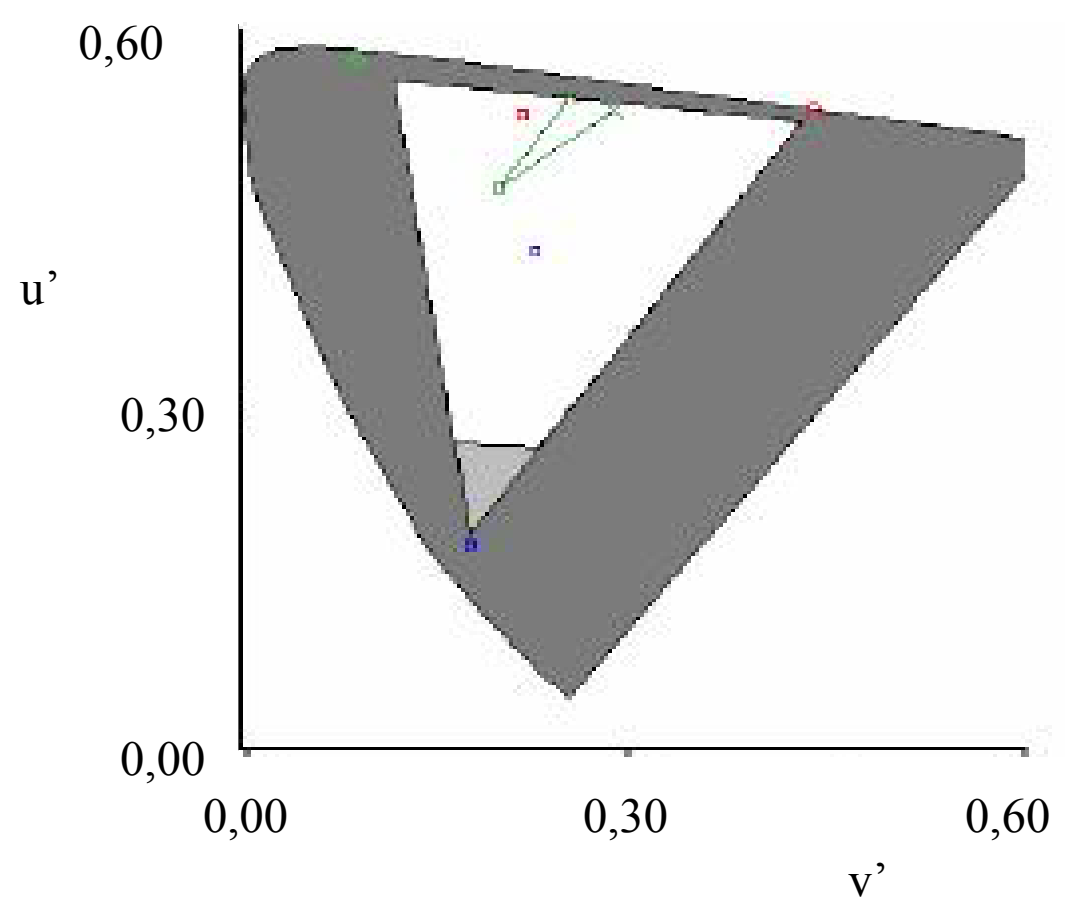

Figura 11: Exemplo da situação inicial do teste, quando vetores partem de um ponto de origem para as diferentes direções do diagrama em que o limiar de discriminação será estabelecido.

Inicialmente, as cores do estímulo são bastante diferentes da cor do fundo, pois é grande a distância entre o ponto do qual parte o vetor (coordenada que representa a cor do fundo) e o ponto que o vetor atinge (coordenada que representa a cor da figura). Esta distância diminui a cada resposta correta que o paciente der; assim a cor da mira torna-se mais parecida com a cor do fundo, até que seja determinado o ponto dentro do diagrama que corresponda ao limiar.

Na medida em que o teste continua, são obtidos pontos de coordenada de cromaticidade equivalentes ao limiar do sujeito em cada direção do diagrama que foi analisada até que o programa determine uma elipse de discriminação (figura 12). 


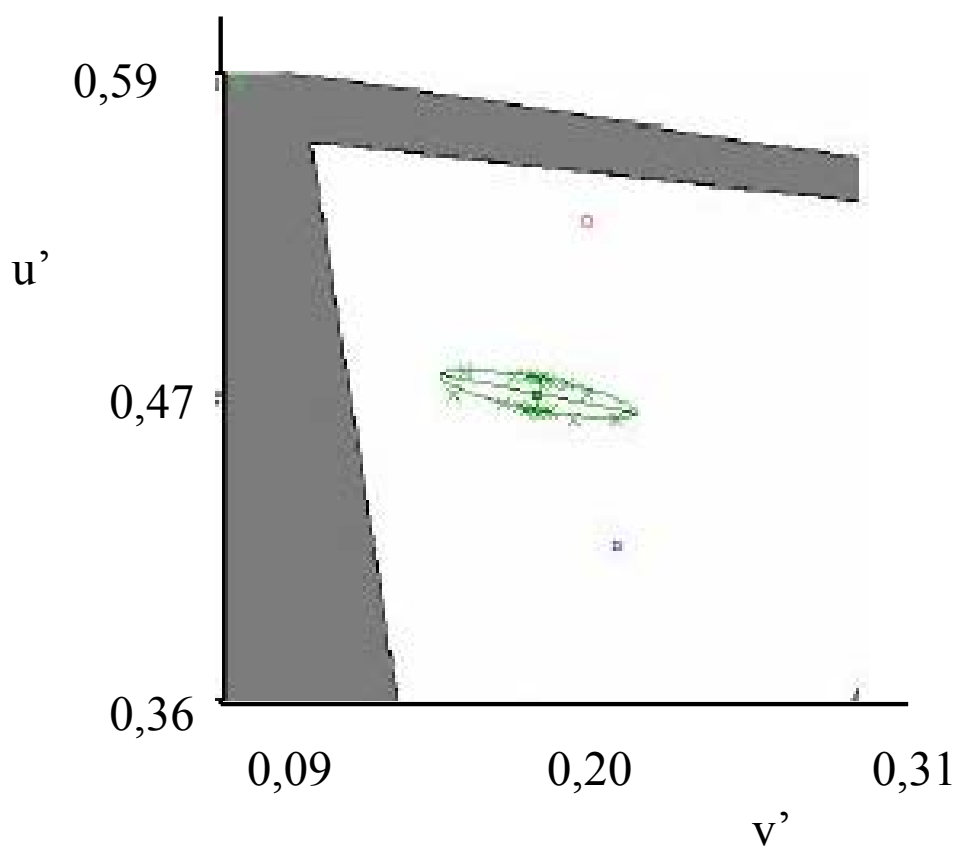

Figura 12: Exemplo de uma elipse obtida ao final do teste. A área desta elipse dentro do espaço de cores corresponde às cores que o sujeito não é capaz de discriminar.

O sujeito submetido a CCT informa suas respostas obedecendo a um método de escolha forçada com quatro alternativas (4 Alternative Forced Choice, 4AFC) já que a cada apresentação, a figura tem quatros posições possíveis e o sujeito deve escolher uma delas. A determinação do limiar é feita com o método da escada.

Ao final do teste são geradas cinco elipses diferentes. A análise quantitativa dos valores numéricos associados à elipse (área, angulação do maior eixo de confusão) permite ao examinador identificar graus bastante leves de discromatopsia. A figura 13 mostra o resultado final de um voluntário normal, mostrando a disposição de cada elipse no diagrama de cores CIE, bem como a extensão da área do diagrama em que estão contidas as cores indistinguíveis para um sujeito tricromata normal. 


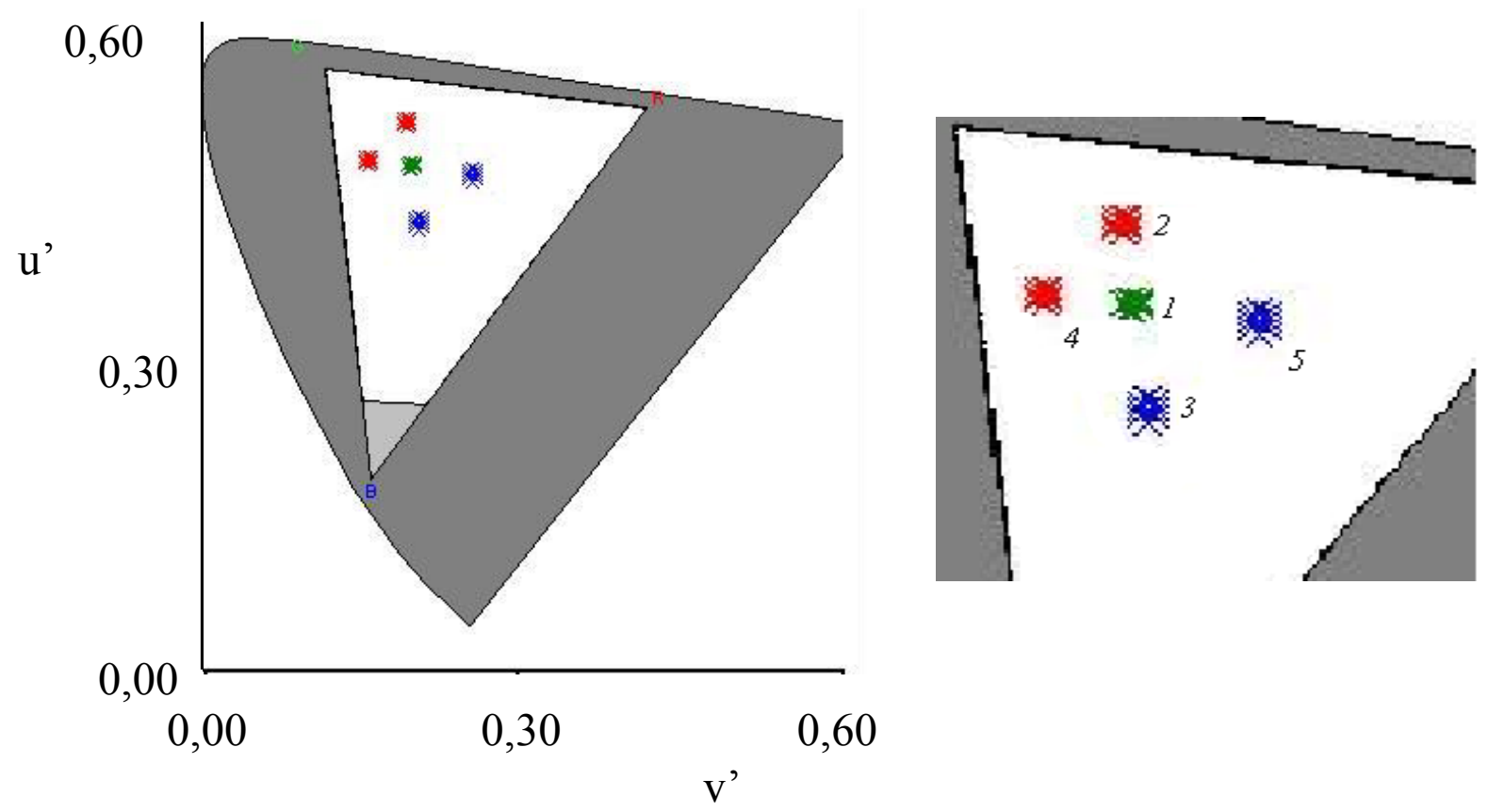

Figura 13:Exemplo de um resultado final normal mostrando a disposição de cada elipse dentro do espaço de cores. A área da elipse corresponde às cores que o sujeito não é capaz de discriminar. No diagrama à direita estão as elipses em aumento e os respectivos números usados para a identificação de cada elipse.

Os valores para cada um dos pontos centrais das elipses são: elipse 1: u’= 0,$1977 ; v^{\prime}=0,4689$, elipse $2: u^{\prime}=0,1925 ; v^{\prime}=0,5092$, elipse $3: u^{\prime}=0,2044 ; v^{\prime}=0$, 4160, elipse 4: u'=1580;v'=4738; elipse 5: u'=2422; $v^{\prime}=4634$.

\subsection{4.b. Métodos eletrofisiológicos}

Os métodos de experimentação eletrofisiológica tiveram grande importância para o conhecimento da seletividade dos fotorreceptores ao comprimento de onda da luz. Os trabalhos de Rushton (Rushton, 1965; Rushton $e$ cols., 1973) que analisando o funcionamento das opsinas visuais (experimentos de bleaching) proporcionaram o estabelecimento de curvas de sensibilidade espectral em indivíduos dicromatas protanopes e deuteranopes. 
Hoje, além de ferramenta para estudos experimentais, a eletrofisiologia visual é um método confiável de diagnóstico oftalmológico amplamente usada no acompanhamento clínico de diversas patologias.

O exame eletrofisiológicos usado neste trabalho foi o eletrorretinograma (ERG). É preciso esclarecer que este exame não avalia discriminação de cores e sim informa sobre o estado da função na retina. A correlação entre a função da retina e o dado sensorial justifica o uso deste teste.

O ERG consiste no registro das correntes intracelulares e extracelulares geradas pelo fluxo iônico entre as estruturas celulares da retina que decorre da estimulação luminosa.

Os primeiros registros de ERG foram feitos por Holmgrem em 1865 utilizando retinas de sapos. No início, a identificação dos componentes do ERG não era bem clara, mas em 1933, Ragnar Granit usando registros de ERG da retina de gatos estabeleceu um tipo de classificação dos componentes de um ERG que é a base da classificação feita atualmente.

Um registro eletrorretinográfico tem um grande número de componentes. Os componentes encontrados em uma onda de ERG variam de acordo com as características da retina (cone ou bastonete dominante). São descritos a seguir apenas os componentes encontrados no ERG humano e dentre esses, aqueles considerados na rotina de uso clínico deste exame: as ondas a e b do ERG.

A onda $a$ é uma onda negativa que surge logo após o estímulo. Sua ocorrência é atribuída à hiperpolarização dos fotorreceptores que ocorrem após a estimulação luminosa (Brown, 1969).

A onda b é um componente positivo observado nos registros de resposta de bastonetes, na resposta máxima e nas respostas fotópicas. A ocorrência da onda b 
é atribuída à atividade de despolarização das células bipolares e das células de Müller que se seguem à hiperpolarização dos fotorreceptores provocada pela incidência de luz sobre a retina (Brown, 1969).

O padrão estabelecido pela Sociedade Internacional para Eletrofisiologia Visual Clínica (International Society for Clinical Electrophysiology of Vision, ISCEV) para um exame de ERG é composto por cinco registros:

- Resposta de bastonetes - registro escotópico eliciado por flash com intensidade suficientemente baixa para que o componente atribuído aos fotorreceptores, a onda a, ocorra apenas em função da atividade dos bastonetes;

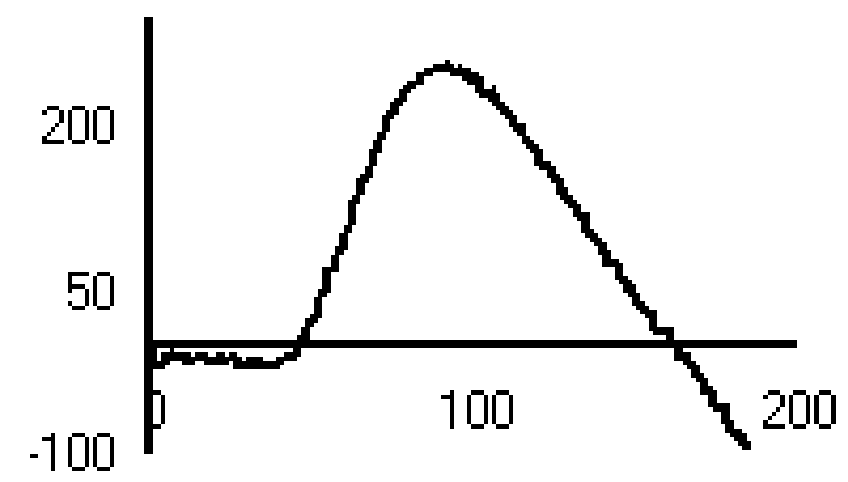

Figura 14: Exemplo de um registro da resposta de bastonetes.

- Resposta escotópica máxima - registro escotópico eliciado por um flash de alta intensidade. Sua onda a reflete atividade combinada de cones e bastonetes. ERG negativo é definido como uma resposta na qual a onda a derivada da atividade dos fotorreceptores tem amplitude maior que a onda 
b de forma a resultar em uma relação b/a menor que um. A presença de ERG negativo é comum em algumas patologias oculares, tais como doenças vasculares, miopia degenerativa, amaurose noturna estacionária congênita, intoxicações por drogas e fármacos. Uma série de estudos farmacológicos usando agonistas de receptores glutamatérgicos das células bipolares (2-amino-4- ácido fosfanobutírico) para bloquear a integração sináptica entre receptores e bipolares tiveram como resultado a presença de ERGs negativos (Knapp e cols., 1984; Nakajima e cols., 1993);

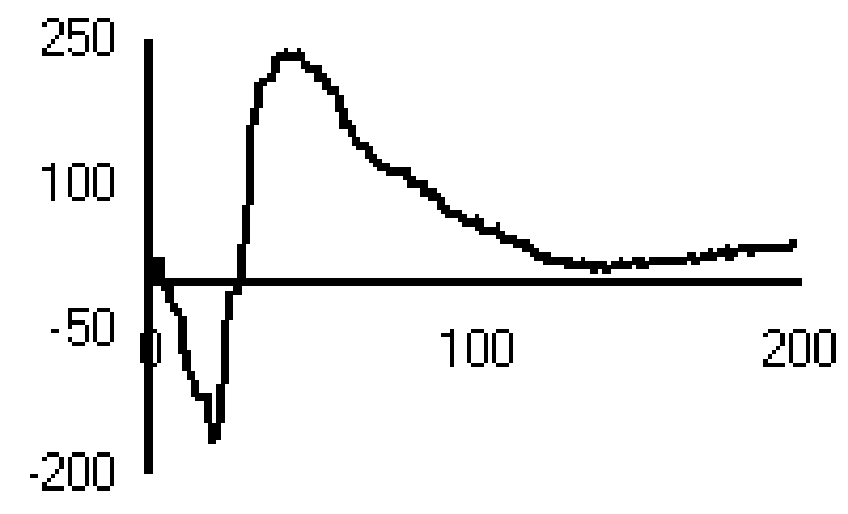

Figura 15: Exemplo de um registro da resposta escotópica máxima.

- Potenciais oscilatórios (PO) - componente de pequena amplitude e de alta freqüência composto por 4 a 7 picos. Os PO refletem a interação entre as células amácrinas e células bipolares e/ou entre ganglionares e amácrinas e podem ser observados na porção ascendente da onda $b$ da resposta escotópica máxima do ERG ou em um registro específico.Esta é a resposta mais comprometida nos diabéticos, pois esse é um registro altamente 
ligado à atividade vascular da retina (Tzekov e cols., 1999; Wachtmeister, 1998);

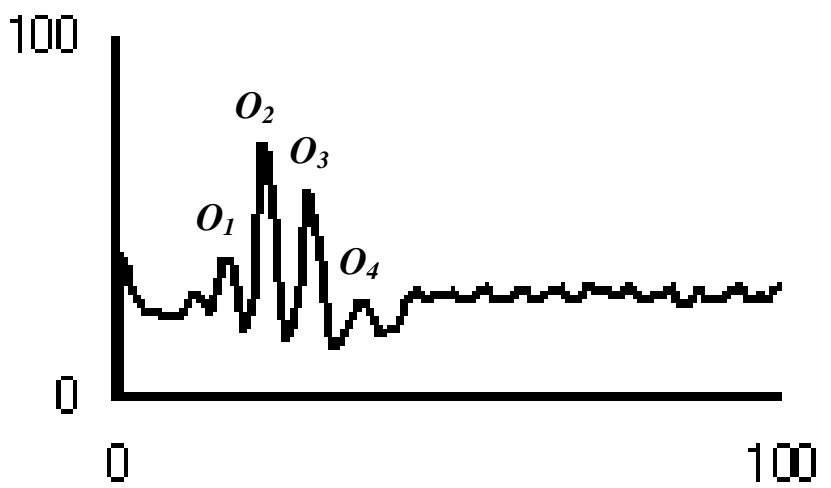

Figura 16: Exemplo de um registro de potenciais oscilatórios.

- Resposta de cones adaptados à luz - registro feito sob estado de adaptação fotópica, obtido em resposta a um flash de alta intensidade. O estado de adaptação e a intensidade do estímulo saturam a resposta dos bastonetes e assim, a onda a deste registro resulta da atividade exclusiva dos cones;

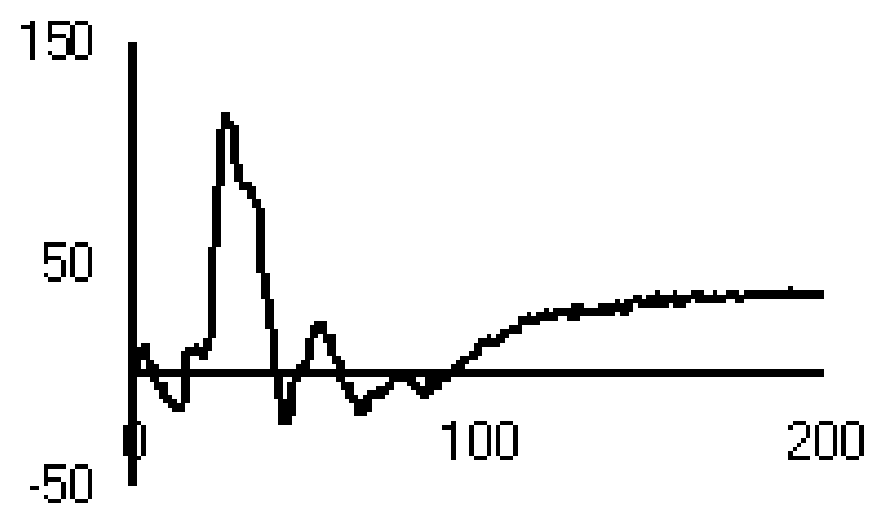

Figura 17: Exemplo de um registro da resposta de cones. 
- Flicker $30 \mathrm{~Hz}$ - registro fotópico eliciado por estímulo de alta intensidade e modulados com alta freqüência temporal. Mostra atividade de cones.

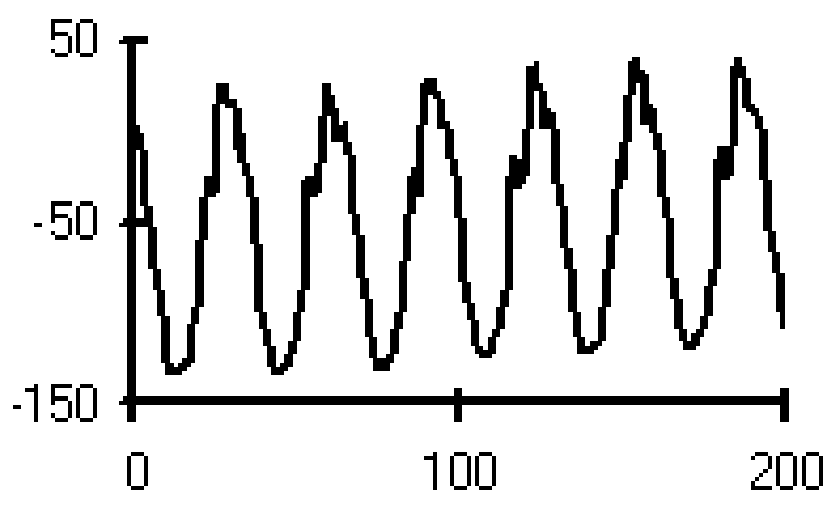

Figura 18: Exemplo de um registro normal de flicker $30 \mathrm{~Hz}$.

A aplicação clínica deste teste para o acompanhamento de patologias implica na padronização dos resultados esperados em indivíduos normais. Por conta disso, uma série de trabalhos de padronização do ERG tem sido publicada. A tabela 2 traz valores normais propostos para o ERG. Comparando-se os limites estabelecidos nos diferentes trabalhos fica clara a diferença entre os parâmetros de cada autor; atribui-se a disparidade dos resultados a diferenças da calibração de equipamentos e estímulos utilizados. Constatando esta diferença, a ISCEV tem sugerido que cada laboratório estabeleça limites próprios de normalidade. 
Tabela 2: Valores normais para os registros do ERG de campo total, segundo diferentes autores

\begin{tabular}{|c|c|c|c|c|c|c|}
\hline & & & $\begin{array}{c}\text { Grupo } \\
\text { controle } \\
\text { deste } \\
\text { trabalho }\end{array}$ & $\begin{array}{c}\text { Pereira e cols. } \\
\text { (2003) }\end{array}$ & $\begin{array}{l}\text { Paranhos e } \\
\text { cols. (1997) }\end{array}$ & $\begin{array}{c}\text { Zrenner e } \\
\text { cols. (1993) }\end{array}$ \\
\hline \multirow{10}{*}{ 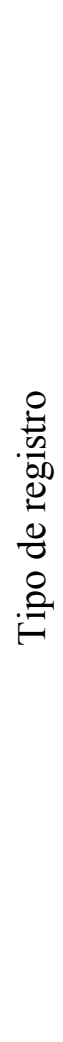 } & \multirow{2}{*}{$\begin{array}{c}\text { Resposta de } \\
\text { bastonetes }\end{array}$} & $A$ & 154 a 221 & 220,9 a 261,3 & 218 a 267 & 84 a 393 \\
\hline & & $T I$ & 83 a 94 & 82,9 a 87,5 & 83 a 88 & 68 a 96 \\
\hline & \multirow{2}{*}{$\begin{array}{l}\text { Resposta } \\
\text { escotópica } \\
\text { máxima }\end{array}$} & $A$ & 223 a 395 & 363,7 a 407,1 & - & 263 a 747 \\
\hline & & $\begin{array}{c}\text { Relação } \\
\text { b/a }\end{array}$ & 1,5 a 2,6 & 1,5 a 3,8 & - & - \\
\hline & \multirow{2}{*}{$\begin{array}{l}\text { Potenciais } \\
\text { Oscilatórios }\end{array}$} & $A$ & 78 a 118 & 165,9 a 195,3 & 224 a 278 & 43 a 127 \\
\hline & & $T I$ & 15,9 a 16,7 & 10 a 13 & - & 22,8 a 24,7 \\
\hline & \multirow{2}{*}{$\begin{array}{c}\text { Resposta de } \\
\text { cones a flash } \\
\text { único }\end{array}$} & $A$ & 75 a 122 & 91,6 a 113,6 & 184 a 244 & 78 a 244 \\
\hline & & $T I$ & 21 a 44 & 27,4 a 28,2 & 30 a 32 & 25,5 a 30,8 \\
\hline & \multirow{2}{*}{ Flicker $30 \mathrm{~Hz}$} & A & 50 a 79 & 61,2 a 77,2 & 134 a178 & 25 a 159 \\
\hline & & $T I$ & 22 a 45 & 27,3 a 28,5 & 27 a 29 & 28 a 31,5 \\
\hline
\end{tabular}

A: amplitude (uv); TI: tempo implícito (ms) 


\subsection{SENSIBILIDADE AO CONTRASTE}

Contraste é uma propriedade física dos objetos que se refere à relação de quantidade de luz emitida ou refletida por diferentes partes de um objeto ou cena.

O valor de contraste de algum estímulo visual pode ser expresso a partir da fórmula:

$$
C=\left(L_{o}-L_{f}\right) / L_{f}
$$

Onde: Lo é a luminância do objeto e Lf é a luminância do fundo sobre o qual está o objeto.

Para medidas de contraste no sistema visual considera-se o contraste relativo às variações do nível de contraste da imagem (contraste de Michelson) que é expresso por:

$$
C=(\text { Lmáx- Lmín) } /(\text { Lmáx. + Lmín) }
$$

Onde: Lmáx é a luminâncias máxima e Lmín é a luminância mínima do padrão de estímulo.

Os estímulos mais empregados atualmente nos experimentos de medida da CSF são as redes senoidais. A aplicação destas redes para a medida da sensibilidade ao contraste deve-se ao trabalho de E.W.H. Selwyn desenvolvido nos anos 40 (Robson, 1993).

Uma rede senoidal é descrita em termos de três atributos: freqüência espacial, contraste e fase.

A freqüência espacial de uma rede refere-se à variação da luminância ao longo do espaço. O conjunto formado pela variação entre um pico de luminância máxima e um vale de luminância mínima (visto como uma barra clara e uma barra 
escura) corresponde à unidade de um ciclo. A quantidade de ciclos contida em uma unidade de medida espacial especifica a freqüência espacial de uma onda. Usualmente, a freqüência espacial é expressa em números de ciclos contidos em um grau de ângulo visual (cpg). A figura 19 mostra à esquerda uma onda com freqüência espacial baixa e à direita uma onda com freqüência espacial alta.
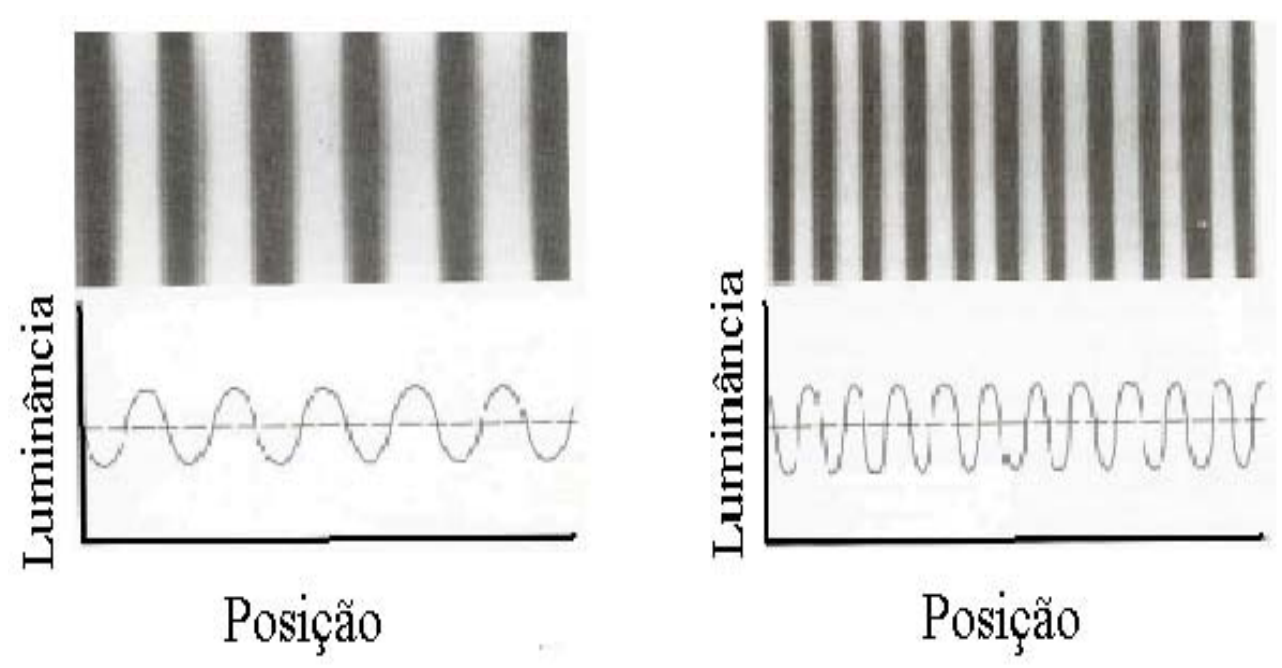

Figura 19: Freqüência espacial de uma onda senoidal. Figura de Schwartz, 2004.

O contraste de Michelson descrito acima é calculado com base nas luminâncias do pico e do vale da onda senoidal. A figura 20 ilustra como a amplitude da variação de luminância de uma onda $(\Delta \mathrm{L})$ determina o seu nível de contraste. 

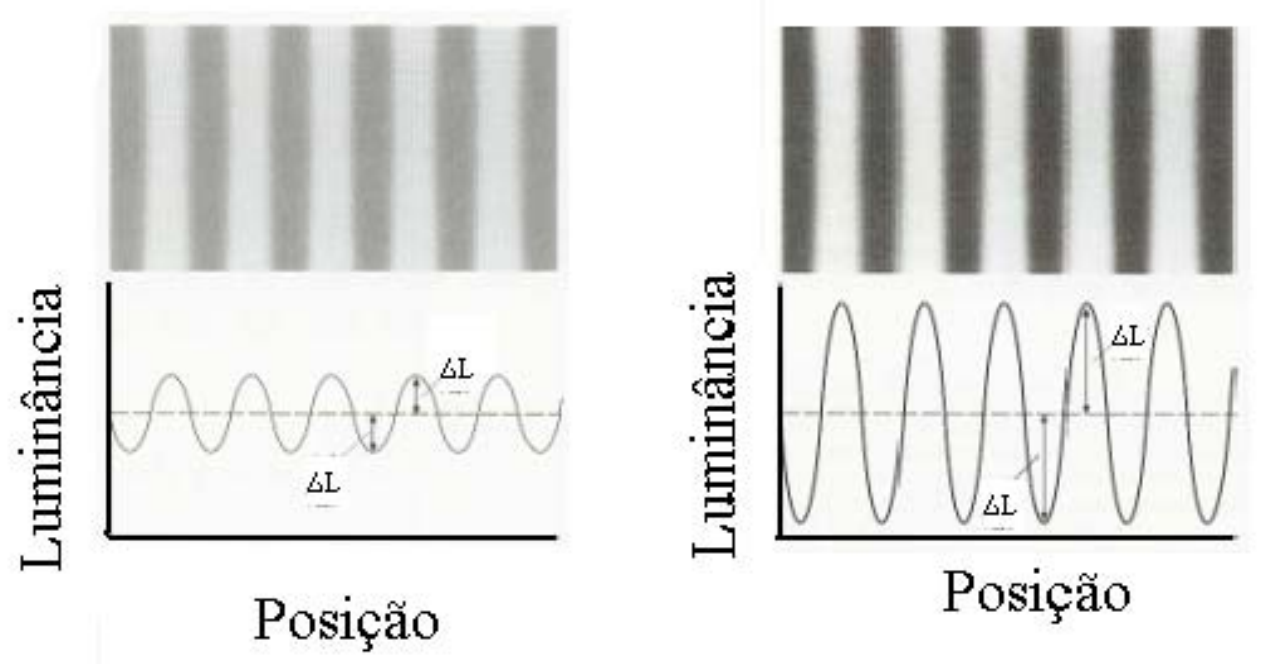

Figura 20: Nível de contraste de uma onda senoidal determinado pela amplitude da variação de luminäncia. Figura de Schwartz, 2004.

Quando os picos e vales da variação de luminância de duas ondas coincidem, diz-se que estas duas ondas estão "em fase"; quando, porém, o vale de uma onda coincide com o pico de luminância de outra, diz-se que elas estão em "contra-fase" ou com uma diferença de fase de $180^{\circ}$. O deslocamento da fase de uma onda é expresso pelo ângulo entre a rede e um referencial, normalmente no plano horizontal.

A variação dos gradientes de contraste de um objeto pode ser analisada nos domínios espacial e temporal. Considerando a formação de imagens por sistemas ópticos, a análise das razões entre o nível de contraste de um objeto e o de sua imagem em função da periodicidade espacial ou temporal do objeto constitui a sua Função de Transferência de Modulação (Modulation Transfer Function, MTF) espacial ou temporal.

Considerando-se o sistema visual humano, a imagem formada sobre a retina não é o único fator determinante sobre a cena que será percebida pelo sujeito. 
Mecanismos neurais como inibição lateral nas células da retina e controle de ganho de contraste no NGL e no córtex visual modulam o processamento da informação de contraste da imagem e, portanto, medidas psicofísicas ou eletrofisiológicas da sensibilidade ao contraste no sistema visual não podem ser consideradas como a reprodução exata de uma MTF.

A capacidade do sistema visual para a detecção de contrastes é, comumente, expressa em termos de sensibilidade ao contraste, que corresponde ao inverso do valor do contraste limiar medido. Por ser um dado resultante de uma razão, o valor de sensibilidade ao contraste é um número adimensional.

A relação entre sensibilidade ao contraste de luminância e tamanho do objeto constitui a função de sensibilidade ao contraste espacial (Contrast Sensitivity Function, CSF).

A curva de sensibilidade ao contraste espacial de luminância tem uma forma de filtro passa banda: a sensibilidade é maior para os estímulos de freqüências espaciais médias e cai para freqüências baixas e altas (figura 21). 


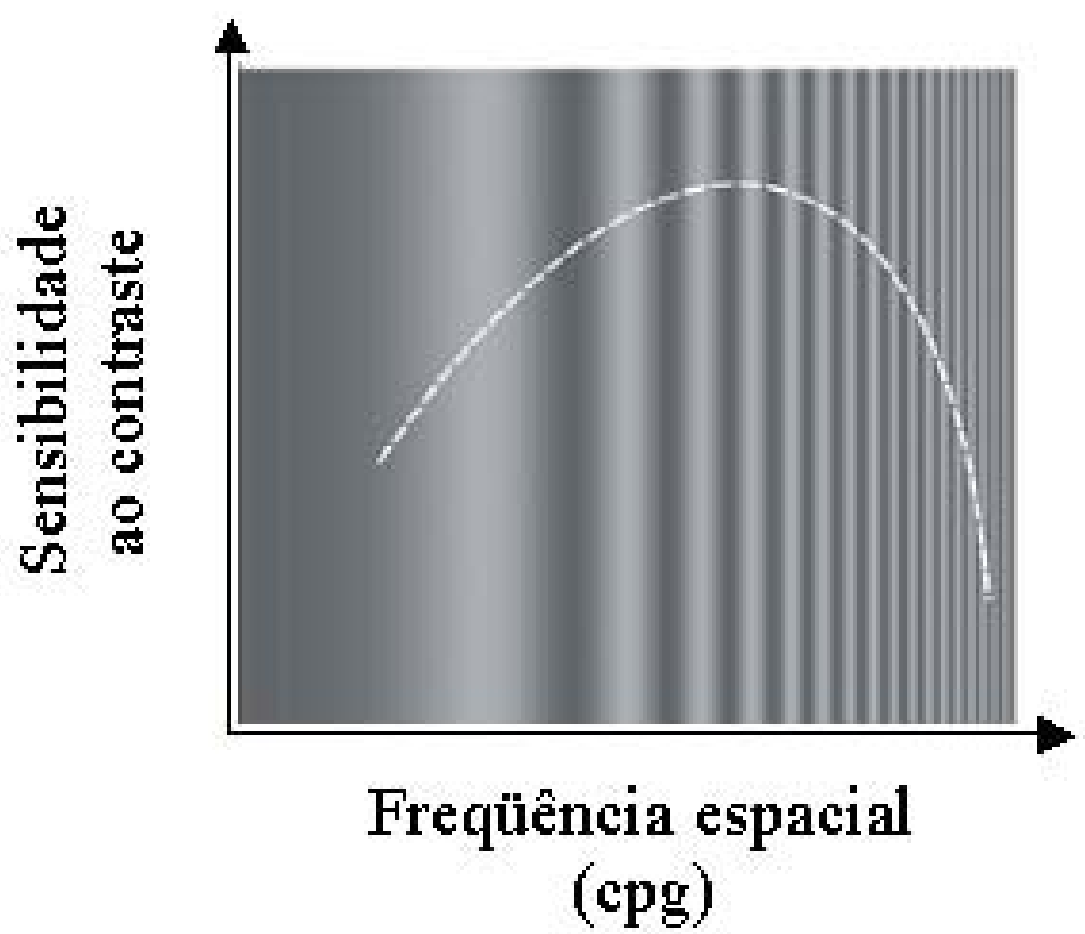

Figura 21: Exemplo de uma curva de sensibilidade ao contraste de luminância linha branca tracejada - em função da freqüência espacial do estímulo ilustrada pelas barras verticais ao fundo.

A queda da sensibilidade para as baixas freqüências é atribuída ao mecanismo de inibição lateral que atenua gradientes de contraste com freqüência espacial baixa. Campbell e Robson (1968) apud Rovamo e cols. (1999). A figura 22 ilustra como a atividade dos campos receptivos se relaciona com estímulos com freqüências espaciais alta e baixa. 

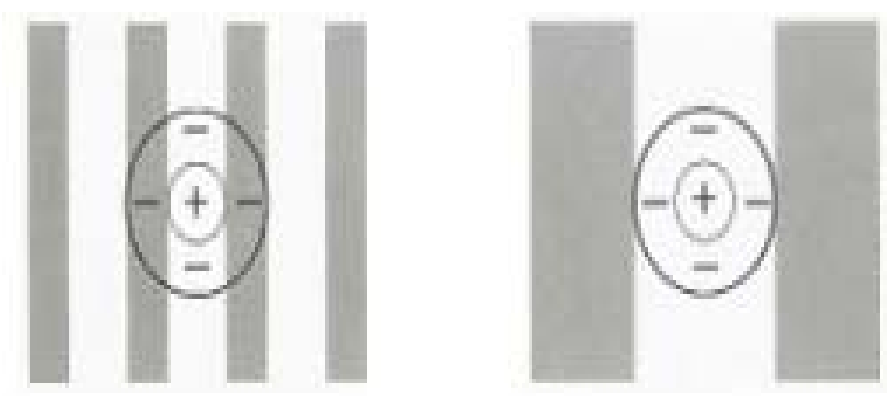

Figura 22: Mecanismo de inibição lateral reduzindo a sensibilidade a estímulos com freqüência espacial baixa. Figura de Schwartz, 2004.

O decréscimo de sensibilidade para os estímulos com freqüência espacial alta deve-se a propriedades do mosaico de fotorreceptores na retina e características ópticas do olho (erros refrativos, aberrações nos meios convergentes).

A avaliação desta função visual é útil no acompanhamento e tratamento de doenças oftálmicas que acabam por provocar distúrbios visuais. Com o uso deste tipo de informação pode-se ter conhecimento de prejuízos não apresentados em testes convencionais de avaliação clínica. Desde o século XVIII quando Bouguer estabeleceu e publicou pela primeira vez um protocolo de avaliação do até então chamado "limiar de diferença de luz" e mais tarde, em1874, com Snellen e Landolt - preconizadores da medida de acuidade visual - a medida psicofísica do limiar de diferença de luz era considerada como de grande utilidade para a avaliação oftalmológica clínica e era sugerido que a medida fosse feita em conjunto com a medida de acuidade visual (Robson, 1993). Entretanto, ainda hoje, a medida da CSF é pouco aplicada na rotina de avaliação visual e sua maior utilização tem, lamentavelmente, ficado restrita a protocolos de pesquisa. 


\subsection{DIABETE MELITO}

Diabete melito (DM) é o termo empregado para designar a condição em que um complexo de alterações metabólicas poligênicas é instalado. É a desordem endócrina mais comum.

Trata-se de um dos maiores problemas médicos mundiais, isto porque causa complicações sistêmicas de longa duração que promovem grande impacto tanto para o paciente quanto para a sociedade, uma vez que a maior parte dos indivíduos acometidos pela patologia pertence à faixa etária da população mais ativa economicamente.

Possíveis sinais e sintomas sistêmicos da patologia incluem: glicosuria (presença de glicose na urina); poliúria (diurese osmótica devida à hiperglicemia extracelular e a glicosuria); polidipsia devida à grande perda de sais e água; polifagia (aumento do apetite); perda de peso e indisposição física - devidas à diminuição do volume de fluido extracelular e à diminuição ou fim das reservas dos tecidos pelos efeitos catabólico da deficiência de insulina (proteólise, lipólise).

Existem tipos variados de diabete. A etiologia da doença difere de um tipo ao outro.

Os casos cuja causa não é totalmente esclarecida compõem a classe primária de diabete. $\mathrm{Na}$ classe secundária estão os tipos com causas bem estabelecidas, por exemplo, secreção aumentada de hormônios hiperglicemiantes e hormônio do crescimento ou destruição das células pancreáticas. Os casos de DM primária são os de maior incidência; nesta classe estão incluídas a diabete tipo 1 e 2 . 
A diabete tipo 1 tem manifestação precoce, por isso é também conhecida coma diabete juvenil e se estabelece em decorrência de uma falta severa ou absoluta de insulina devida à redução da quantidade de células- $\beta$ do pâncreas. Esta redução da massa celular é, na maioria das vezes, resultado de um processo auto-imune. Fatores genéticos têm grande relação com o estabelecimento deste processo - gêmeos idênticos apresentam 40\% de chances de desenvolverem a doença se um deles desenvolve - entretanto, este valor de concordância entre gêmeos indica que o estilo de vida também deve ter papel importante para o desenvolvimento da patologia.

Aproximadamente $90 \%$ dos casos de diabete são do tipo 2 (Federação Internacional de Diabete, 2000). Seu início é tardio quando comparado ao da diabete tipo 1 e sua incidência aumenta com o avanço da idade.

Entre as causas da diabete tipo 2 estão a secreção alterada de insulina, a ineficiência da insulina em sua estrutura e/ou a resistência à captação da insulina nos tecidos periféricos. Elementos genéticos também podem estar presentes e ter um papel determinante no estabelecimento da patologia, mas fatores como o sedentarismo, a dieta desbalanceada e o estresse tem sido considerados fatores de risco para o desenvolvimento da diabete tipo 2 .

\subsubsection{Diabete melito e visão}

Alterações morfológicas e/ou funcionais ocorrem em praticamente todos os tecidos do organismo na presença da diabete.

Altos níveis de glicose sanguínea afetam a estrutura e a fisiologia dos capilares da retina. A explicação mais aceita para tal comprometimento é a 
ativação da via aldose-redutase que ocorre em conseqüência do aumento persistente nos níveis de glicose circulante. A via aldose-redutase converte açúcares em álcoois - por exemplo, glicose em sorbitol e galactose em dulcitol que não se difundem prontamente através das membranas celulares (Lawrenson, 2000).

Como resultado dos altos níveis de álcoois, as células vasculares da retina deixam de cumprir suas funções auto-regulatórias e estabelece-se um quadro de fragilidade das paredes dos capilares que provoca extravasamentos de seu conteúdo. Estes vazamentos caracterizam os microaneurismas - os sinais mais precoces da retinopatia diabética.

A incidência das RDs é diretamente proporcional ao tempo de doença. Após 20 anos de diabete $75 \%$ dos pacientes desenvolvem algum tipo de RD (Conselho Brasileiro de Oftalmologia, 1999) e a qualidade de vida destes pacientes é gravemente afetada. Uma vez que a $\mathrm{RD}$ é desenvolvida, só resta o recurso paliativo da fotocoagulação a laser que melhora a visão afetada pelas hemorragias já ocorridas, mas não melhora o prognóstico oftalmológico do paciente, ou seja, não impede que a retinopatia continue a avançar.

Estima-se que existam aproximadamente 10 milhões de diabéticos no Brasil, destes 50\% não sabem que possuem a doença (Sociedade Brasileira de Diabete, 1998). Dentre os indivíduos que têm consciência da doença apenas metade recebe cuidados oftalmológicos apropriados. A subestimação do número de diabéticos e o baixo número de pacientes que têm acompanhamento oftalmológico correto contribuem para que a retinopatia diabética seja líder entre as causas de cegueira em todo o mundo. 
De acordo com os achados do exame oftalmoscópico as retinopatias diabéticas são classificadas como proliferativas (RDP) ou não proliferativas (RDNP). Não detalharemos as distinções entre os tipos de RDs, pois o tema não é objeto específico deste trabalho.

\subsubsection{Visão de cores, sensibilidade a contrastes e ERG na presença de diabete}

As deficiências de visão de cor como conseqüência da diabete vem sendo mostradas em diversos trabalhos. Num relato recente 2701 pacientes participantes do Early Treatment Diabetic Retinopathy Study (ETDRS) tiveram sua capacidade de discriminar cores medida pelo teste Farnsworth- Munsell 100 Hue Test (Fong $e$ cols., 1999). Aproximadamente 50\% desses pacientes apresentaram anomalias na discriminação de cor, predominantemente um defeito tritan de magnitude proporcional à severidade do acometimento da retina (edema macular e/ou retinopatia diabética).

Perda da discriminação de matizes principalmente em cores dessaturadas e aumento da faixa de equalização metamérica tritan também foram detectados na ausência de retinopatia diabética, tanto em casos de diabete tipo 1 (Kurtenbach $e$ cols., 1994; 1999) quanto em pacientes com diabete tipo 2 (Hardy e cols., 1992; Doucet $e$ cols., 1991).

A relação entre alterações do ERG em função da diabete tem sido relata em uma série de trabalhos (Deschênes e cols., 1998; Ewing e cols., 1998; Greenstein e cols., 2000; Lovasik e Kergoat, 1993; Kurtenbach e cols., 1999; Scholl e Zrenner, 2000; Shirao e Kawasaki, 1998; Tzekov e Arden, 1999). 
A alteração do ERG mais freqüentemente associada à diabete desde seus estágios mais iniciais é a redução e o atraso dos PO. Este achado tem sido atribuído à existência de comprometimento vascular da retina, uma vez que os PO são registros obtidos em função da atividade de grupos celulares da retina interna; esta porção da retina é especialmente susceptível a pequenas alterações da função vascular porque diferente da porção externa da retina cujo suporte metabólico vem da coróide, a retina interna depende de uma restrita rede vascular. (Scholl e Zrenner, 2000; Shirao e Kawasaki, 1998; Tzekov e Arden, 1999). Entretanto, em pacientes com alterações morfológicas significativas (edema macular e retinopatia diabética) também já foram relatados prejuízos da função de receptores detectados pelo ERG (Greenstein e cols., 2000).

Diminuição da sensibilidade ao contraste em pacientes diabéticos também tem sido freqüentemente relatada (Bangstad e cols.,1994; Dean, Arden e Dornhorst,1997; DeMarco e cols; Di Leo e cols, 1992; Harris e cols., 1996). Devido à diversidade de estímulos que podem ser aplicados em testes de medida da sensibilidade ao contraste (variação de eixos de cromaticidade e de freqüências temporal e espacial) esta medida pode ser especialmente útil para revelar possíveis especificidades para o acometimento funcional da visão decorrente da diabete. Contudo, os trabalhos que buscaram identificar tais mecanismos têm indicado não haver seletividade para o estabelecimento do déficit (Di Leo e cols, 1992).

A tabela 3, a seguir, mostra alguns trabalhos que analisaram déficits da visão de cores, sensibilidade ao contraste e do ERG em pacientes diabéticos. 
Tabela 3: Visão de cores, sensibilidade ao contraste e eletrorretinograma em pacientes diabéticos. Trabalhos relacionados.

\begin{tabular}{|c|c|c|c|c|c|c|c|c|c|c|}
\hline & \multirow{3}{*}{ Autor } & \multirow{3}{*}{ Data } & \multicolumn{5}{|c|}{ Pacientes } & \multirow{3}{*}{$\begin{array}{c}\text { Testes } \\
\text { aplicados }\end{array}$} & \multicolumn{2}{|c|}{ Correlação com } \\
\hline & & & \multicolumn{2}{|c|}{$\begin{array}{l}\text { Tipo de } \\
\text { diabete }\end{array}$} & \multirow{2}{*}{$n$} & \multicolumn{2}{|c|}{ Retinopatia } & & \multirow{2}{*}{$\begin{array}{c}\text { Tempo } \\
\text { de } \\
\text { diabete }\end{array}$} & \multirow{2}{*}{$\begin{array}{c}\text { Controle } \\
\text { metabólico }\end{array}$} \\
\hline & & & 1 & 2 & & Com & Sem & & & \\
\hline \multirow{7}{*}{ 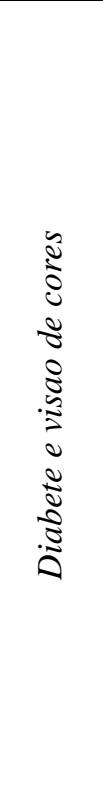 } & Fong e cols. & 1999 & $\mathrm{x}$ & $\mathrm{x}$ & 2701 & & & FM100 & - & $\operatorname{sim}$ \\
\hline & $\begin{array}{l}\text { Ismail e } \\
\text { Whitaker }\end{array}$ & 1998 & - & $\mathrm{x}$ & 30 & - & $\mathrm{x}$ & FM100 & $\operatorname{sim}$ & $\operatorname{sim}$ \\
\hline & $\begin{array}{l}\text { Kurtenbach e } \\
\text { cols. }\end{array}$ & 1994 & $\mathrm{x}$ & & 20 & $\mathrm{x}(16)$ & $\mathrm{x}(4)$ & $\begin{array}{l}\text { FM100/ } \\
\text { HFP }\end{array}$ & - & - \\
\hline & $\begin{array}{l}\text { Banford e } \\
\text { cols. }\end{array}$ & 1994 & - & $\mathrm{x}$ & 42 & x (37) & $x(5)$ & FM100 & $\operatorname{sim}$ & $\operatorname{sim}$ \\
\hline & Hardy e cols. & 1992 & $\mathrm{x}$ & - & 38 & - & $\mathrm{x}$ & $\begin{array}{l}\text { Ishihara/ } \\
\text { City } \\
\text { University } \\
\text { / FM100 }\end{array}$ & não & não \\
\hline & $\begin{array}{c}\text { Doucet e } \\
\text { cols. }\end{array}$ & 1991 & - & - & 100 & $\mathrm{x}(30)$ & $\mathrm{x}(70)$ & $\begin{array}{l}\text { Lanthony } \\
\text { D15-D }\end{array}$ & - & $\operatorname{sim}$ \\
\hline & Trick e cols. & 1988 & $\mathrm{x}$ & - & 57 & $\mathrm{x}(20)$ & $\mathrm{x}(37)$ & FM100 & não & $\operatorname{sim}$ \\
\hline \multirow{5}{*}{ 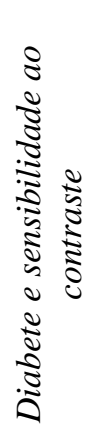 } & $\begin{array}{l}\text { Ismail e } \\
\text { Whitaker }\end{array}$ & 1998 & - & $\mathrm{x}$ & 30 & - & $\mathrm{x}$ & $\begin{array}{l}\text { Pelli- } \\
\text { Robson }\end{array}$ & $\operatorname{sim}$ & $\operatorname{sim}$ \\
\hline & Dean e cols. & 1997 & $\mathrm{x}$ & - & 37 & \multicolumn{2}{|c|}{$\mathrm{x}$} & $*$ & - & - \\
\hline & Harris e cols. & 1996 & $\mathrm{x}$ & - & 12 & \multicolumn{2}{|c|}{$\mathrm{x}$} & CSV-1000 & - & - \\
\hline & $\begin{array}{c}\text { Banford e } \\
\text { cols. }\end{array}$ & 1994 & - & $\mathrm{x}$ & 42 & $x(37)$ & $x(5)$ & $\begin{array}{l}\text { VCTS } \\
6500\end{array}$ & $\operatorname{sim}$ & $\operatorname{sim}$ \\
\hline & Trick e cols. & 1988 & $\mathrm{x}$ & - & 57 & $\mathrm{x}(20)$ & $x(37)$ & $\begin{array}{l}\text { VCTS } \\
6500\end{array}$ & não & não \\
\hline \multirow{2}{*}{ 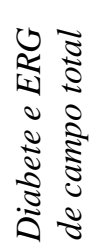 } & $\begin{array}{l}\text { Holopigian e } \\
\text { cols. }\end{array}$ & 1997 & & & 12 & & $\mathrm{x}$ & $\begin{array}{c}\text { ERG } \\
\text { campo } \\
\text { total }\end{array}$ & & não \\
\hline & $\begin{array}{c}\text { Lovasik e } \\
\text { Kergoat }\end{array}$ & 1993 & $\mathrm{x}$ & & 11 & $\mathrm{x}$ & - & $\begin{array}{c}\text { ERG } \\
\text { campo } \\
\text { total }\end{array}$ & - & - \\
\hline
\end{tabular}

* teste desenvolvido pelos autores (Arden, Gunduz e Perry, 1988)

CSV-100: tabela para medida de sensibilidade ao contraste; ERG: FM100: FarnsworthMunsell 100hue test; eletrorretinograma; HFP: fotometria por flicker heterocromático; Pelli-Robson: tabela para medida de sensibilidade ao contraste; VCTS: Vision contrast test system; 
A tabela 3 mostra alguns trabalhos em que sujeitos com e sem retinopatia foram agrupados (Dean e cols., 1997; Fong e cols., 1999; Harris e cols., 1996), não permitindo, portanto conclusões a respeito da possibilidade de haver perdas visuais na ausência de retinopatia. Outros trabalhos estudam apenas pacientes com retinopatia diabética. Finalmente, dentre os trabalhos que estudam pacientes aspectos funcionais da visão de pacientes sem retinopatia diabética separando claramente os grupos de pacientes com e sem retinopatia, vários avaliaram apenas pacientes com diabete tipo 1 (Kurtenbach e cols. 1994, North e cols., 1997, Trick e cols, 1988). Apenas os trabalhos de Doucet e cols. (1991), Ismail e Whitaker (1998) e de Banford (1994) avaliaram funções visuais por métodos psicofísicos em diabéticos do tipo 2. Os estudos de Holopigian e cols (1997) e de Lovasik e Kergoat (1993) encontraram alterações no ERG de campo total, mas além de avaliarem apenas pacientes com diabete tipo 1, não fizeram medidas psicofísicas. 



\section{JUSTIFICATIVA}

A ocorrência cada vez mais precoce da diabete tipo 2 somada ao aumento da expectativa de vida que se observa, resulta em mais tempo de vida com a doença e, conseqüentemente, maior probabilidade para o estabelecimento de complicações nos pacientes acometidos pela patologia.

Como mostrado na tabela 3, poucos trabalhos têm avaliado apenas pacientes com diabete tipo 2 sem retinopatia e, nestas condições, não há trabalhos avaliando conjuntamente a visão de cores, a sensibilidade a contrastes e o eletrorretinograma.

Um projeto piloto feito em nosso laboratório (Ventura e cols., 2003a) em um grupo composto apenas por diabéticos do tipo 2, com aspecto retiniano completamente normal ao exame de fundo de olho. O trabalho mostrou que a discriminação de cores nesta população é pior em relação a um grupo controle de mesma idade.

Entretanto, neste estudo apenas a discriminação de cores foi avaliada e alem disso, não foi feito controle da glicemia dos pacientes examinados, o que pode levar a dificuldades de interpretação dos resultados, uma vez que a visão de cores é afetada pelo nível glicêmico observado durante a avaliação.

Assim, a avaliação de um número maior de indivíduos diabéticos com um número maior de aspectos analisados (sensibilidade ao contraste, função da retina, controle metabólico e tempo de doença) proposta neste estudo, pode confirmar o comprometimento da visão de cores nestes sujeitos e possivelmente detalhar os mecanismos envolvidos. 


\section{OBJETIVO}

As alterações de visão de cores e sensibilidade a contrastes em indivíduos com de DM. tipo 2 com alterações visíveis do fundo de olho já são conhecidas.

Este trabalho teve como objetivo verificar se a visão de cores e de contrastes está prejudicada em pacientes diabéticos sem sinais clínicos de retinopatia diabética no fundo de olho (retina) no exame oftalmológico de fundoscopia. A constatação de prejuízos funcionais poderá ter utilidade de diagnóstico precoce.

Os objetivos específicos são:

- Avaliar a discriminação cromática através do Cambridge Colour Test (CCT);

- Avaliar a sensibilidade ao contraste espacial acromático de luminância e cromático equiluminante.

- Estudar o padrão das respostas eletrofisiológicas na retina desses pacientes através do eletrorretinograma de campo total (ERG);

- Verificar se há correlação entre o déficit de visão de cores, a alteração de resposta eletrofisiológica, o tempo de doença e o controle metabólico. 


\section{METODOLOGIA}

Este estudo foi aprovado pelos Comitês de Ética em Pesquisa (CEP) do Instituto de Psicologia e do Hospital Universitário da USP (anexo A).

\subsection{SUJEITOS}

Os pacientes diabéticos foram encaminhados ao nosso serviço pelas clínicas de Oftalmologia e Clínica Médica do Hospital Universitário da Universidade de São Paulo. A avaliação foi feita entre março de 2003 e maio de 2004.

Os critérios para inclusão no grupo experimental foram:

- Acuidade visual melhor ou igual a 20/30, segundo tabela de optotipos de Snellen, com a melhor correção óptica para erros refrativos;

- Ausência de opacidade dos meios oculares que comprometam bom desempenho das funções visuais;

- Ausência de sinais de retinopatia diabética ou de qualquer outra alteração da retina;

- Ausência de tratamentos retinianos anteriores.

A descrição dos pacientes que compuseram o grupo experimental deste trabalho está na tabela 4. 
Tabela 4: Tabela descritiva dos pacientes do grupo experimental

\begin{tabular}{|c|c|c|c|c|c|c|c|c|}
\hline \multicolumn{2}{|c|}{ Paciente } & \multirow{2}{*}{$\frac{\text { Sexo }}{}$} & \multirow{2}{*}{$\begin{array}{c}\text { Idade } \\
60\end{array}$} & \multirow[t]{2}{*}{$\begin{array}{c}\text { Olho } \\
\text { examinado }\end{array}$} & \multirow[t]{2}{*}{$\begin{array}{c}\text { Acuidad } \\
\text { e Visual } \\
\text { A.V. } \\
20 / 20\end{array}$} & \multirow[t]{2}{*}{$\begin{array}{c}\text { Tempo } \\
\text { de } \\
\text { diabete } \\
\text { (anos) } \\
1,00\end{array}$} & $\begin{array}{c}\text { Glicose } \\
\text { no dia } \\
\text { do teste } \\
\text { (mg/dl) }\end{array}$ & \multirow{2}{*}{$\begin{array}{c}H b A(\%) \\
6,20\end{array}$} \\
\hline 1 & $\mathrm{AB}$ & & & & & & 139,00 & \\
\hline 2 & $\mathrm{AD}$ & $\mathrm{M}$ & 56 & OD & $20 / 20$ & 1,00 & 79,00 & - \\
\hline 3 & APP & $\mathrm{F}$ & 76 & $\mathrm{OE}$ & $20 / 30$ & 15,00 & 83,00 & - \\
\hline 4 & ASS & M & 47 & $\mathrm{OE}$ & $20 / 20$ & 8,00 & 69,00 & 5,30 \\
\hline 5 & CAA & M & 46 & OD & $20 / 30$ & 0,16 & 161,00 & 5,00 \\
\hline 6 & CAS & $\mathrm{F}$ & 35 & $\mathrm{OE}$ & $20 / 20$ & 1,00 & 138,00 & 6,90 \\
\hline 7 & $\mathrm{CPT}$ & $\mathrm{F}$ & 59 & $\mathrm{OE}$ & $20 / 20$ & 10,00 & 139,00 & - \\
\hline 8 & CTA & M & 48 & OD & $20 / 20$ & 6,00 & 85,00 & 4,20 \\
\hline 9 & CVS & $\mathrm{F}$ & 57 & OD & $20 / 20$ & 6,00 & 84,00 & 6,40 \\
\hline 10 & DPA & $\mathrm{F}$ & 57 & OD & $20 / 20$ & 3,00 & 117,00 & 4,50 \\
\hline 11 & DU & $\mathrm{F}$ & 74 & OD & $20 / 25$ & 15,00 & 255,00 & 10,90 \\
\hline 12 & ELA & $\mathrm{F}$ & 65 & OD & $20 / 20$ & 13,00 & 78,00 & 5,70 \\
\hline 13 & ES & $\mathrm{M}$ & 53 & OD & $20 / 20$ & 1,00 & 108,00 & 5,40 \\
\hline 14 & EVM & $\mathrm{F}$ & 44 & OD & $20 / 20$ & 7,00 & 72,00 & 7,80 \\
\hline 15 & FHI & M & 56 & OD & $20 / 20$ & 4,50 & 125,00 & - \\
\hline 16 & FP & M & 61 & $\mathrm{OE}$ & $20 / 25$ & 10,00 & 168,00 & 8,70 \\
\hline 17 & GB & M & 53 & $\mathrm{OE}$ & $20 / 25$ & 0,67 & 120,00 & - \\
\hline 18 & GCF & M & 43 & $\mathrm{OE}$ & $20 / 20$ & 6,00 & 164,00 & 4,60 \\
\hline 19 & $\mathrm{HCS}$ & $\mathrm{F}$ & 66 & OD & $20 / 20$ & 20,00 & 115,00 & - \\
\hline 20 & IR & M & 59 & OD & $20 / 20$ & 15,00 & 120,00 & 6,20 \\
\hline 21 & JAF & M & 73 & OD & $20 / 20$ & 6,00 & 112,00 & 5,90 \\
\hline 22 & JBS & M & 47 & OD & $20 / 20$ & 4,00 & 110,00 & 5,50 \\
\hline 23 & JLO & M & 50 & OD & $20 / 20$ & 4,00 & 220,00 & 6,30 \\
\hline 24 & JMSS & M & 64 & OD & $20 / 20$ & 10,00 & 165,00 & 7,10 \\
\hline 25 & LCCA & M & 43 & OD & $20 / 20$ & 0,25 & 89,00 & 6,50 \\
\hline 26 & LMR & M & 47 & OD & $20 / 20$ & 20,00 & 165,00 & - \\
\hline 27 & MAN & $\mathrm{F}$ & 43 & OD & $20 / 20$ & 6,00 & 155,00 & 9,00 \\
\hline 28 & $\mathrm{MBC}$ & $\mathrm{F}$ & 51 & & $20 / 20$ & 2,00 & 169,00 & 6,00 \\
\hline 29 & MCMS & $\mathrm{F}$ & 67 & $\mathrm{OE}$ & $20 / 25$ & 13,00 & 115,00 & - \\
\hline
\end{tabular}


Tabela 4: continuação.

\begin{tabular}{|c|c|c|c|c|c|c|c|c|}
\hline \multicolumn{2}{|c|}{ Paciente } & \multirow{2}{*}{$\frac{\operatorname{Sexo}}{\mathrm{F}}$} & \multirow{2}{*}{$\frac{\text { Idade }}{51}$} & \multirow{2}{*}{$\begin{array}{c}\text { Olho } \\
\text { examinado }\end{array}$} & \multirow{2}{*}{$\begin{array}{c}\text { Acuidad } \\
\text { e Visual } \\
\text { A.V. } \\
20 / 20\end{array}$} & \multirow{2}{*}{$\begin{array}{c}\text { Tempo } \\
\text { de } \\
\text { diabete } \\
\text { (anos) }\end{array}$} & \multirow{2}{*}{$\begin{array}{c}\text { Glicose } \\
\text { no dia } \\
\text { do teste } \\
\text { (mg/dl) }\end{array}$} & \multirow{2}{*}{$\begin{array}{c}H b A(\%) \\
-\end{array}$} \\
\hline 30 & MCRGF & & & & & & & \\
\hline 31 & $\mathrm{MD}$ & M & 62 & $\mathrm{OE}$ & $20 / 20$ & 15,00 & 129,00 & - \\
\hline 32 & MJPAO & $\mathrm{F}$ & 53 & OD & $20 / 25$ & 20,00 & 113,00 & 6,90 \\
\hline 33 & MJS & $\mathrm{F}$ & 59 & $\mathrm{OE}$ & $20 / 20$ & 2,00 & 156,00 & 5,80 \\
\hline 34 & MOV & $\mathrm{F}$ & 66 & $\mathrm{OE}$ & $20 / 25$ & 4,00 & 121,00 & 10,00 \\
\hline 35 & MPO & $\mathrm{F}$ & 48 & OD & $20 / 20$ & 0,50 & 240,00 & 6,80 \\
\hline 36 & ND & $\mathrm{F}$ & 62 & OD & $20 / 20$ & 12,00 & 99,00 & 6,90 \\
\hline 37 & PL & M & 61 & $\mathrm{OE}$ & $20 / 20$ & 3,00 & 196,00 & 6,00 \\
\hline 38 & SB & M & 50 & OD & $20 / 20$ & 3,00 & 131,00 & 5,70 \\
\hline 39 & SLL & F & 62 & OD & $20 / 20$ & 2,00 & 90,00 & 6,30 \\
\hline 40 & SPF & $\mathrm{F}$ & 52 & $\mathrm{OE}$ & $20 / 20$ & 10,00 & 180,00 & 9,70 \\
\hline Média & & & 56 & & & 7 & 133 & 7 \\
\hline $\begin{array}{l}\text { Desvio } \\
\text { Padrão }\end{array}$ & & & 9 & & & 6 & 44 & 2 \\
\hline
\end{tabular}

OD: olho direito; OE: F: feminino; M:

olho esquerdo masculino

O desempenho dos pacientes foi comparado aos de sujeitos controle sem história de patologias oculares e/ou neurológicas e com acuidade visual mínima de 20/25. A constituição dos grupos controle foi diferente para cada tipo de teste.

O grupo controle do teste CCT foi composto por 23 voluntários; 11 mulheres e 12 homens com idade média $=62$ anos \pm 9 . Os resultados do ERG dos pacientes foram comparados aos de oito voluntários, 3 mulheres e 5 homens com idade média $=36$ anos \pm 8 . O grupo controle usado para a comparação com os dados de sensibilidade ao 
contraste foi formado por 14 voluntários, 7 mulheres e 7 homens com idade média= $61,43 \pm 13,54$

Todos os sujeitos (pacientes e controles) assinaram termo de consentimento (anexo D) atestando o conhecimento dos procedimentos realizados e a participação totalmente voluntária no estudo.

\subsection{CAMBRIDGE COLOUR VISION TEST (CCT)}

O exame foi realizado monocularmente, no olho dominante, em ambiente totalmente escurecida e com o sujeito posicionado a três metros do monitor de apresentação dos estímulos. A figura 23 mostra um sujeito em situação de teste.

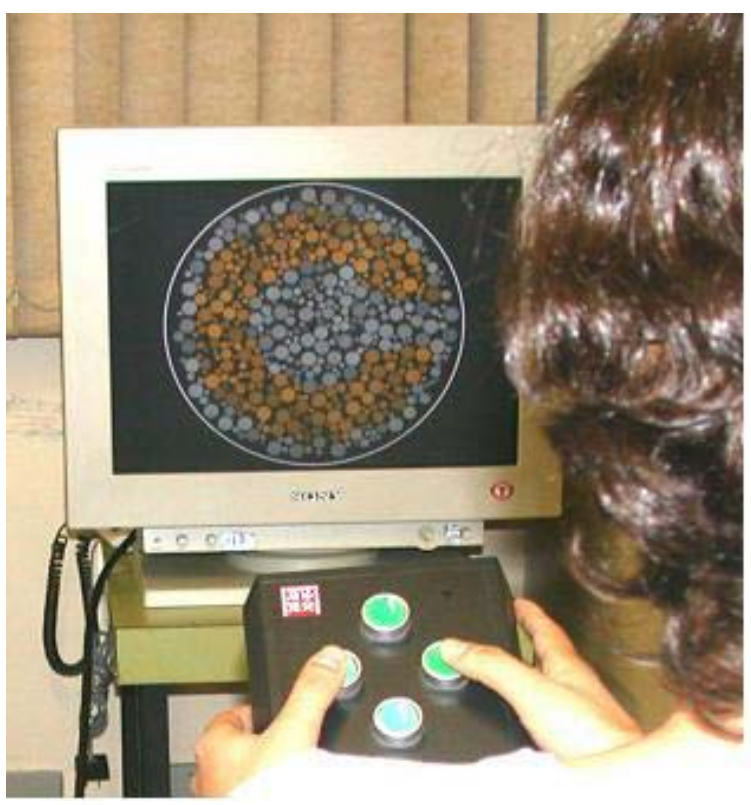

Figura 23: Simulação da situação de teste com sujeito posicionado a frente do monitor segurando a caixa de respostas. 


\subsubsection{Estímulo e equipamento}

O estímulo utilizado, o "C", teve as seguintes dimensões: 5,4 graus de ângulo visual para o diâmetro externo, 2,75 para o diâmetro interno e 1,25 para a abertura como mostrado na figura 24. A luminância dos componentes do estímulo variou numa faixa de 4 a $18 \mathrm{~cd} / \mathrm{m} 2$, dividida em seis níveis.

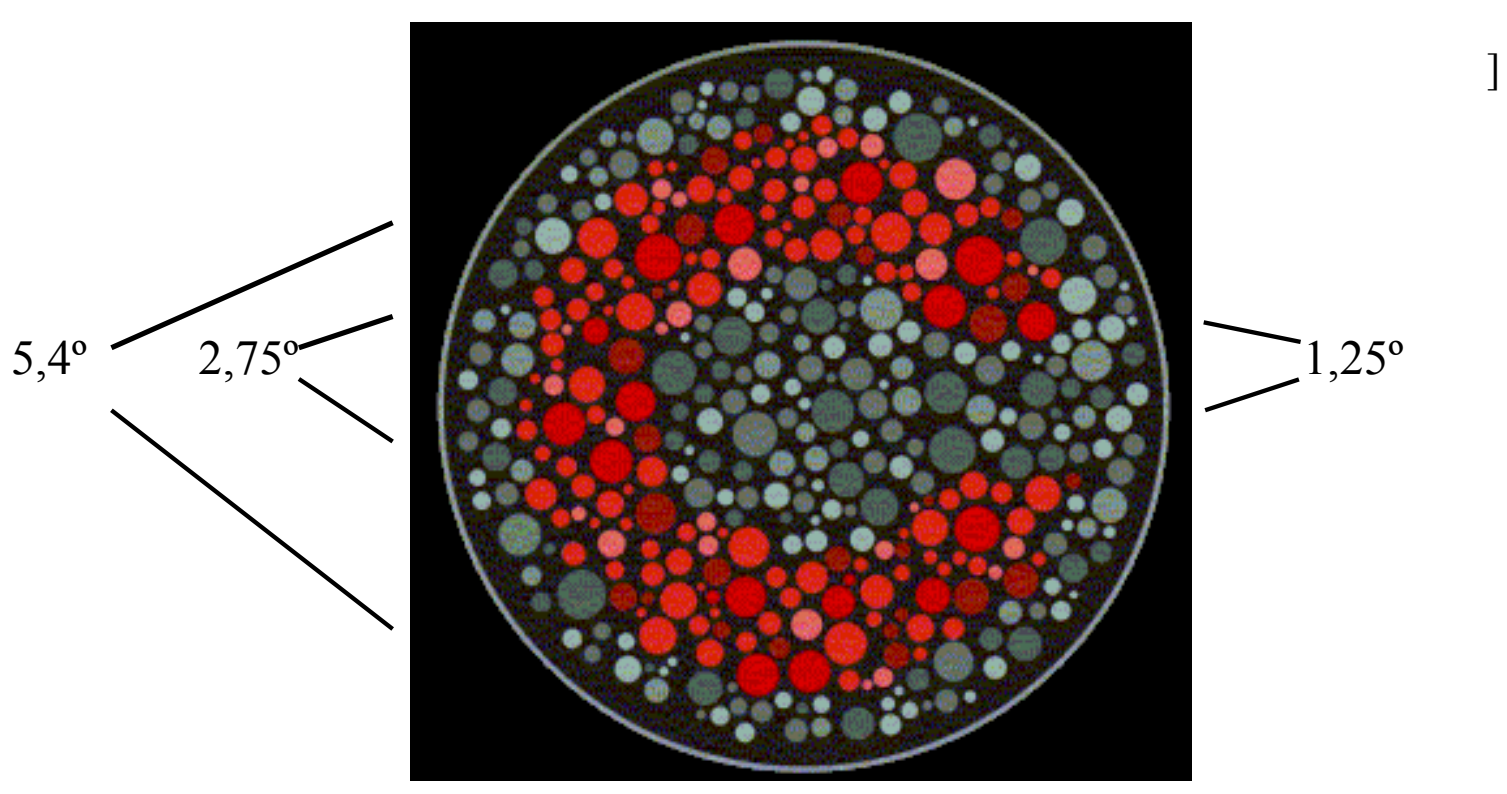

Figura 24: Um exemplo do estímulo usado no teste CCT e suas dimensões em graus de ângulo visual.

Os equipamentos usados para a aplicação do teste incluem:

- Micro-computador (Dell, Dimension X7s T600); 
- Programa Cambridge Colour Vision Test (Cambridge Research System, CRS);

- Placa gráfica com resolução de 15 bits (VSG 2/5- CRS Ltd.) para a construção dos estímulos;

- Monitor Trinitron 20" (Sony GDM-F500T9) com frame rate de $100 \mathrm{~Hz} \mathrm{e}$ resolução de 800 x 600 pixels.

As coordenadas de cromaticidade dos fósforos RGB do monitor usado para o CCT que determinam a gama ou gamut de cores que o monitor é capaz de reproduzir foram:

- Fósforo Vermelho $\mathrm{x}=0,610 ; \mathrm{y}=0,0340$;

- Fósforo Verde $\mathrm{x}=0,280 ; \mathrm{y}=0,595$;

- Fósforo Azul $\mathrm{x}=0,141 ; \mathrm{y}=0,070$.

\subsection{ELETRORRETINOGRAMA (ERG)}

\subsubsection{Preparação do paciente}

$\mathrm{O}$ teste foi feito monocularmente (no olho dominante). Os passos para a preparação do paciente incluíram:

- Dilatação da pupila do olho testado (olho dominante) com colírio de tropicamida $1 \%$ e fenilefrina $2,5 \%$, feita com a finalidade de se ter a maior área da retina possível sendo estimulada; 
- Adaptação ao escuro durante 20 minutos - já que a primeira etapa do teste corresponde a sua fase escotópica;

- Anestesia da córnea com colírio de hidrocloreto de proparacaína $0,5 \%$ - para evitar que o paciente sinta qualquer desconforto durante a colocação do eletrodo corneal;

- Colocação do eletrodo - este foi preenchido com colírio de metilcelulose $2 \%$ com a finalidade de manter a lubrificação corneal durante o exame.

A figura 25 mostra o eletrodo de registro colocado e em seguida como o paciente é posicionado diante da cúpula de apresentação dos estímulos.
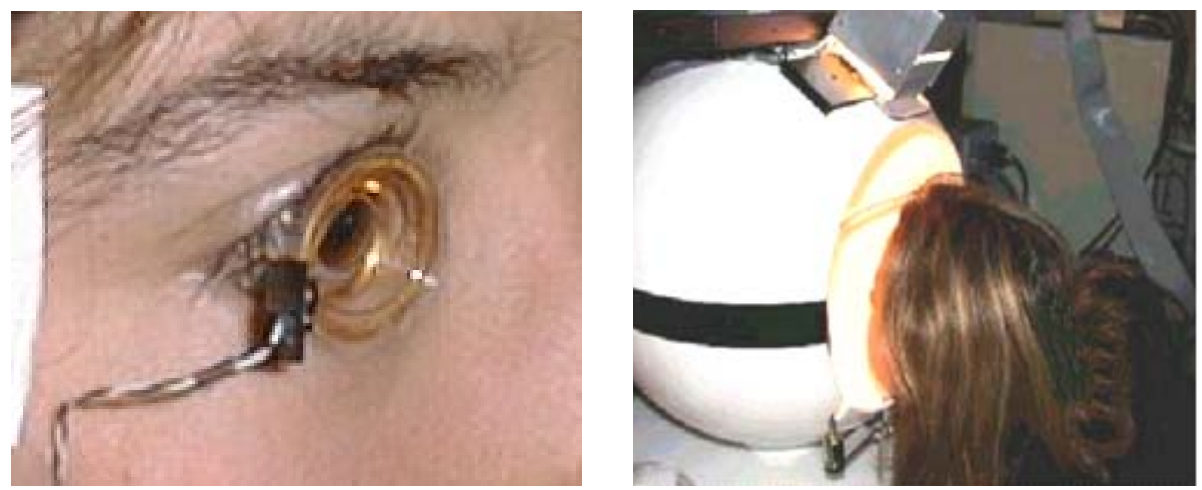

Figura 25: Posicionamento do eletrodo de registro, à esquerda, e do paciente diante da cúpula de estimulação, à direita. 


\subsubsection{Estímulo e equipamento}

A intensidade dos flashes usados, a duração do intervalo entre os estímulos e a quantidade de estímulos foram modificados de acordo com o tipo de resposta a ser registrada. A tabela 5 mostra os parâmetros adotados em cada resposta. 
Tabela 5: Condições de Estimulação para o ERG de Campo Total segundo protocolo da ISCEV

\begin{tabular}{|c|c|c|c|c|c|}
\hline & & $\begin{array}{l}\text { Intensidade } \\
\text { do flash } \\
\text { (cd/m2 }\end{array}$ & $\begin{array}{c}\text { Intervalo } \\
\text { inter- } \\
\text { estímulo } \\
\text { (segundos) }\end{array}$ & $\begin{array}{l}\text { Intensidade } \\
\text { da luz de } \\
\text { fundo } \\
(\mathrm{cd} / \mathrm{m} 2)\end{array}$ & $\begin{array}{l}\text { Número } \\
\text { de } \\
\text { registros }\end{array}$ \\
\hline \multirow{5}{*}{ 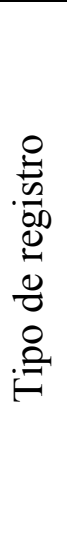 } & $\begin{array}{c}\text { Resposta de } \\
\text { bastonetes }\end{array}$ & 0,01 & 2,00 & - & 20,00 \\
\hline & $\begin{array}{l}\text { Resposta } \\
\text { escotópica } \\
\text { máxima }\end{array}$ & 2,80 & 10,00 & - & 20,00 \\
\hline & $\begin{array}{c}\text { Potenciais } \\
\text { oscilatórios }\end{array}$ & 2,80 & 15,00 & - & 20,00 \\
\hline & $\begin{array}{l}\text { Resposta de } \\
\text { cones }\end{array}$ & 2,80 & 5,00 & 32,00 & 20,00 \\
\hline & Flicker $30 \mathrm{~Hz}$ & 2,80 & 0,03 & 32,00 & 50,00 \\
\hline
\end{tabular}

Os flashes foram emitidos por foto estimulador Grass Instruments, modelo PS33 plus acoplado a uma cúpula refletora - Ganzfeld - LKC Systems, modelo 2503B.

A aquisição dos registros foi feita com programa desenvolvido por David Birch e Stephen Nusinowitz. Os sinais eram amplificados por amplificador Grass modelo ICP 511A e digitalizados com placa NB1 (National Instruments).

O eletrodo usado para a captação dos registros foi o eletrodo bipolar corneal Goldlens (Doran Instruments). O aterramento foi feito com eletrodos Grass, F-E5GH colocados no lobo auricular contra-lateral ao olho examinado. 


\subsubsection{Condições de registro e análise de resultados}

As respostas foram amplificadas em 104 vezes e o valor do filtro passa-banda utilizado foi para a faixa entre $3 \mathrm{~Hz}$ e $3 \mathrm{kHz}$ em todos os registros, exceto no dos potenciais oscilatórios para o qual o filtro selecionou sinais entre $100 \mathrm{~Hz}$ e $1 \mathrm{kHz}$.

A análise do ERG foi baseada no padrão clínico de análise (ISCEV, 2003). Assim, foram considerados os parâmetros de amplitude pico-a-pico, que corresponde à amplitude da onda b, e tempo implícito das ondas - a e -b de cada registro. Nos potenciais oscilatórios, a amplitude analisada corresponde à soma das amplitudes de cada potencial $(\mathrm{O} 1$ a $\mathrm{O} 7)$ e a latência corresponde ao intervalo entre o estímulo e o primeiro pico $(\mathrm{O} 1)$. A amplitude da onda $\mathrm{b}$ corresponde à medida em microvolts do vale da onda $a$ até o seu pico. A latência de cada onda corresponde ao intervalo em milissegundos existente entre o estímulo e a culminância de cada onda. A figura 26 mostra como são medidos os parâmetros de amplitude e latência das ondas a e b de um registro de ERG.

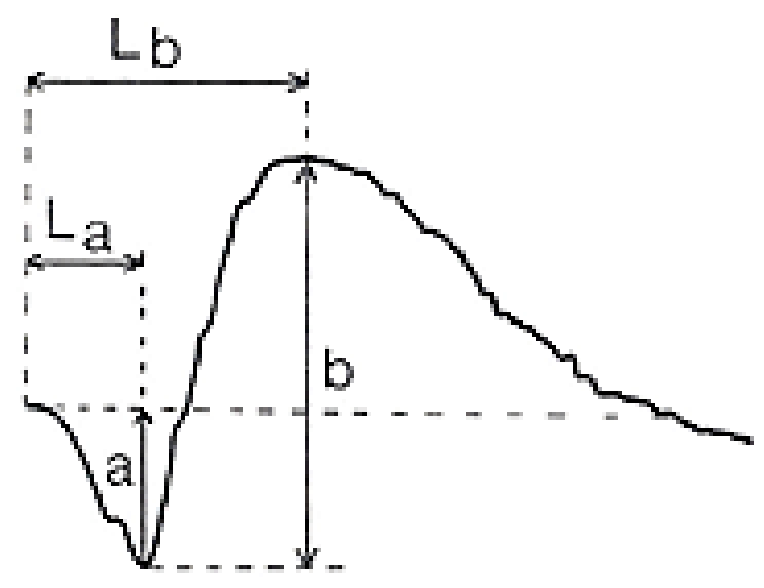


Figura 26: ERG - representação das medidas extraídas de um registro eletrorretinográfico. “a” representa a amplitude da onda $a ; b=$ amplitude da onda $b ; L a=$ latência da onda $a$ $L b=$ latência da onda $b$.

\subsection{SENSIBILIDADE AO CONTRASTE}

A avaliação da sensibilidade ao contraste foi precedida por um procedimento de fotometria por flicker heterocromático (Heterochromatic Flickerphotometry, HFP) com a finalidade de tornar equiluminantes os pares de cores usados em cada série de teste.

O resultado da HFP corresponde a um valor de ajuste de luminância para cada cor, feito pelo sujeito em função da freqüência espacial do estímulo. Este valor foi usado para ajustar os estímulos usados no teste de sensibilidade ao contraste de cada paciente.

Ambos os procedimentos de HFP e medida da CSF foram feitos monocularmente, no olho dominante, em ambiente escurecido e com o sujeito posicionado a um metro do monitor de apresentação do estímulo.

As medidas foram feitas pelo método do ajuste, no qual parte-se de estímulos ora supra-limiares, ora infra-limiares e o sujeito recebe instruções para que ajuste o estímulo até desaparecer se a série for descendente, ou aparecer, se a série for ascendente (anexo F). O limiar de ajuste de luminância - para a HFP - ou de sensibilidade ao contraste para a CSF - foi obtido pela média de seis valores de ajuste, três ascendentes e três descendentes. 


\subsubsection{Estímulo}

Tanto para os testes de fotometria heterocromática quanto de sensibilidade ao contraste, foram utilizados estímulos centrais - área de quatro graus de ângulo visualcompostos por ondas cromáticas ou acromáticas com variação senoidal de luminância sobrepostas em contra-fase de 180 graus de modo a formar redes horizontais vermelho/verde; azul/amarelo ou preto/branco (figura 27).

A figura 27 mostra o perfil da variação de luminância de duas ondas acromáticas (acima) e cromáticas (abaixo) superpostas em contra-fase de $180^{\circ}$ de forma que quando uma das ondas tem luminância máxima, a outra tem luminância mínima. À direita dos gráficos de ondas é mostrada a aparência do estímulo formado pelas duas ondas senoidais em contra-fase que o sujeito vê durante o teste.

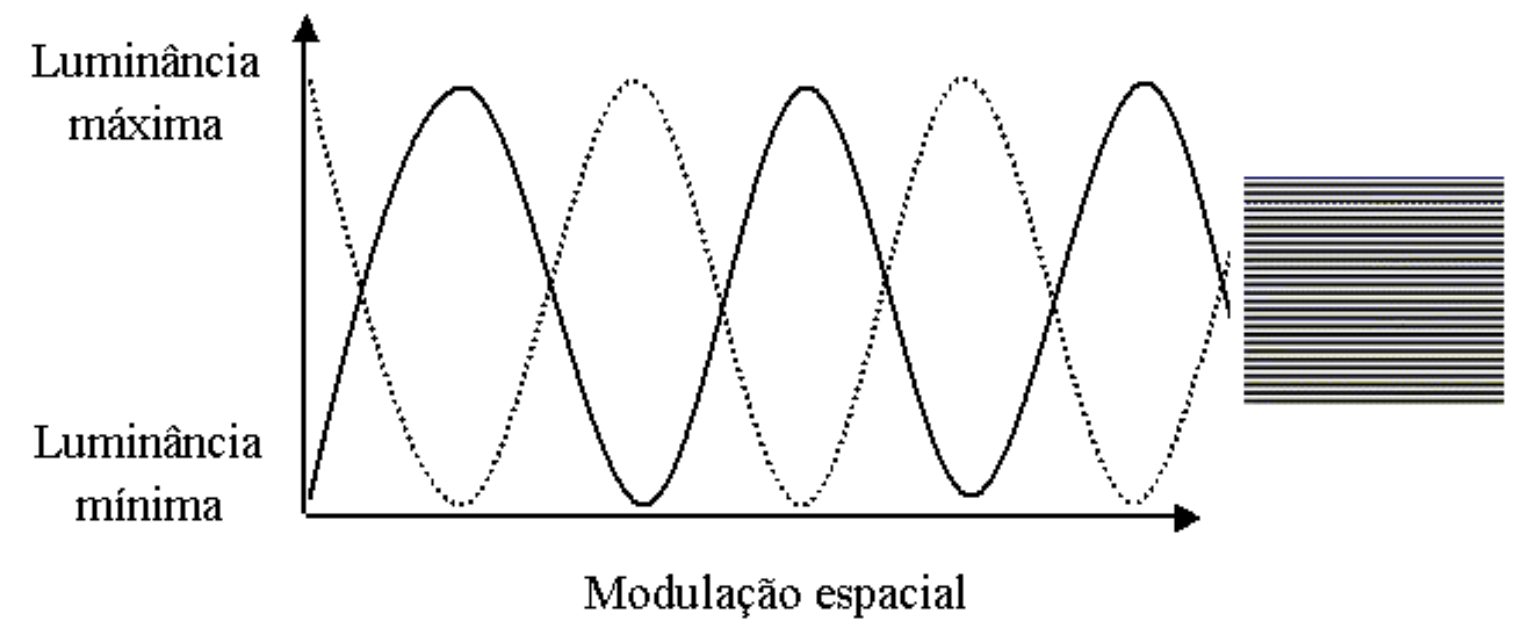




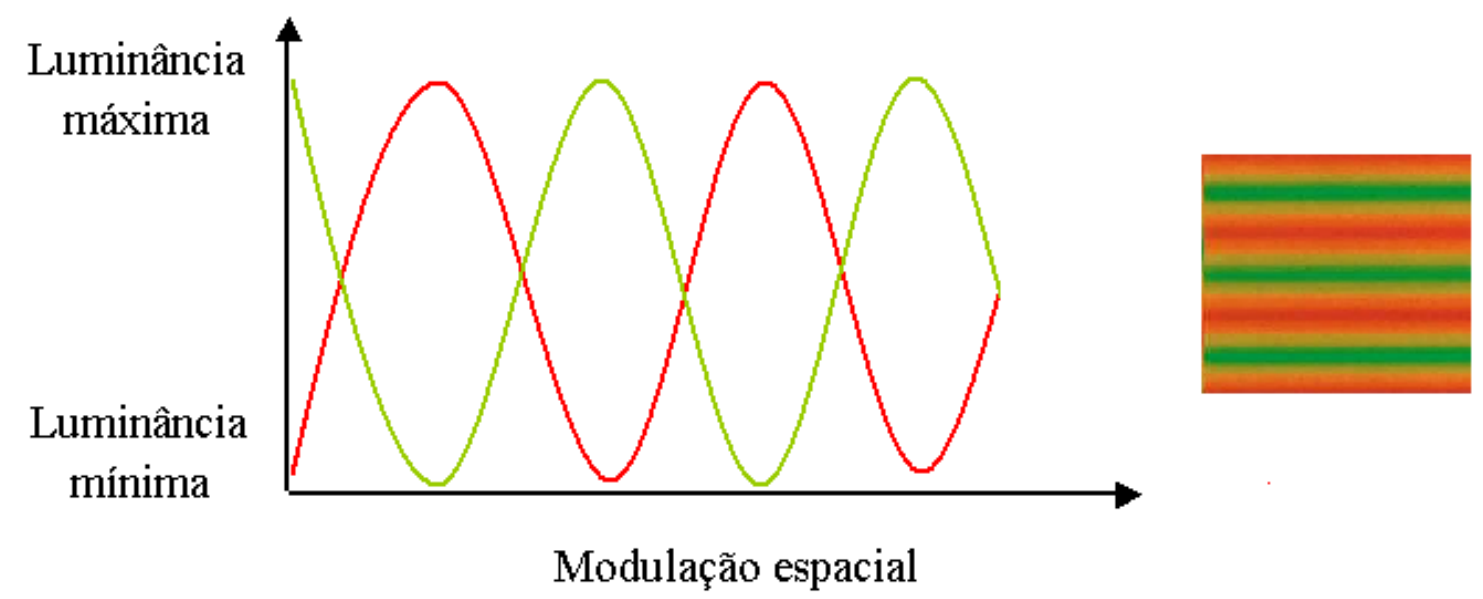

Figura 27: Redes senoidais com modulação espacial da luminância para uma onda acromática (acima) e ondas cromáticas no eixo vermelho/verde (abaixo).

A luminância média dos padrões foi de $34.4 \mathrm{~cd} / \mathrm{m} 2$, medida com fotômetro Optical modelo OP-200E (CRS). Nas séries de estímulos cromáticos apresentados na HFP a modulação senoidal temporal foi de $20 \mathrm{~Hz}$.

As coordenadas de cromaticidade para os estímulos foram escolhidas de modo a favorecer o isolamento a resposta dos diferentes tipos de cones a cada série de testes (Mac Leod e Boynton, 1979). Os valores das coordenadas foram: vermelho: $\mathrm{x}=0.370, \mathrm{y}$ $=0.289$; verde: $\mathrm{x}=0.227, \mathrm{y}=0.355 ;$ azul: $\mathrm{x}=0.274, \mathrm{y}=0.230$; amarelo $\mathrm{x}=0.393, \mathrm{y}=$ 0.511 (figura 28). 


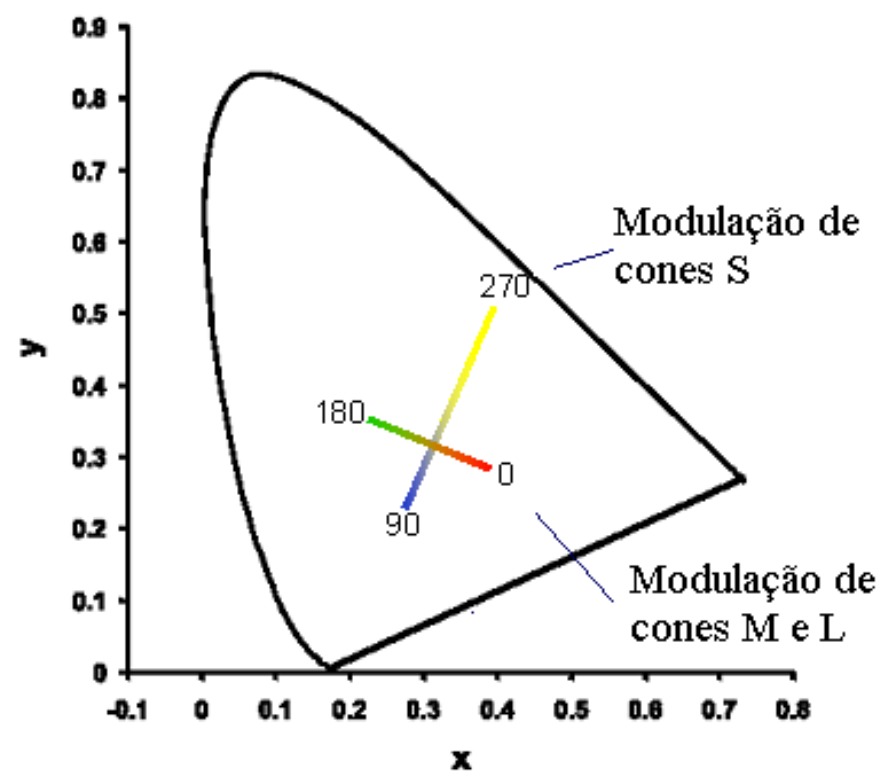

Figura 28: Disposição das coordenadas de cromaticidade dos estímulos usados nos testes de sensibilidade ao contraste de cor e de fotometria por flicker heterocromático.

\subsubsection{Equipamento}

Os testes foram executados com o programa PSYCHO for Windows v. $2.36 \AA$ (CRS), desenvolvido para configurar testes de avaliação psicofísica visual.

Para a apresentação dos estímulos foi usado monitor de 19" (Sony CPD-G420) com frame rate de $100 \mathrm{~Hz}$ e resolução de 800 x 600 e comandado por placa gráfica de 12 bits VSG 2/4 (CRS).

\subsection{FATORES PARA CORRELAÇÃO}

Os resultados do CCT e ERG foram correlacionados com três fatores:

- O tempo de diagnóstico de diabete - relatado na anamnese; 
- A porcentagem de hemoglobina glicosilada (HbA) em amostras de sangue dos pacientes - a HbA é um composto formado por hemácias que se ligam quimicamente à glicose. Esta ligação ocorre normalmente em todos os indivíduos e a razão de glóbulos vermelhos ligados à glicose é diretamente relacionada à quantidade de glicose circulante. Logo, a porcentagem de $\mathrm{HbA}$ é um índice altamente confiável para refletir o controle metabólico que o paciente manteve no período de até três meses antes do exame. Pela técnica adotada, o limite máximo normal neste teste é de $6,3 \%$. Os resultados foram extraídos dos exames regulares a que todos os pacientes são submetidos no HU-USP e estão na tabela 4;

- A taxa de glicose no dia do exame - da mesma forma que a hiperglicemia crônica, picos de hipoglicemia aguda têm sido considerados danosos à função visual. Portanto, o objetivo desta medida era identificar picos de hipoglicemia durante o teste. A medida foi feita com glicosímetro portátil e digital, sistema Advantage II (Roche, 2001), que usa o princípio da amperimetria (fluxo de elétrons liberados pela amostra após reagir com a fita de medida) para estabelecer a concentração de glicose. Todo o procedimento foi feito com material descartável. 


\subsection{ANÁLISE DOS RESULTADOS}

As respostas dos pacientes foram comparadas às dos controles de duas formas. Primeiro, foram comparados os resultados da análise descritiva de cada grupo a fim de se identificar diferenças significantes entre os dois grupos (teste $t$ para os dados com distribuição normal e teste Kruskal-Wllis para resultados que não tiveram distribuição normal). Depois, o desempenho individual dos pacientes em cada teste foi analisado quanto à sua inclusão ou exclusão nos limites de confiança $\pm 95 \%$ determinados pelos resultados obtidos com os grupos controle (Dixon e Massey, 1957). Foram consideradas como alteradas as respostas de pacientes que estivessem fora destes limites.

A relação entre os resultados do $\mathrm{CCT}$, ERG e $\mathrm{SC}$ e os fatores descritos no item anterior foi feita com teste de correlação de Pearson.

Para todas as análises o nível de significância admitido no teste de hipótese nula foi de 0,05 . 


\section{RESULTADOS}

\subsection{CAMBRIDGE COLOUR VISION TEST - CCT}

Os resultados da avaliação de discriminação de cor estão divididos de acordo com as duas etapas do CCT: teste trivector e teste das elipses.

A figura 29 mostra os resultados de limiar de pacientes e controles medidos no teste trivector. Nos gráficos de caixa (box plot) estão representados os valores de mediana (linha horizontal); valores mínimos e máximos (caixa), quartis 25\% e 75\% (barras verticais) e de valores discrepantes. A comparação destes resultados mostrou haver diferença significativa entre pacientes diabéticos e controles apenas para o resultado do limiar protan ( $\mathrm{p}=0,05$ teste Kurskal-Wallis).

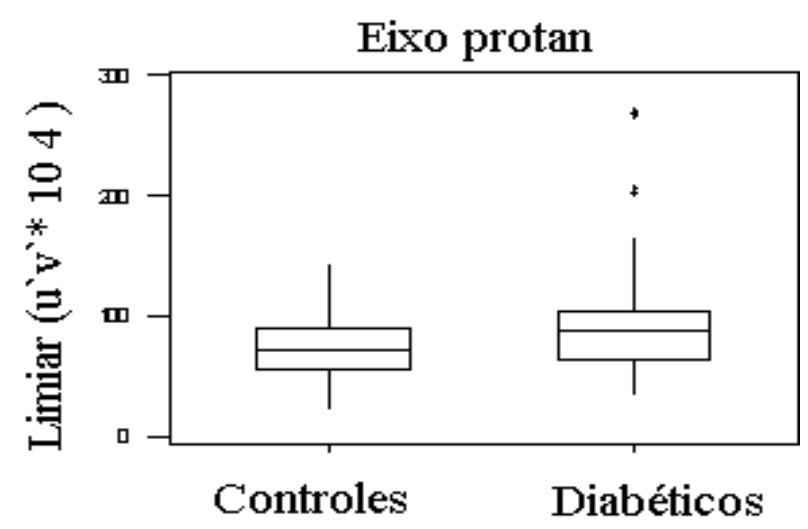



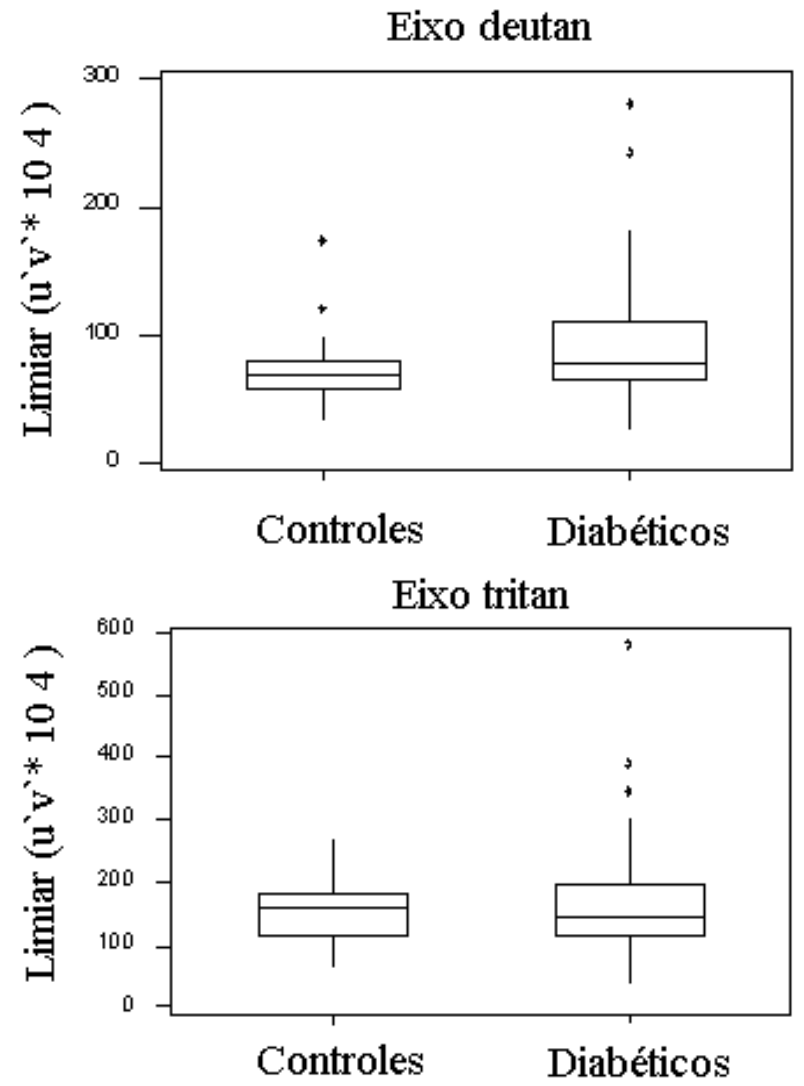

Figura 29: CCT - Teste trivector. Limiar de pacientes e controles nos eixos protan, deutan e tritan.

Os gráficos de pontos da figura 30 permitem examinar o desempenho de cada paciente e confrontá-lo com o parâmetro normal. As proporções de pacientes com resultados acima do limite normal nos eixo protan, deutan e tritan foram respectivamente de $20 / 40,15 / 40$ e $11 / 40$. 
Eixo protan

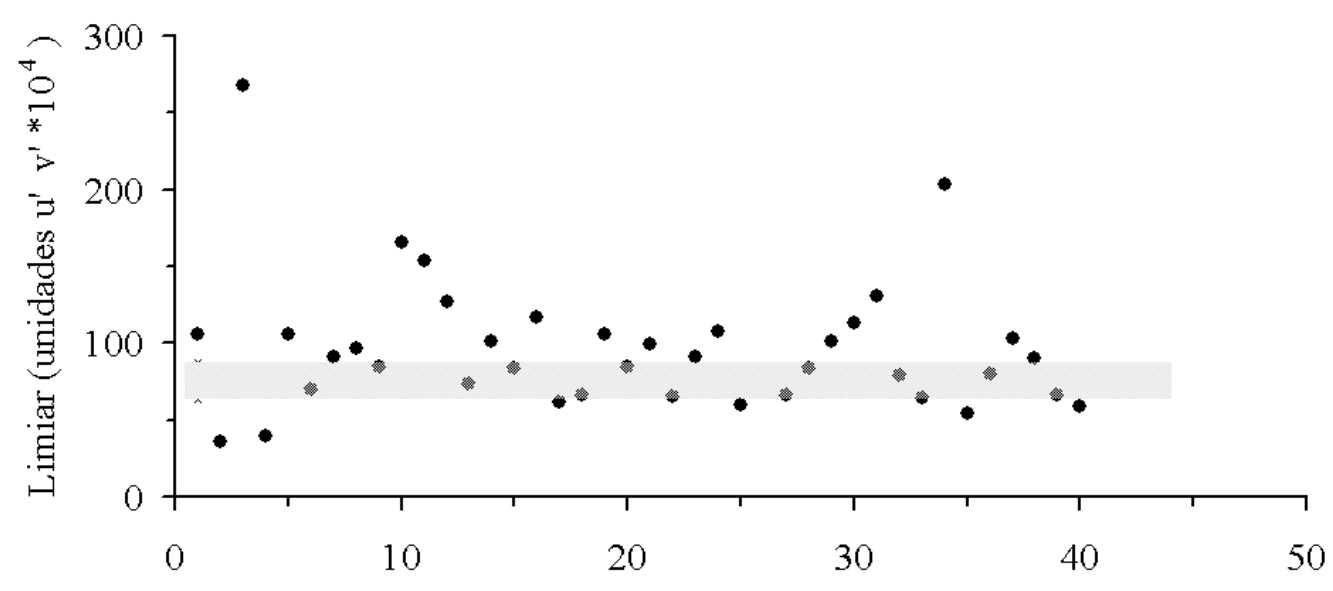

Eixo deutan

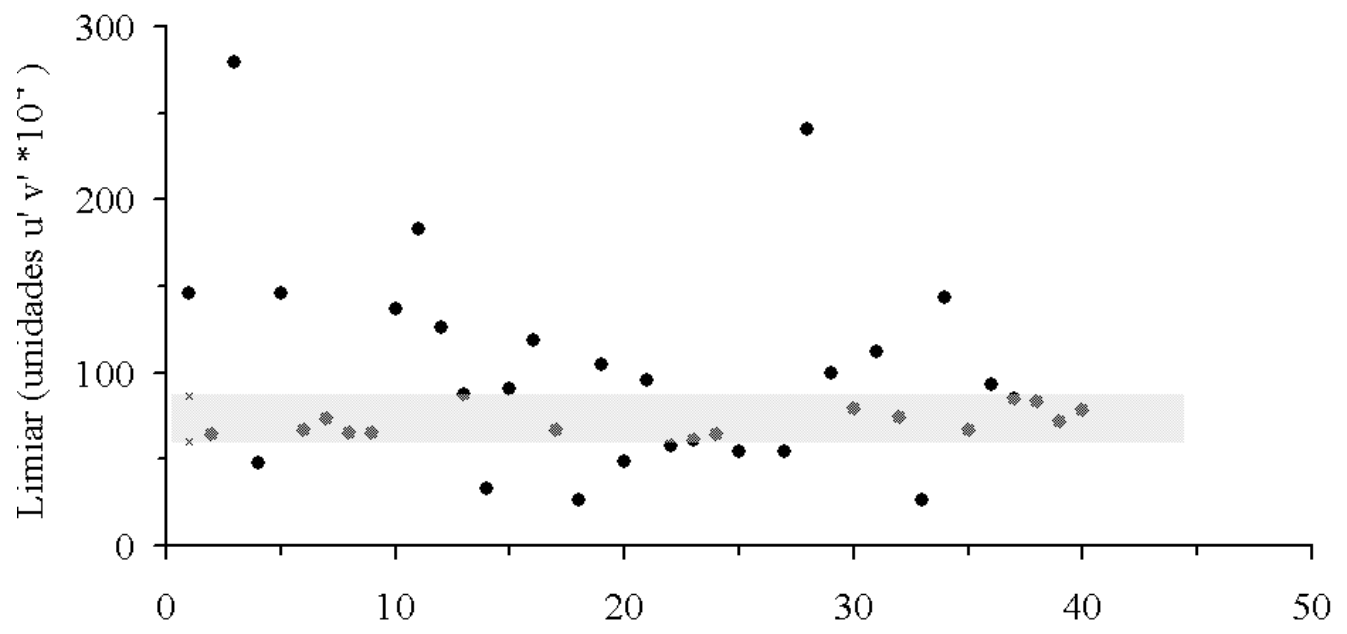


Eixo tritan

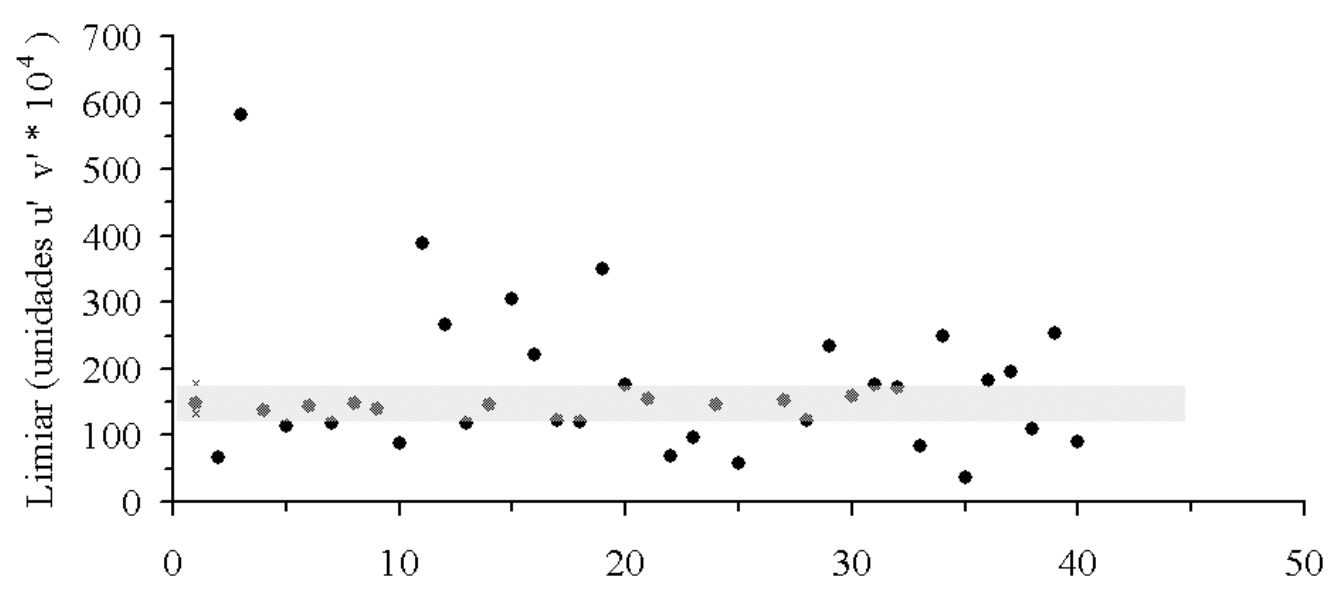

Figura 30: CCT-Teste trivector. Resultados individuais de limiar para o grupo de pacientes diabéticos para os eixos protan, deutan e tritan. A faixa na área do gráfico indica o limite de normalidade para este resultado.

No teste das elipses foram considerados os valores de área da elipse. A determinação destes dados foi feita usando-se os parâmetros de comprimento do maior eixo da elipse e da razão entre os eixos - maior e menor - que são os dados fornecidos pelo programa. Para tanto, em primeiro lugar foi extraído o valor do menor eixo da elipse dividindo-se o valor do maior eixo pela razão entre os dois e a partir de então, a área foi determinada.

As áreas de todas as elipses dos pacientes diabéticos foram maiores que as elipses dos controles, indicando uma maior área dentro do espaço CIE na qual os diabéticos não foram capazes de discriminar cor. As figuras 31 e 32 foram feitas somando-se os resultados de área das elipses obtidas no grupo de pacientes e de 
controles. As elipses resultantes apresentadas nas figuras representam a discriminação média de cada grupo.

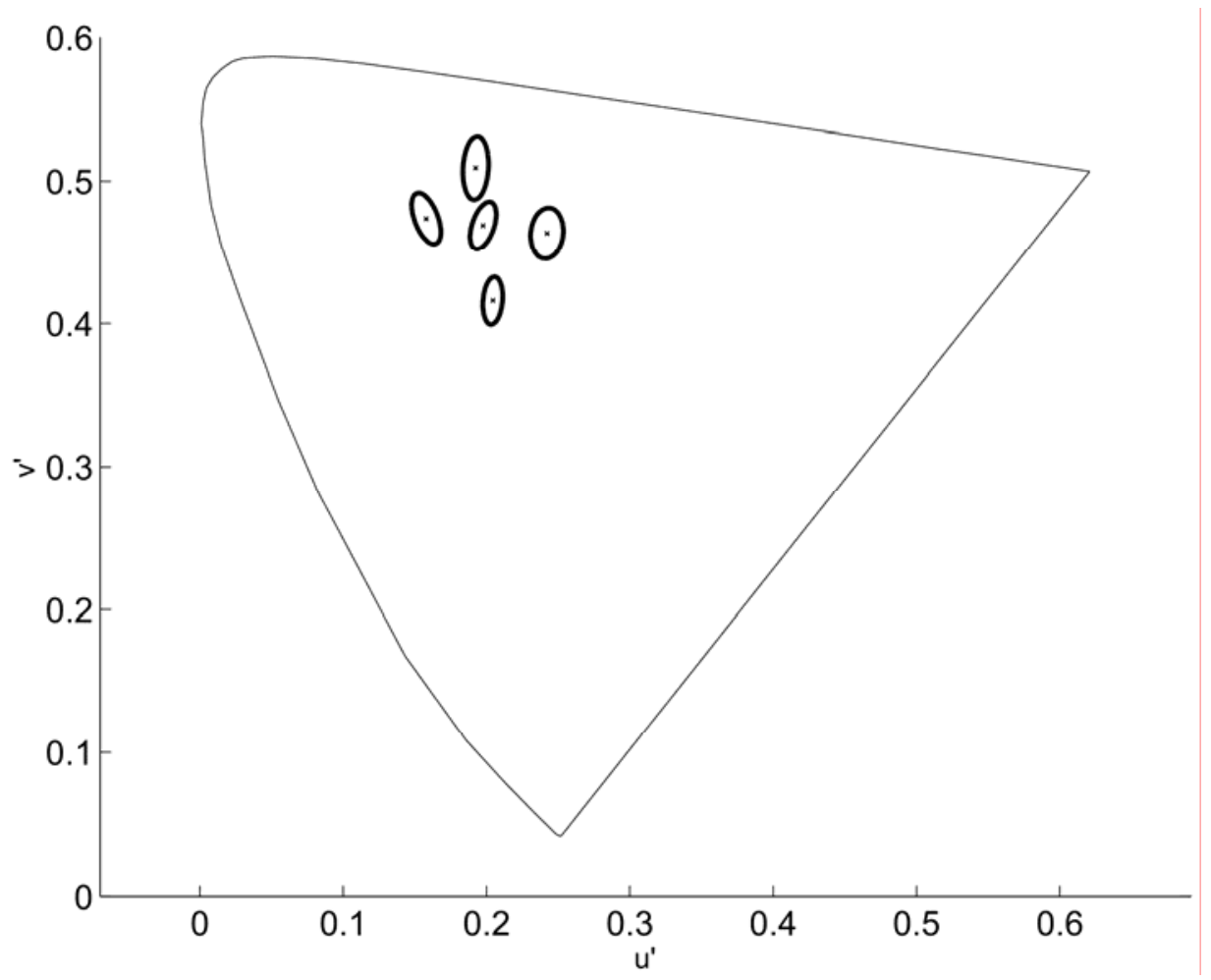

Figura 31: CCT - Teste das elipses. Média das elipses de discriminação dos pacientes diabéticos dispostas no diagrama de cores CIE u'v'. 


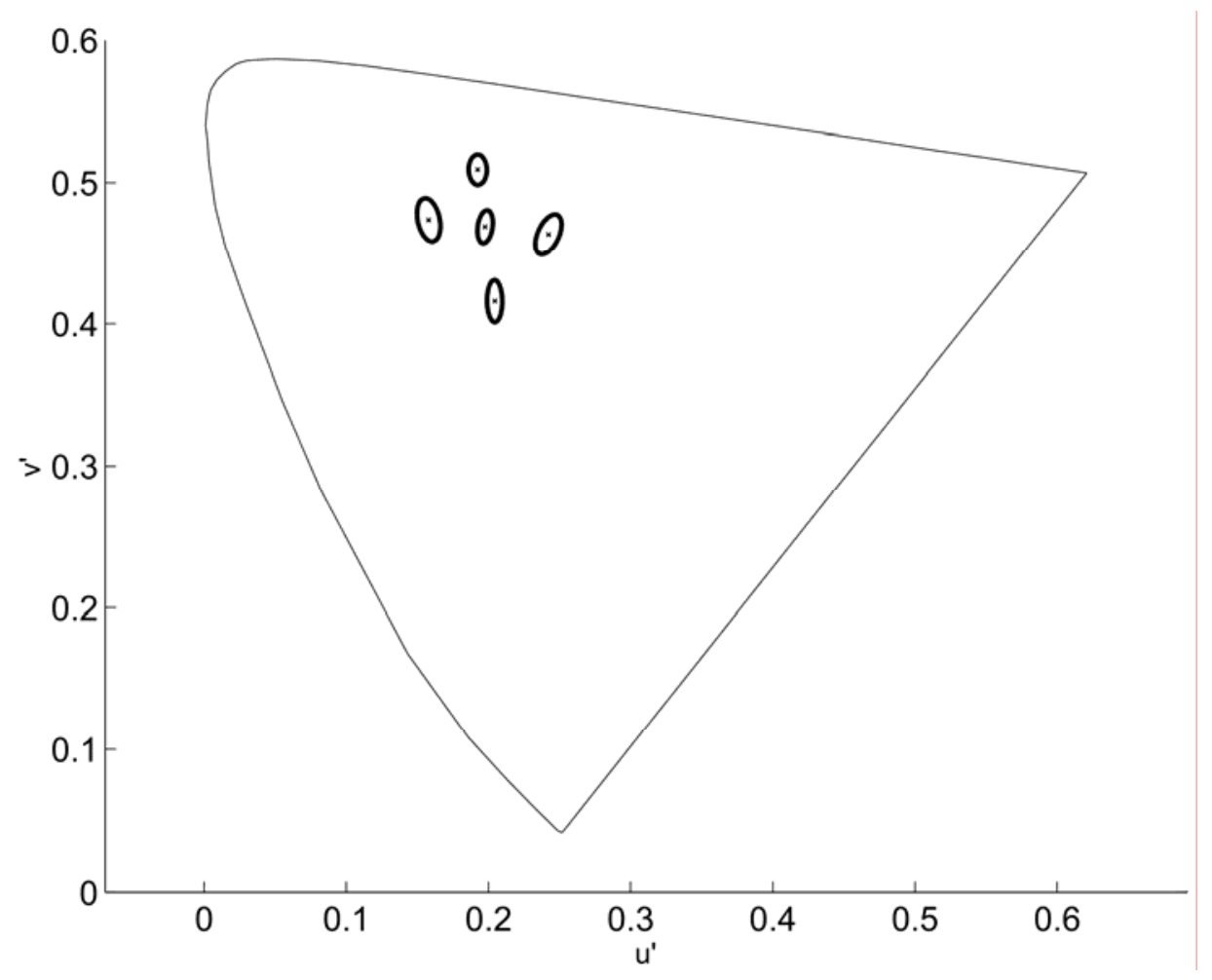

Figura 32: CCT - Teste das elipses. Média das elipses de discriminação dos sujeitos controle dispostas no diagrama de cores CIE u'v'.

Os gráficos da figura 33 mostram o desempenho de ambos os grupos e para cada elipse através dos valores de mediana (linha horizontal), mínimo e máximo (caixa), quartil $25 \%$ e $75 \%$ e valores discrepantes.

Foi observada diferença significativa entre pacientes e controles apenas nos resultados da elipse 1 ( $\mathrm{p}=0,00$ - teste de Kruskal-Wallis). Para os resultados das demais elipses houve um comportamento semelhante entre os dois grupos e não foi verificada diferença estatística. 
Elipse 1
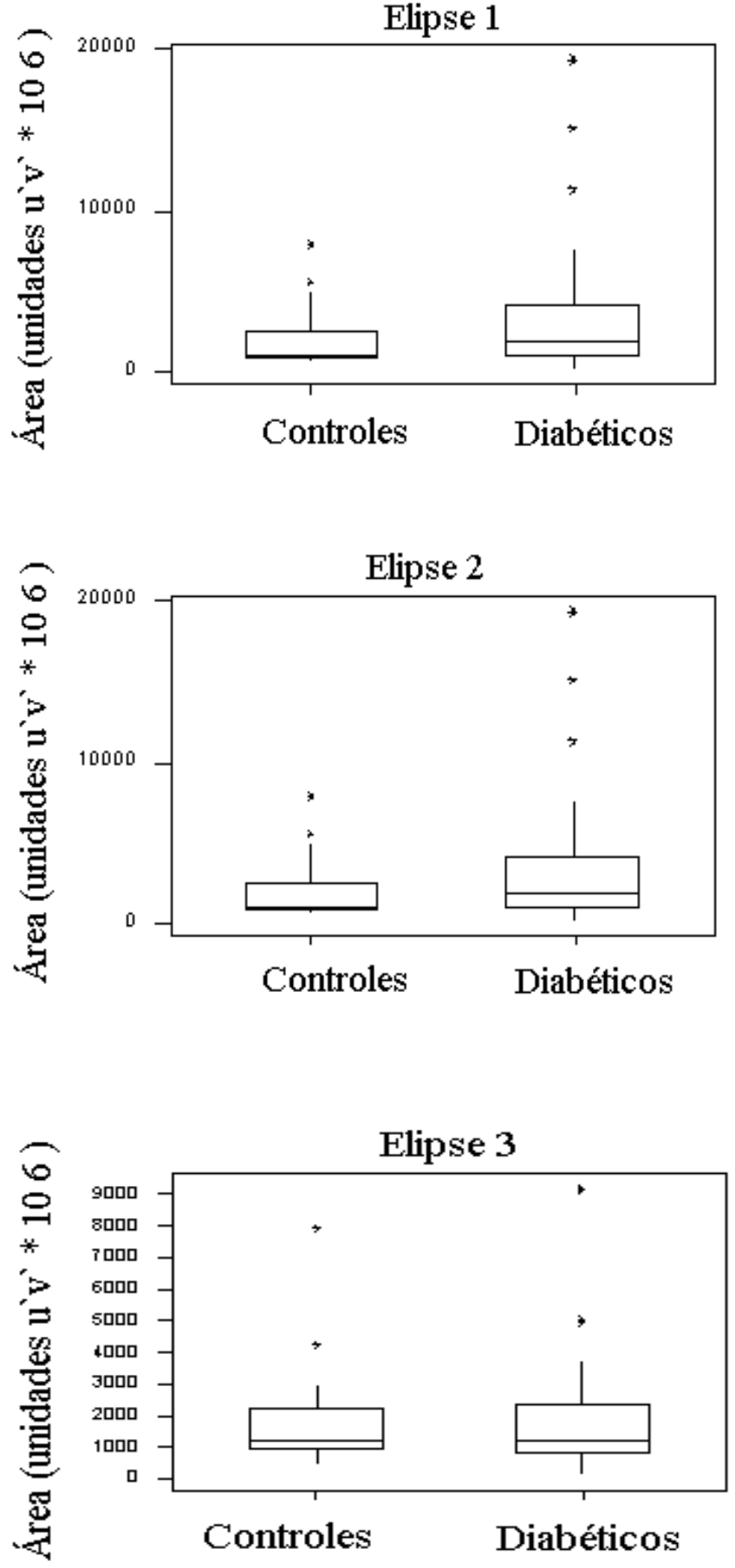

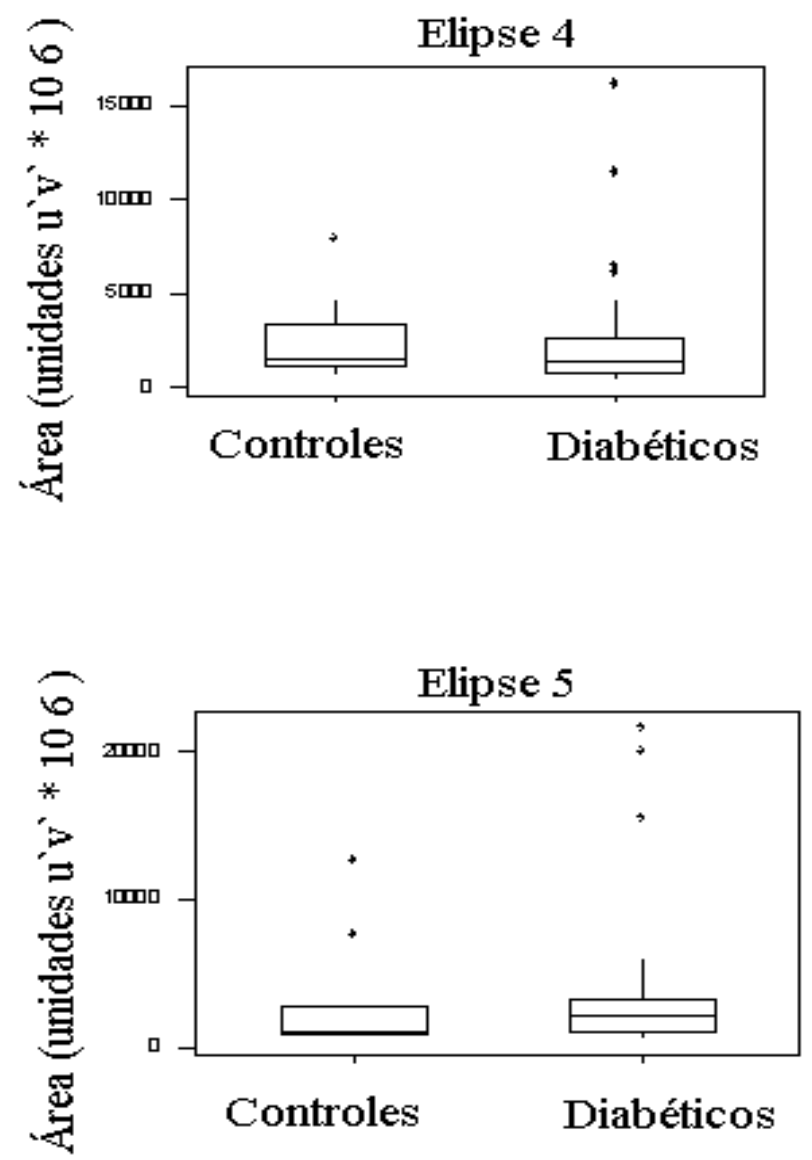

Figura 33: CCT - Teste das elipses. Desempenho de pacientes e controles para o parâmetro de área.

Na comparação dos resultados de área das elipses dos pacientes com os limites de normalidade, o número de pacientes cuja área excedeu o limite normal para as elipses de um a cinco foi respectivamente, 19/40; 10/40; 5/40; 7/40 e 4/40.

A posição da elipse dentro do diagrama de cores também é um dado importante, pois informa a respeito do eixo de confusão em que o déficit ocorreu. 
Com o objetivo de identificar o eixo de confusão predominante nos resultados do teste das elipses, foram selecionadas as respostas individuais cujas elipses tiveram um de confusão - vermelho/verde ou azul/amarelo - bem definido. Estes dados estão dispostos de forma a contrapor a quantidade de respostas específicas para cada eixo e assim, a região do gráfico que contem maior numero de pontos indica qual o eixo de confusão predominante. As respostas que indicaram defeito difuso foram descartadas uma vez que a análise teve o propósito de identificar a predominância de defeitos com eixo de confusão específico.

A distribuição dos ângulos e/ou eixos de confusão de ambos os grupos obedeceu a um mesmo padrão (figura 34). Estes dados não foram diferentes estatisticamente ( $>>0,05$ teste Krukal-Wallis).

Em ambos os grupos, todas as elipses tiveram disposição tritanópica, ou seja, ambos os grupos têm discriminação pior no eixo azul/amarelo que no vermelho/verde. 
Elpise 1 - Diabéticos

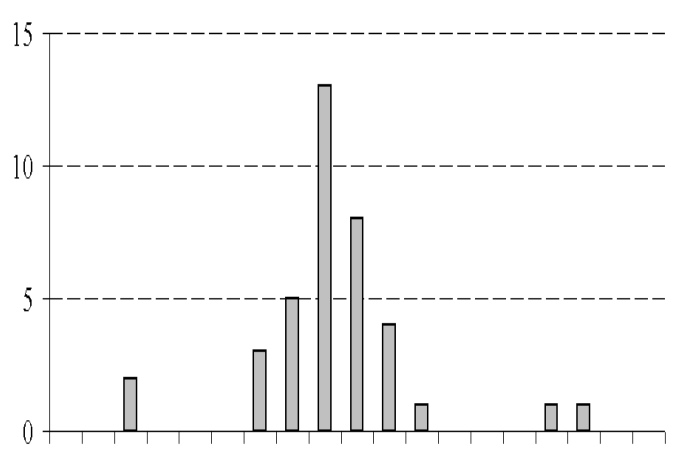

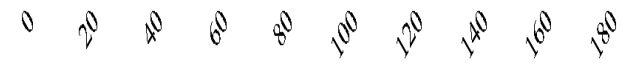
Elpise 2- Diabéticos

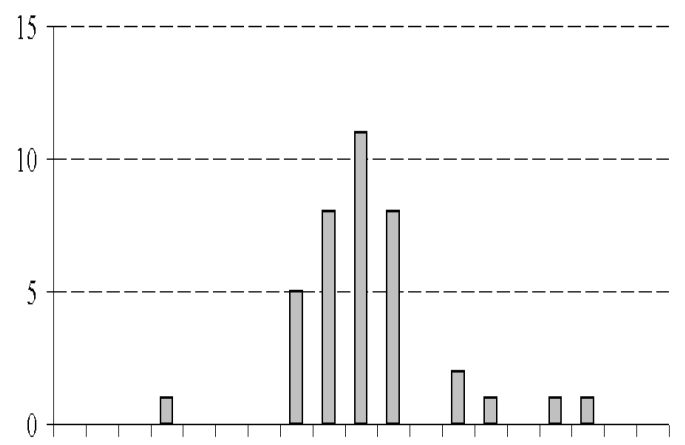

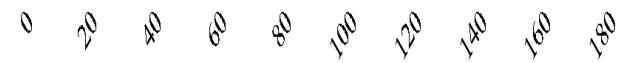

Elpise 3-Diabéticos

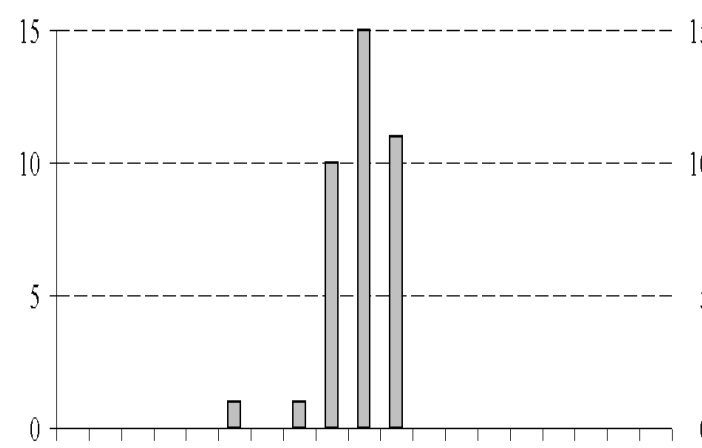

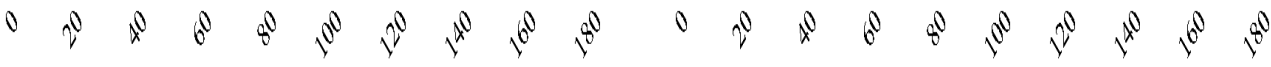

Elipse 1 - Controles

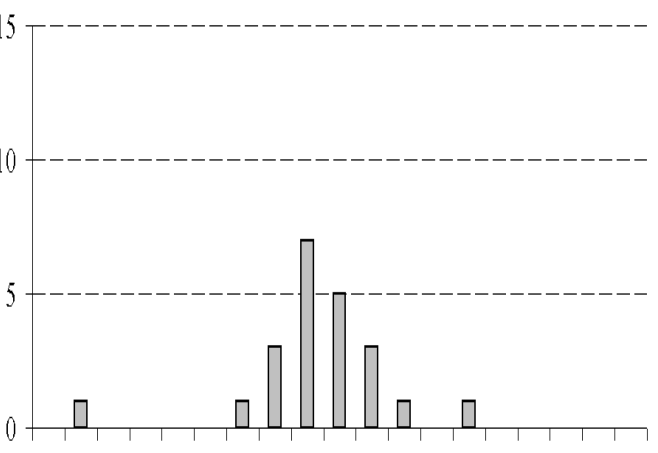

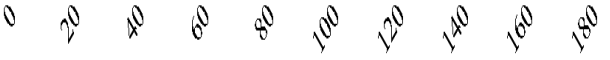

Elipse 2-Controles

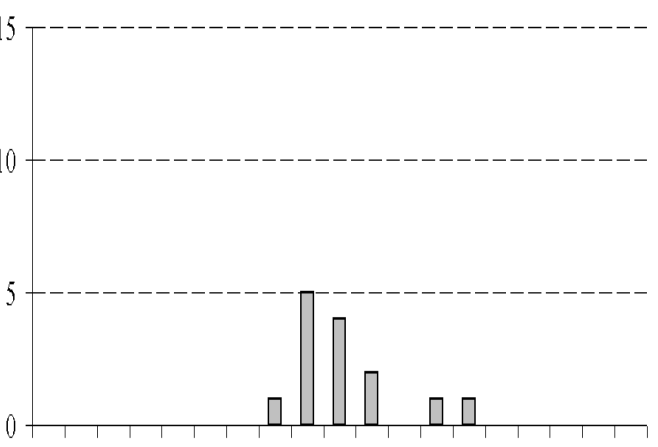

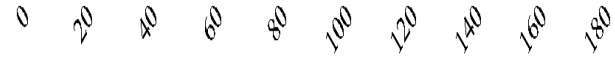

Elipse 3 -Controles

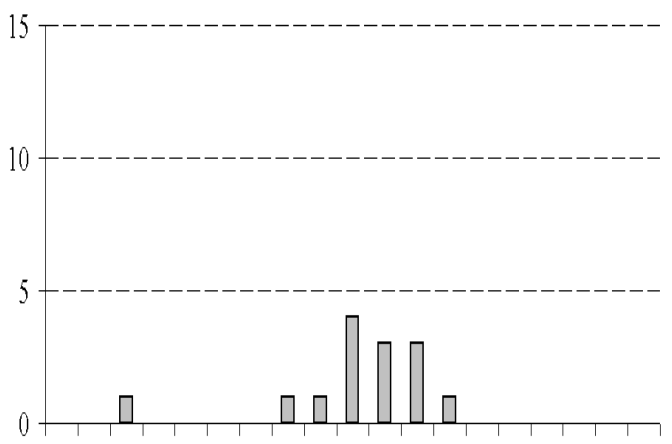




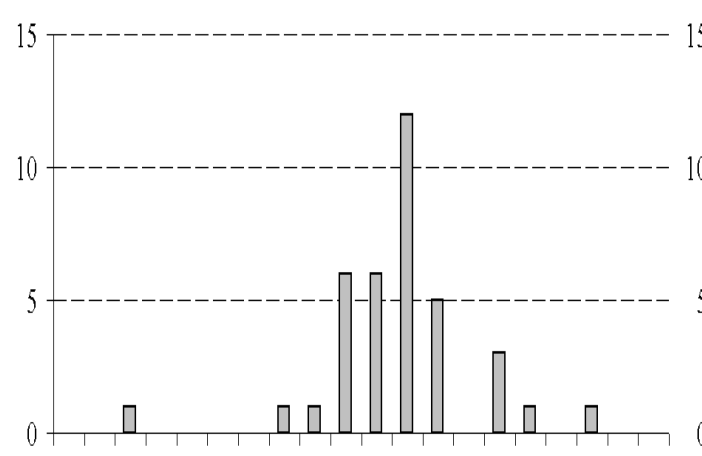

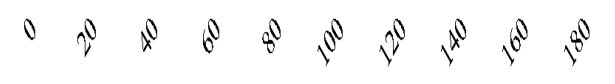

Elpise 5- Diabéticos

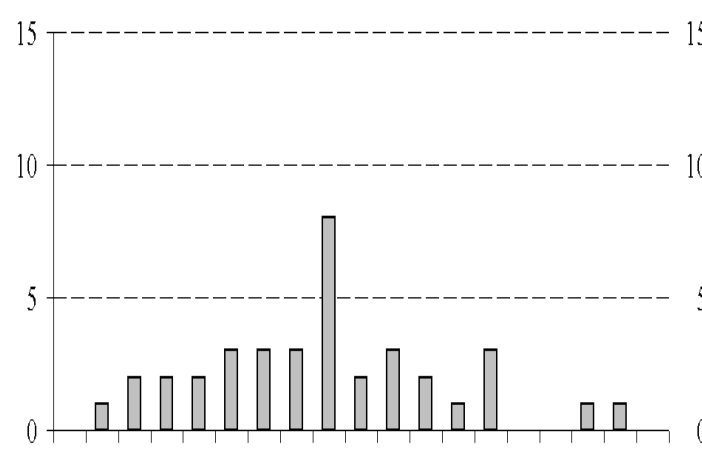

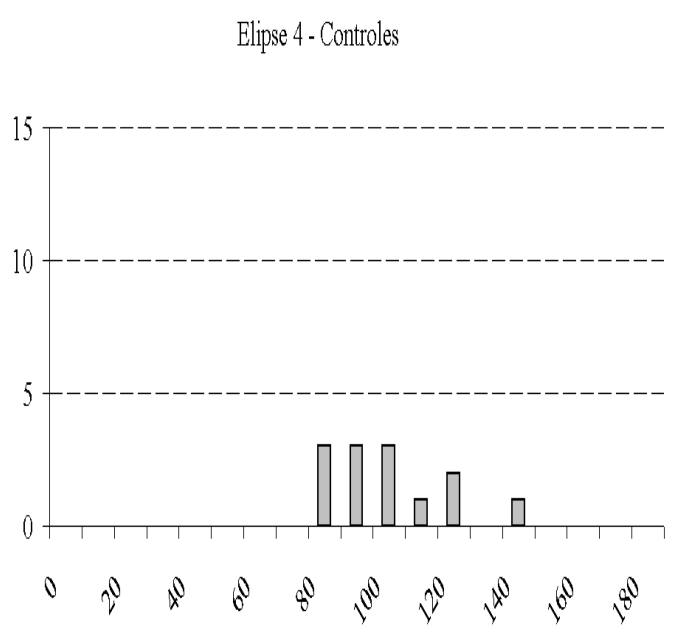

Elipse 5 - Controles

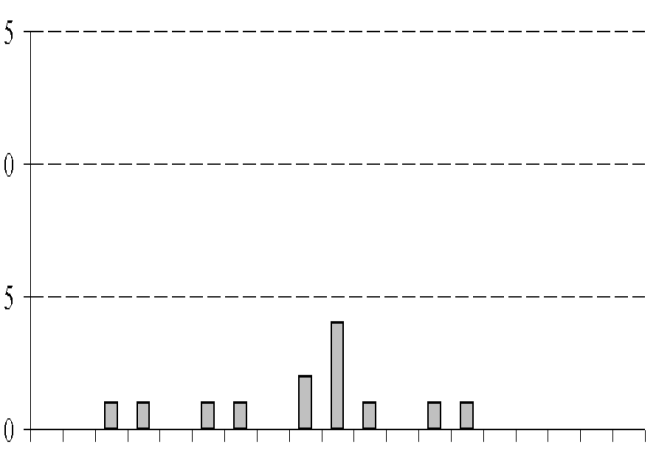

Figura 34: CCT -Teste das elipses. Freqüência da distribuição dos ângulos de cada elipse para diabéticos e controles. Na abscissa de cada gráfico estão os valores de ângulos enquanto na ordenada estão os números de indivíduos.

A preponderância do eixo de confusão tritan nas elipses de discriminação é provavelmente, conseqüência do processo fisiológico de amarelecimento do cristalino e que ocorre tanto nos diabéticos quanto nos controles. Assim, parte dos defeitos no eixo tritanópico deve-se, possivelmente, mais ao avanço da idade do que a um possível mecanismo de alteração causado pela diabete. 
Tais considerações são indicativas de que a perda da discriminação de cores dos pacientes não ocorre em um eixo específico; trata-se de uma discromatopsia difusa. Os resultados do teste trivector em que a porcentagem de pacientes fora dos limites normais foi maior nos eixos protan e deutan ratificam a idéia de que o defeito seja difuso.

Na tabela 6 estão os resultados da análise de correlação entre os resultados do CCT, o tempo de diabete, a taxa de glicose no dia do teste e o nível de HbA.

Os limiares protan e tritan do teste trivector e a área das elipses 1, 3 e 5 tiveram correlação positiva significante com a duração da doença. Para os demais resultados não foi observada correlação significativa.

Na correlação com a taxa de glicemia medida no dia do teste, apenas a área da elipse 3 apresentou fraca correlação significante.

Dentre todos os fatores, a taxa de $\mathrm{HbA}$ foi o que mais se relacionou com os resultados do CCT. Todos os parâmetros exceto os limiares protan e deutan do teste trivector, tiveram correlação significativa. 
Tabela 6: Correlação entre os resultados do CCT e o tempo de diagnóstico, a glicose no dia do teste e a \% HbA

\begin{tabular}{ccccccc} 
CCT & \multicolumn{2}{c}{$\begin{array}{c}\text { Tempo de Diabete } \\
\text { (anos) }\end{array}$} & \multicolumn{2}{c}{ Glicose no dia do teste } & \multicolumn{2}{c}{ HbA (\%) } \\
& $r$ & $p$ & $r$ & $p$ & $r$ & $p$ \\
\hline Eixo protan & $\mathbf{0 , 3 9 8}$ & $\mathbf{0 , 0 2 7} *$ & 0,093 & 0,658 & 0,237 & 0,302 \\
Eixo deutan & 0,162 & 0,383 & 0,25 & 0,229 & 0,155 & 0,502 \\
Eixo tritan & $\mathbf{0 , 6 1 9}$ & $\mathbf{0} *$ & 0,11 & 0,601 & $\mathbf{0 , 6 4 6}$ & $\mathbf{0 , 0 0 2}$ \\
Elipse 1 & $\mathbf{0 , 3 9 8}$ & $\mathbf{0 , 0 2 4} *$ & 0,033 & 0,872 & $\mathbf{0 , 5 8 3}$ & $\mathbf{0 , 0 0 5}$ \\
Elipse 2 & 0,225 & 0,216 & 0,175 & 0,393 & $\mathbf{0 , 4 5 5}$ & $\mathbf{0 , 0 3 8}$ \\
Elipse 3 & $\mathbf{0 , 3 9 7}$ & $\mathbf{0 , 0 2 7} *$ & $\mathbf{0 , 4}$ & $\mathbf{0 , 0 4 8} *$ & $\mathbf{0 , 5 3 4}$ & $\mathbf{0 , 0 1 3}$ \\
Elipse 4 & 0,33 & 0,081 & 0,448 & 0,68 & $\mathbf{0 , 6 8}$ & $\mathbf{0 , 0 0 1} *$ \\
Elipse 5 & $\mathbf{0 , 4 4 5}$ & $\mathbf{0 , 0 1 5} *$ & 0,293 & 0,174 & $\mathbf{0 , 7 3 2}$ & $\mathbf{0} *$ \\
\hline
\end{tabular}

os valores em negrito representam os índices estatisticamente significantes. 


\subsection{ELETRORRETINOGRAMA - ERG}

Os resultados de avaliação eletrofisiológica da retina através do ERG incluem os exames de apenas 33 dos 40 pacientes descritos na tabela 4.

Em todas as respostas registradas no ERG foram encontradas respostas fora dos limites de normalidade. Na figura 35 estão exemplos de resultados dos pacientes diabéticos para cada tipo de registro do ERG. À esquerda estão as respostas com parâmetros normais e à direita as respostas alteradas.
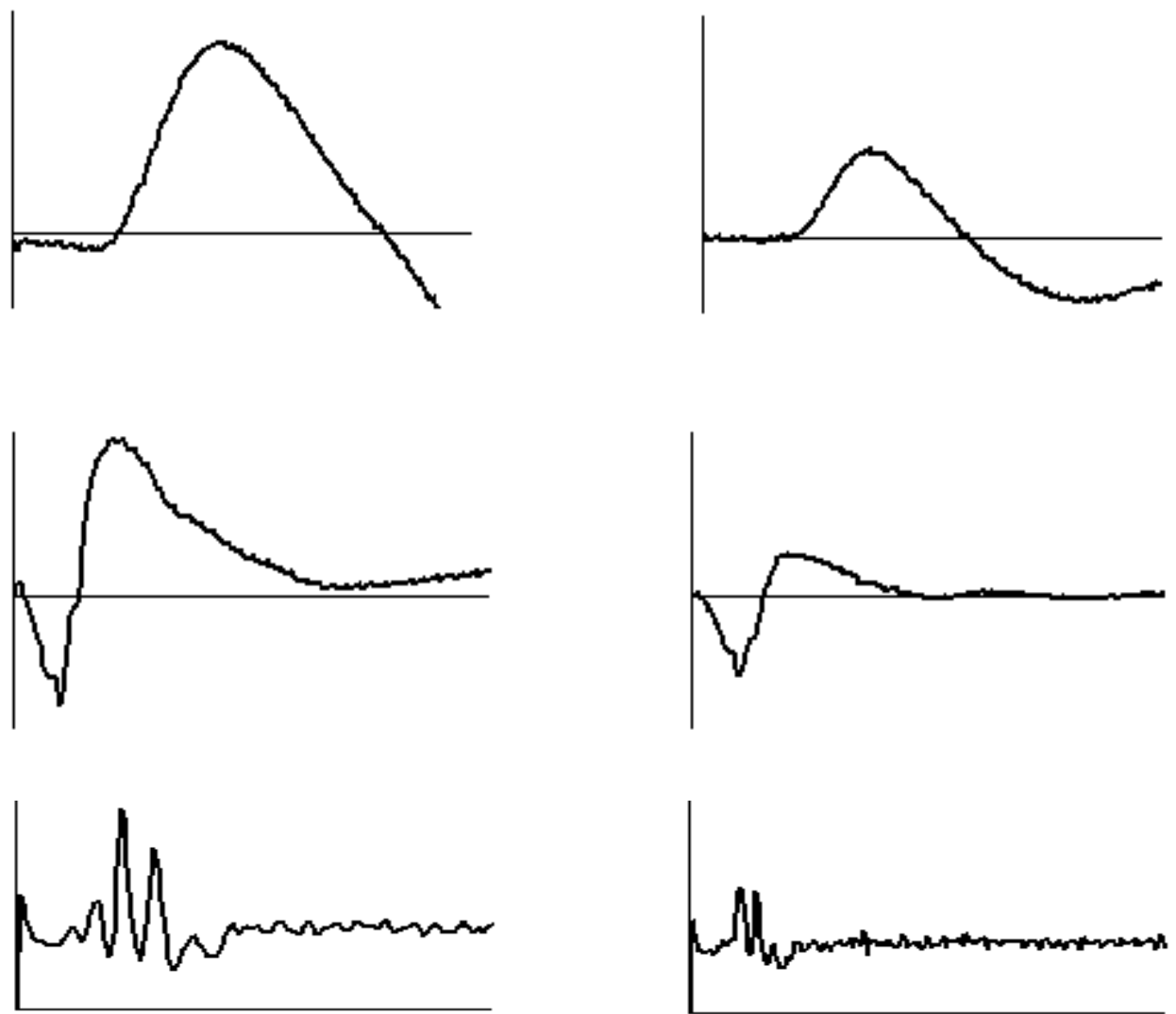

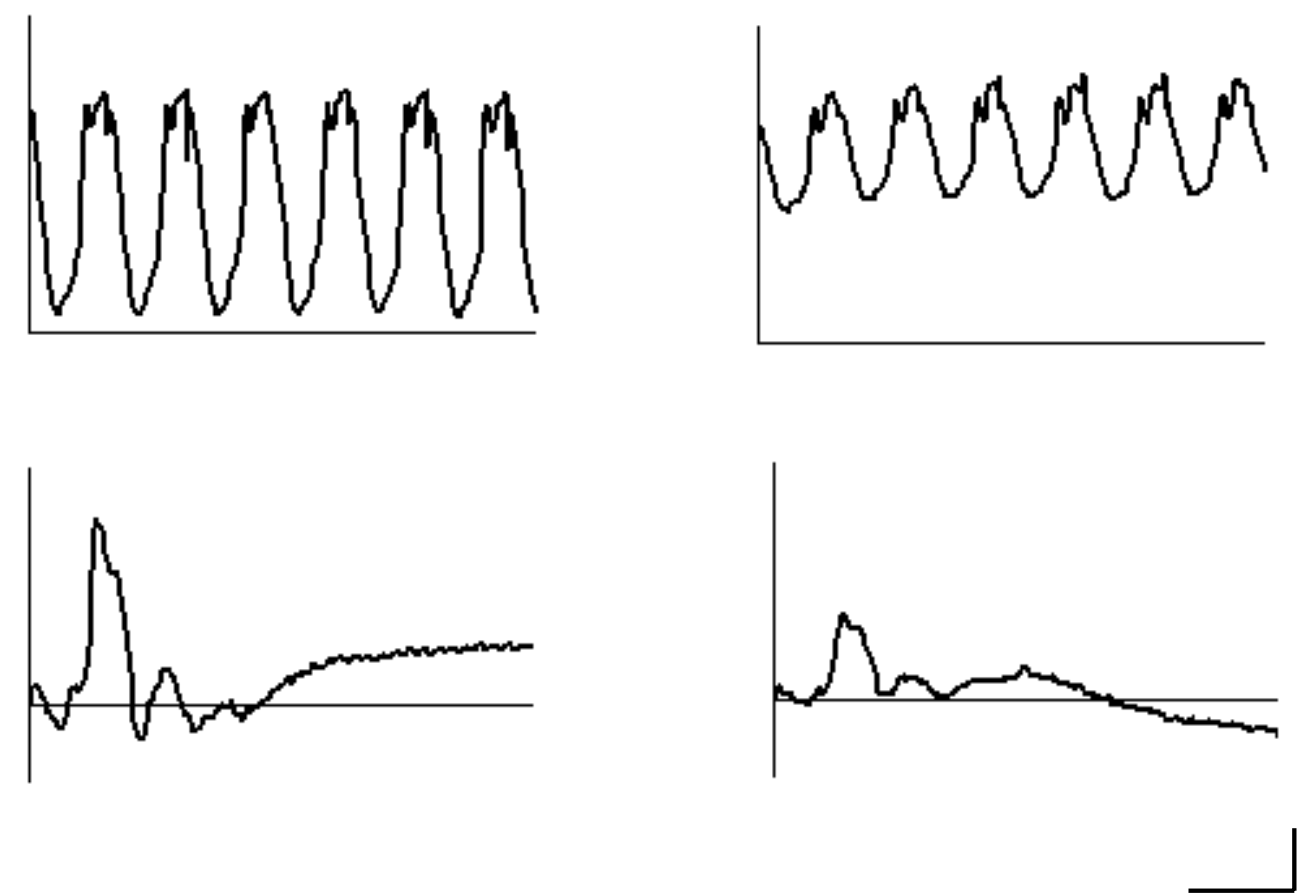

50

$50 \mathrm{~ms}$

Figura 35: ERG - Exemplos de resposta de pacientes diabéticos obtidas nos cinco registros do exame. À esquerda estão as respostas normais e à direita, as respostas alteradas.

$\mathrm{Na}$ figura 36 estão representados os dados de amplitude e latência das respostas de cada grupo.

Foi observada diferença significativa entre os resultados de diabéticos e controles para o parâmetro de amplitude nos registros de potenciais oscilatórios e resposta de cones; para o parâmetro de latência foi observada diferença significante nos registros de resposta de bastonetes, potenciais oscilatórios e resposta de cones $(\mathrm{p}<0,05$ no teste-t ou teste Kruskal-Wallis, dependendo da normalidade dos dados), vide tabela 7. 
Resposta de bastonetes
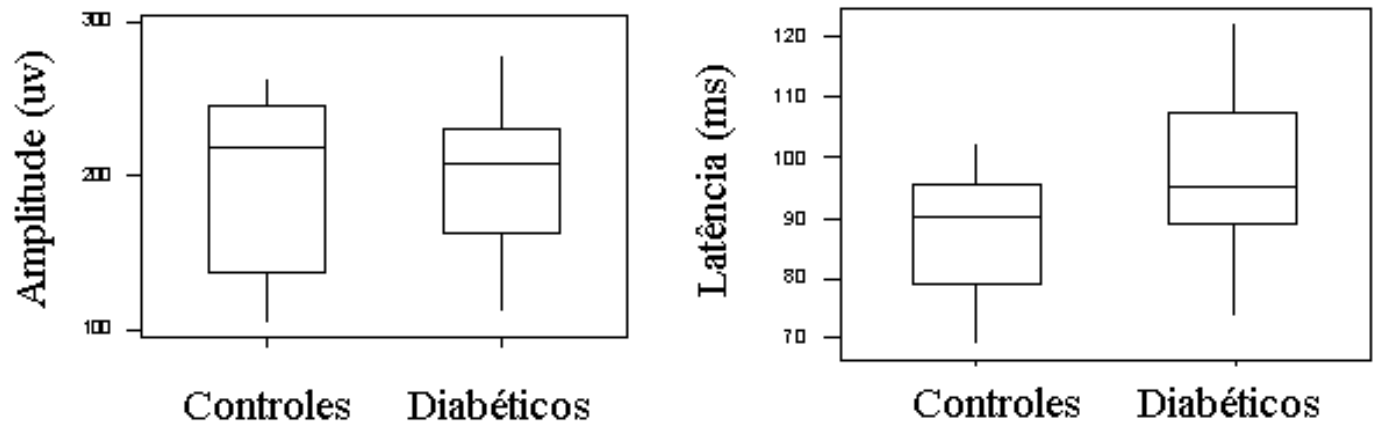

Escotópica máxima
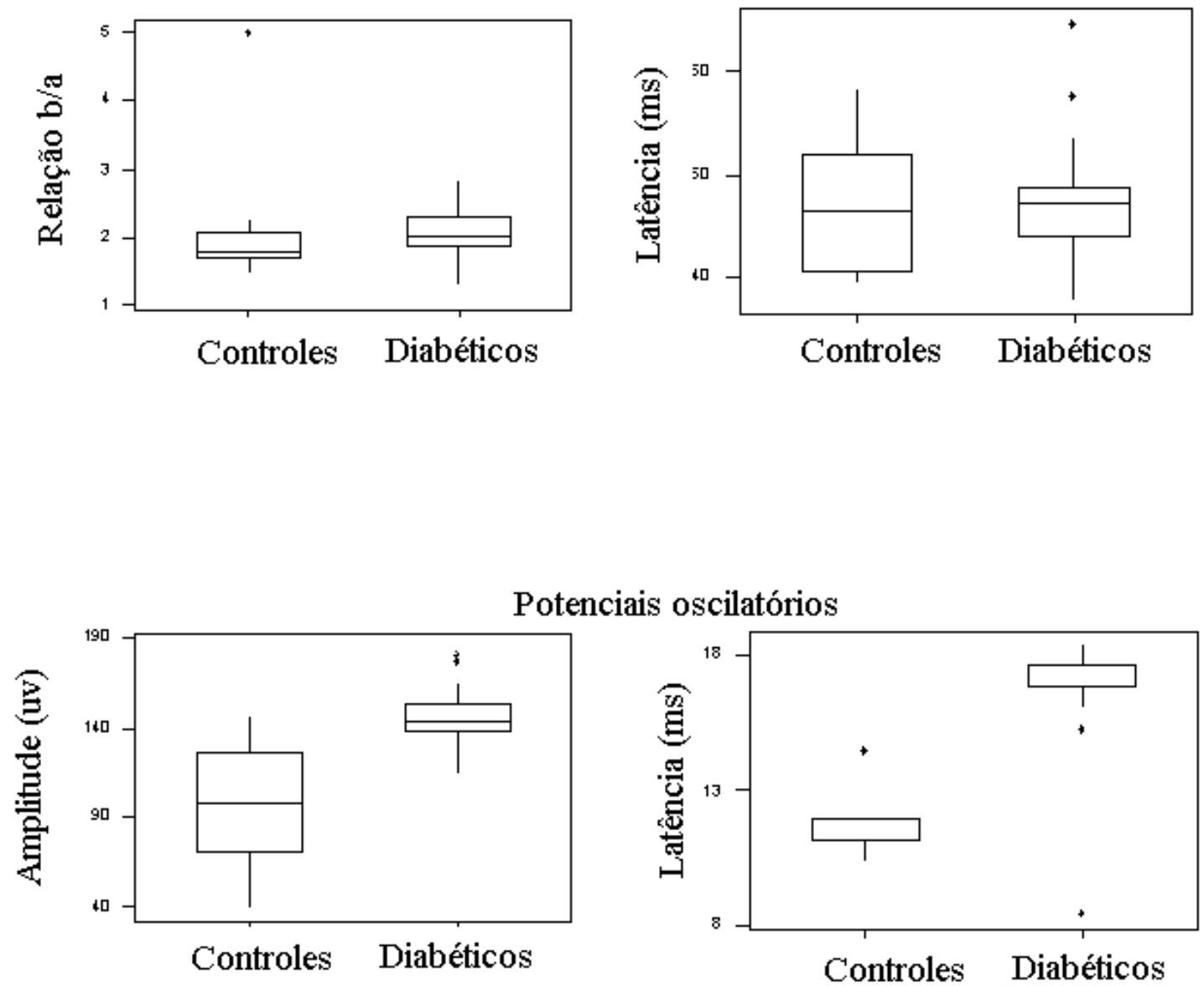


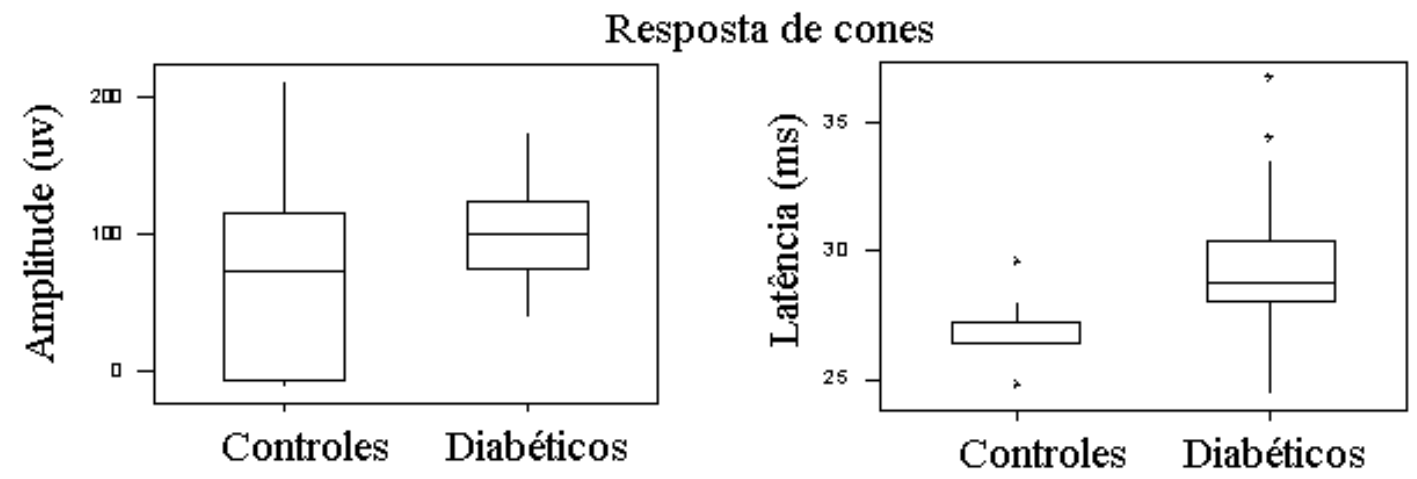

Flicker $30 \mathrm{~Hz}$
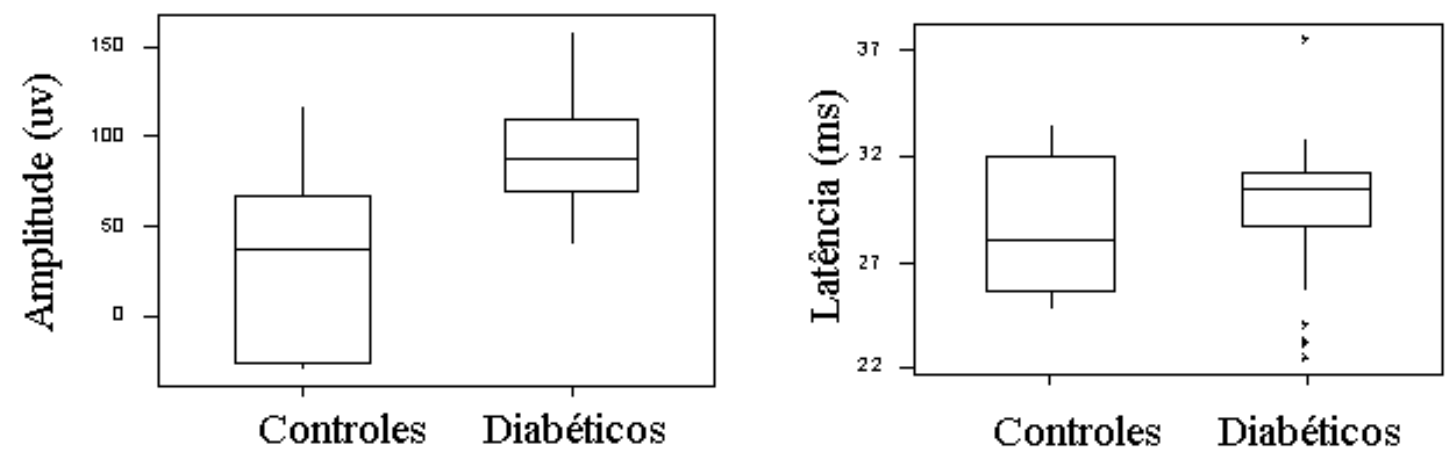

Figura 36: ERG - Resultados de amplitude e latência de pacientes e controles. Na resposta escotópica máxima está representada a amplitude da relação b/a; nos potenciais oscilatórios a amplitude corresponde à soma dos picos 01 a 04 ; nos demais registros estão representadas as amplitudes pico-a-pico. Os valores de latência são os da onda b de cada registro; para os potenciais oscilatórios foi considerada a latência do 01. 
Tabela 7: ERG - Resultados da comparação entre diabéticos e controles para os parâmetros de amplitude e latência (valores do nível significância $\boldsymbol{p}$ do teste de hipótese).

ERG

Amplitude Latência

\begin{tabular}{ccc}
\hline Resposta de Bastonetes & 0,807 & $\mathbf{0 , 0 1 2 *}$ \\
$\begin{array}{c}\text { Resposta Escotópica } \\
\text { Máxima }\end{array}$ & 0,054 & 0,872 \\
Potenciais Oscilatórios & $\mathbf{0 , 0 0 1 *}$ & $\mathbf{0}$ \\
Resposta de Cones & 0,111 & $\mathbf{0 *}$ \\
Flicker30Hz & $\mathbf{0 , 0 0 1}^{*}$ & 0,221 \\
\hline
\end{tabular}

As figuras 38 a 42, mostram os dados individuais dos pacientes. Em cada gráfico a amplitude da onda é apresentada em função de sua latência. Os limites de normalidade para cada um dos dois parâmetros são representados pelas linhas dispostas sobre a área do gráfico. As linhas horizontais marcam o valor mínimo de amplitude normal, enquanto as linhas verticais marcam o valor máximo de latência normal; assim a área do gráfico é dividida em quatro quadrantes.

No quadrante superior esquerdo estão as melhores respostas: amplitude e latência dentro do limite normal. No quadrante inferior direito estão as piores respostas: amplitude e latência fora do limite normal. No quadrante superior direito estão as respostas que indicam amplitude normal e latência fora do limite. No quadrante inferior esquerdo estão as respostas com amplitude fora da normalidade, mas com latência normal (figura 37). 


\begin{tabular}{|c|c|}
\hline $\begin{array}{l}\text { Amplitude normal } \\
e \\
\text { Latencia normal }\end{array}$ & $\begin{array}{l}\text { Amplitude nomal } \\
\text { e } \\
\text { Latêtncia aumentada }\end{array}$ \\
\hline $\begin{array}{l}\text { Amplitude reduzida } \\
\text { e } \\
\text { Latência nomal }\end{array}$ & $\begin{array}{l}\text { Amplitude reduzida } \\
\text { e } \\
\text { Latência aumentada }\end{array}$ \\
\hline
\end{tabular}

Figura 37: Esquema de representação das respostas do ERG.

$\mathrm{Na}$ resposta de bastonetes, a amplitude da onda $\mathrm{b}$ da foi inferior ao limite normal em 8/33 pacientes e o valor de tempo implícito excedeu o limite normal em 15/33 pacientes (figura 38). 
ERG - Resposta de bastonetes

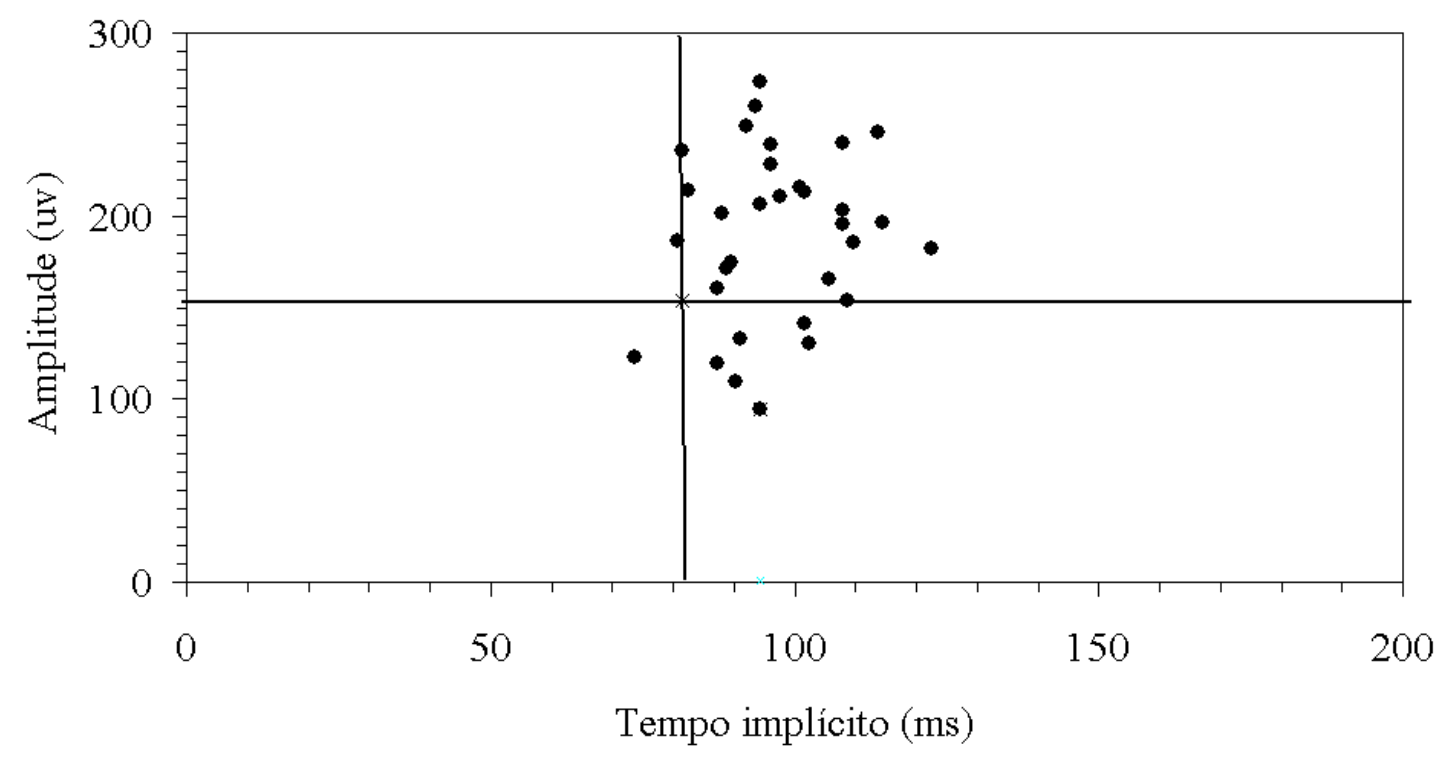

Figura 38: ERG - Resposta de bastonetes. Resultados individuais de amplitude e latência da onda b dos pacientes. As linhas horizontal e vertical indicam, respectivamente, os limites de normalidade para os parâmetros de amplitude e latência.

Na resposta escotópica máxima, foi considerado como índice para análise o valor da razão entre as amplitudes das ondas b e a. A relação b/a mostra a relação entre as funções pré e pós receptores; valores baixos indicam alteração dos mecanismos de processamento pós-receptores, enquanto valores demasiadamente altos indicam comprometimento da resposta dos receptores. Dentre 33 pacientes, 3 tiveram relação b/a abaixo do limite normal (figura 39). 
ERG - Resposta escotópica máxima

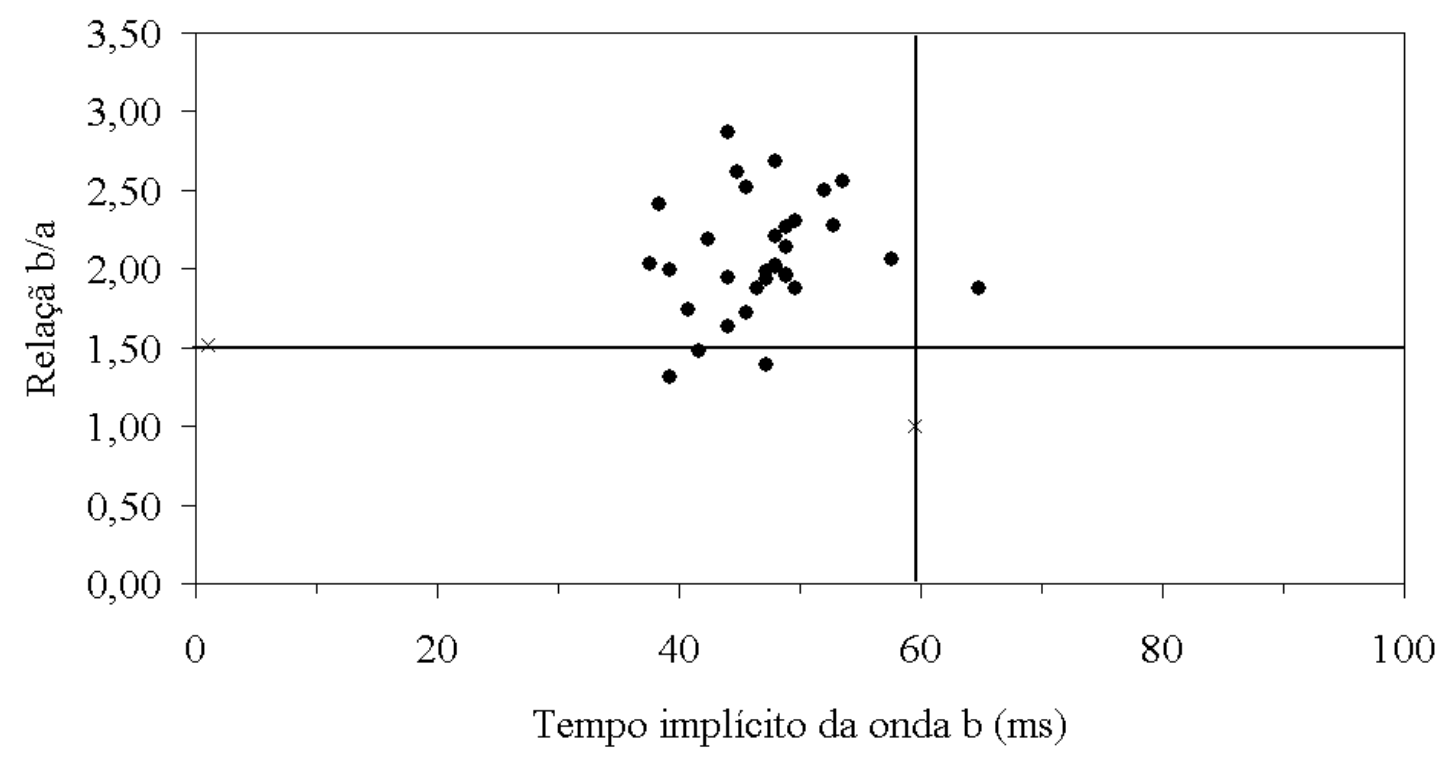

Figura 39: ERG - Resposta escotópica máxima. Resultados individuais de amplitude e latência da onda b dos pacientes. As linhas horizontal e vertical indicam, respectivamente, os limites de normalidade para os parâmetros de amplitude e latência.

O maior número de respostas alteradas foi verificado no registro dos potenciais oscilatórios. A soma das amplitudes de $\mathrm{O} 1$ a $\mathrm{O} 4$ teve valores abaixo do limite em 13/33 pacientes; a latência de $\mathrm{O} 1$ foi atrasada em 25/33 pacientes (figura 40). 
ERG - Potenciais oscilatórios

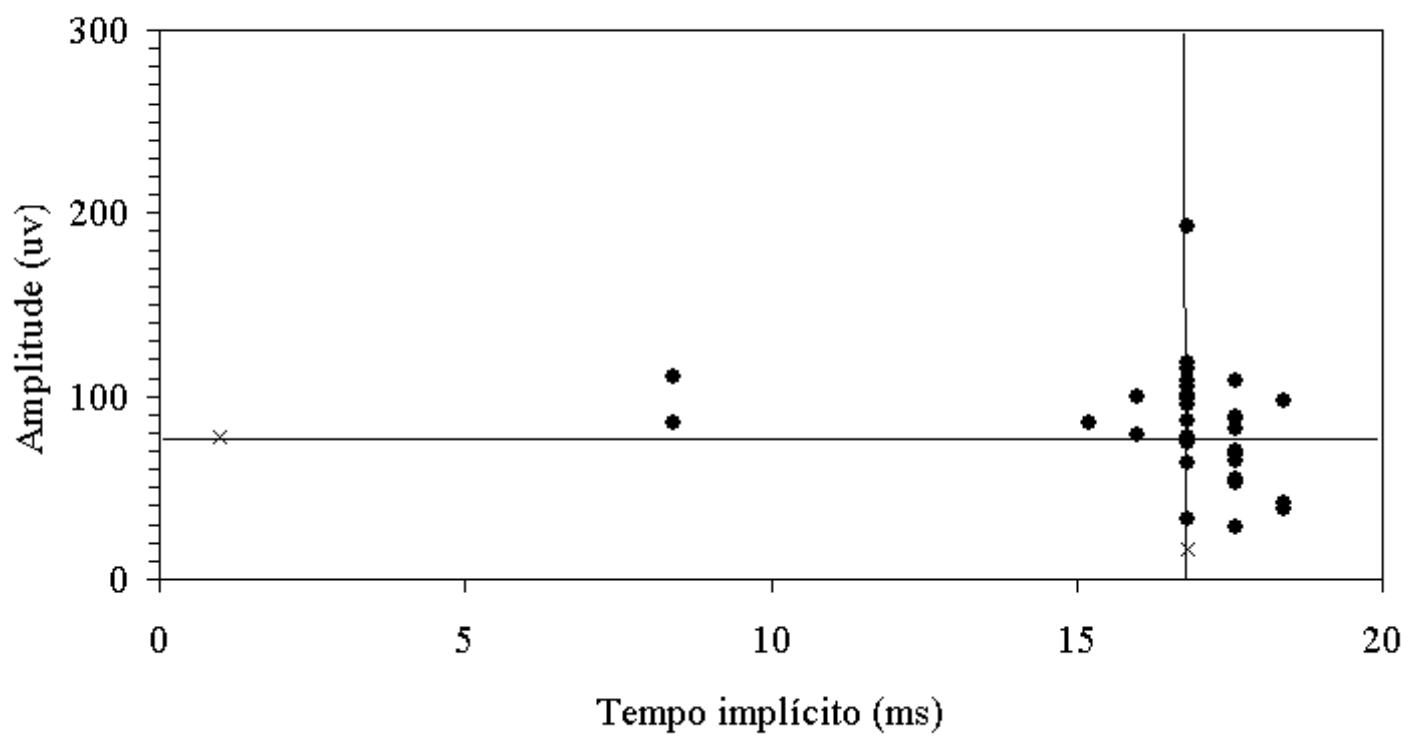

Figura 40: ERG - Potenciais Oscilatórios. Resultados individuais para a soma das amplitudes de $\mathrm{Ol}$ a $\mathrm{O} 4$ versus a latência de $\mathrm{O} 1$ dos pacientes. As linhas horizontal e vertical indicam, respectivamente, os limites de normalidade para os parâmetros de amplitude e latência.

Respostas fora dos limites normais para o registro de resposta de cones foram encontradas em 9/33 e 2/33 pacientes nos parâmetros de amplitude e latência da onda b. A figura 41 mostra a dispersão dos resultados de reposta de cones a flash único. 
ERG - Resposta de cones

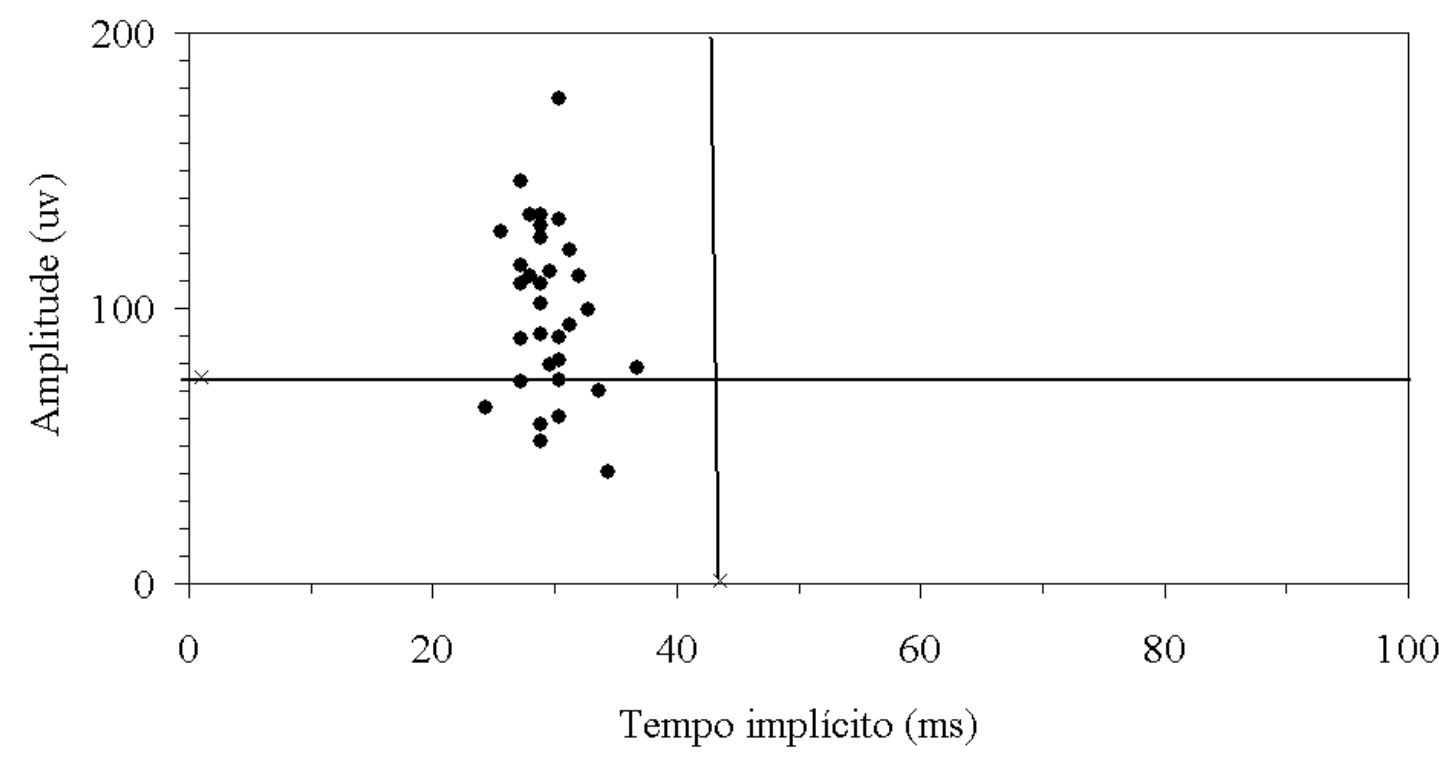

Figura 41: ERG - Resposta fotópica de cones.- Resultados individuais de amplitude versus latência da onda $b$ dos pacientes. As linhas horizontal e vertical indicam, respectivamente, os limites de normalidade para amplitude e latência.

A amplitude da onda b registrada na resposta de cones ao flicker $30 \mathrm{~Hz}$ foi alterada em 24/33 diabéticos; em 3/33 a amplitude foi menor que o limite e em 21/33 a amplitude foi maior que o limite da em pacientes e a latência foi normal em todos os pacientes (figura 42). 
ERG - Flicker $30 \mathrm{~Hz}$

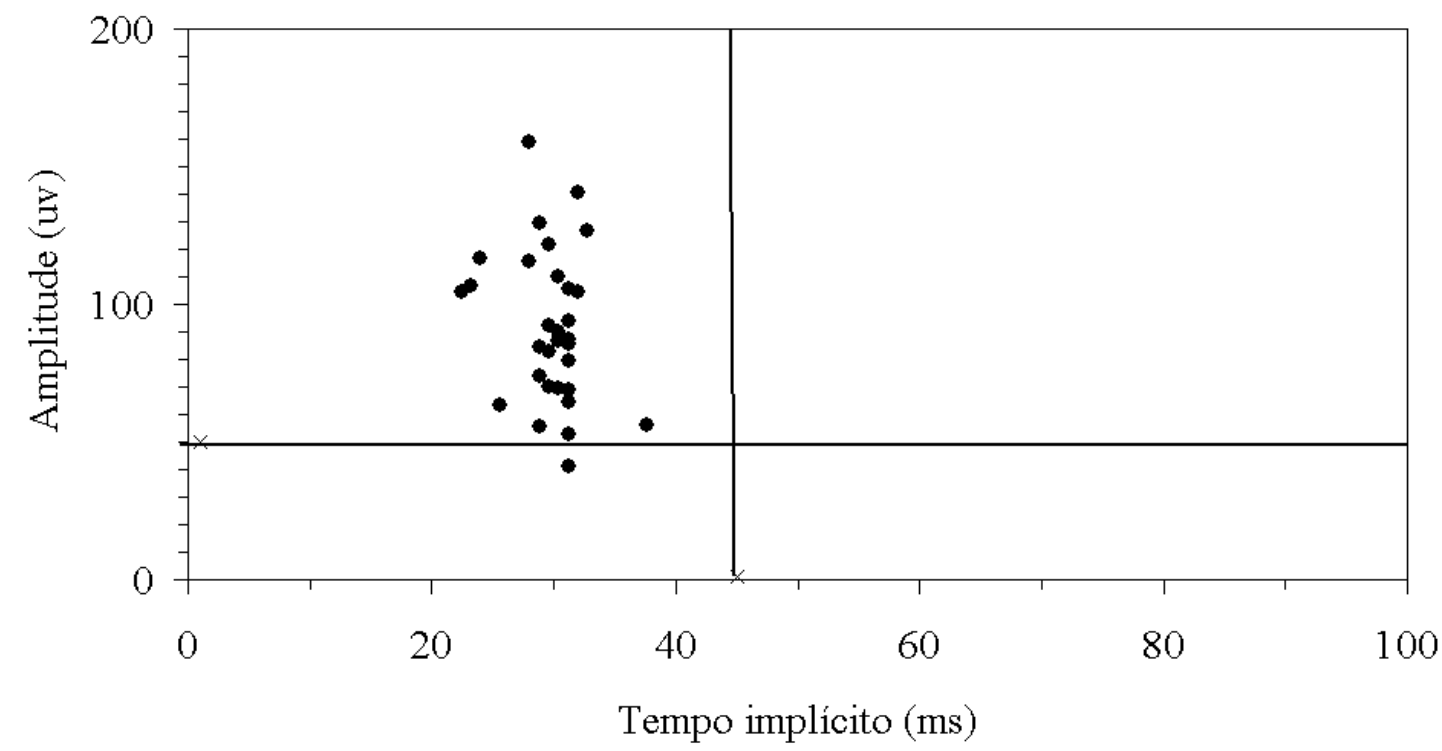

Figura 42: ERG - Flicker 30Hz.- Resultados individuais de amplitude versus latência da onda b dos pacientes. As linhas horizontal e vertical indicam, respectivamente, os limites de normalidade para amplitude e latência.

O tempo de diabete, a taxa de glicemia capilar no dia da avaliação visual e a porcentagem de HbA no sangue não mostraram correlação com os dados do ERG. A próxima tabela 8 mostra os índices de correlação e significância da associação entre os registros do ERG e cada um dos fatores mencionados. 
Tabela 8: Correlação entre os resultados do ERG e o tempo de diagnóstico de diabete, a glicemia no dia do teste e a \% de HbA.

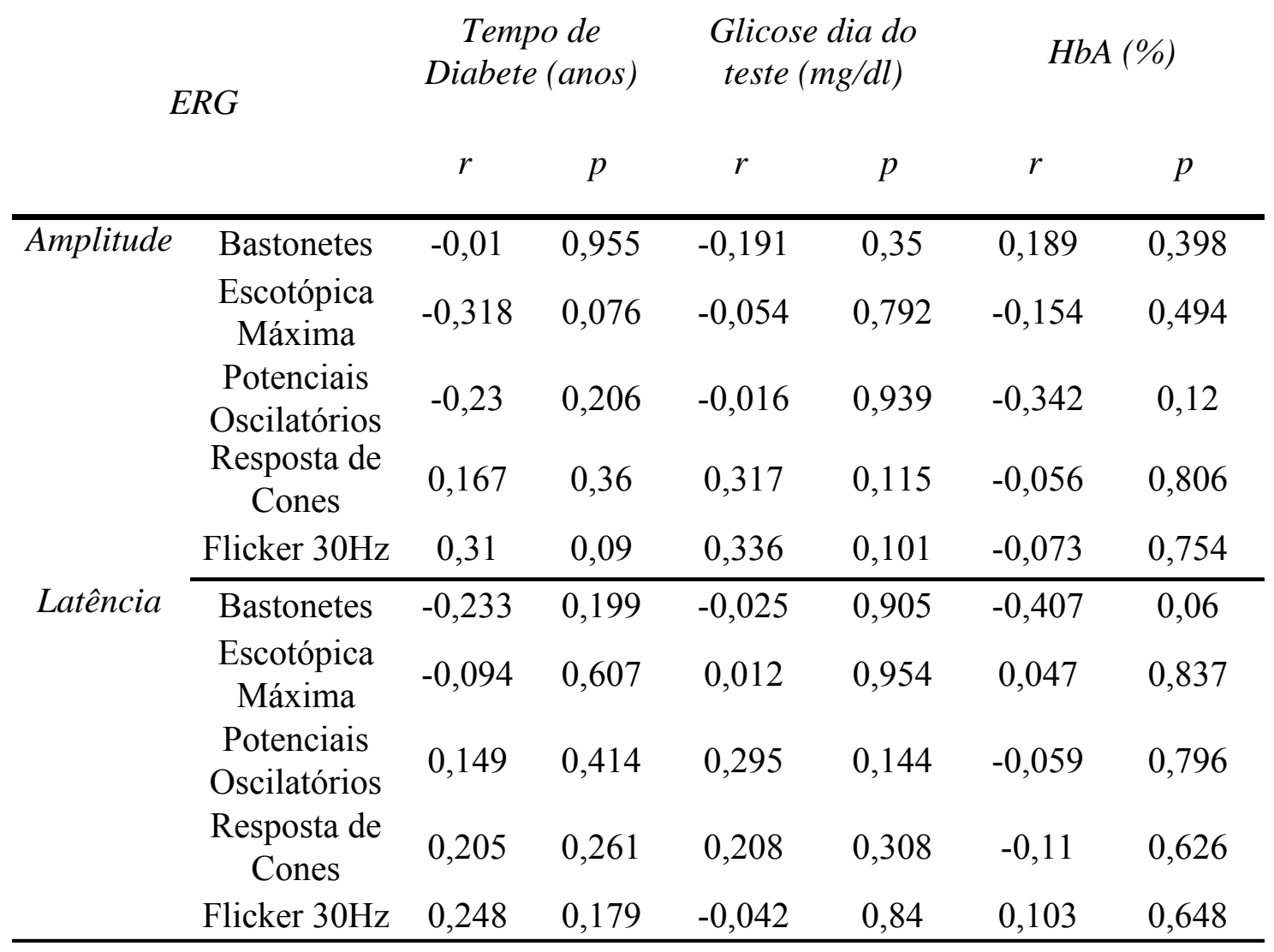




\subsection{SENSIBILIDADE AO CONTRASTE}

A sensibilidade ao contraste dos pacientes foi menor que a dos sujeitos controles em todos os tipos de estímulo (cromáticos ou acromáticos). A diferença entre o resultado dos dois grupos foi significativa $(\mathrm{p}<0,05$ - teste Kruskal-Wallis) em todas as freqüências espaciais testadas e para todas as séries de testes.

Tabela 9: Resultado da comparação entre os testes de sensibilidade ao contrate de pacientes e controles (valores de significância no teste Kruskal-Wallis).

\begin{tabular}{|c|c|c|c|c|}
\hline & & \multicolumn{3}{|c|}{ Sensibilidade ao contraste } \\
\hline & & Vermelho/verde & Azul/amarelo & Luminância \\
\hline \multirow{9}{*}{ 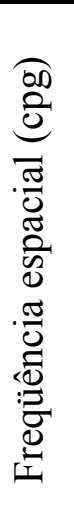 } & 0,2 & 0* & 0,008* & $0,008^{*}$ \\
\hline & 0,3 & $0,002 *$ & $0,006 *$ & \\
\hline & 0,5 & $0,001 *$ & $0,007 *$ & $0,007 *$ \\
\hline & 0,7 & 0* & $0,002 *$ & \\
\hline & 1 & 0* & 0* & $0,002 *$ \\
\hline & 2 & 0* & 0* & 0* \\
\hline & 5 & & & $0,001 *$ \\
\hline & 10 & & & $0,001 *$ \\
\hline & 20 & & & $0,004^{*}$ \\
\hline
\end{tabular}

Nas figuras 43 a 45 estão expressos os valores médios e o erro-padrão das CSF de pacientes e controles. Examinando as figuras é possível notar que a disparidade entre os resultados de controles e pacientes foi maior nas funções de sensibilidade a contrastes cromáticos, confirmando a precocidade, ou talvez seletividade, de déficit nas vias de processamento de cores em relação àquelas que processam preferencialmente informações de luminância. 


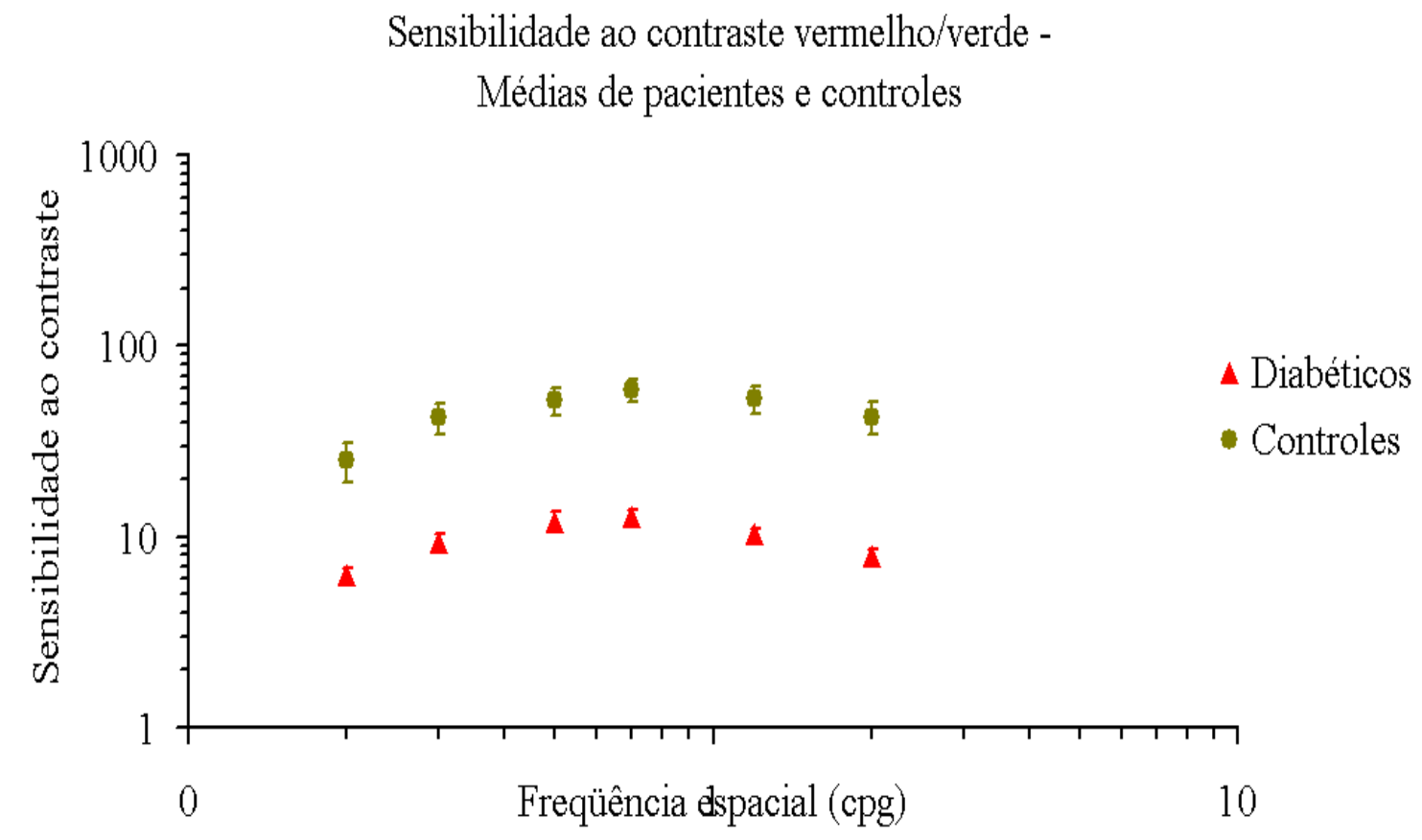

Figura 43: Sensibilidade ao contraste vermelho/verde. Curvas determinadas pelos valores médios de pacientes e controles. As barras verticais representam \pm o erro padrão da média de cada grupo. 
Sensibilidade ao contraste azul/amarelo -

Médias de pacientes e controles

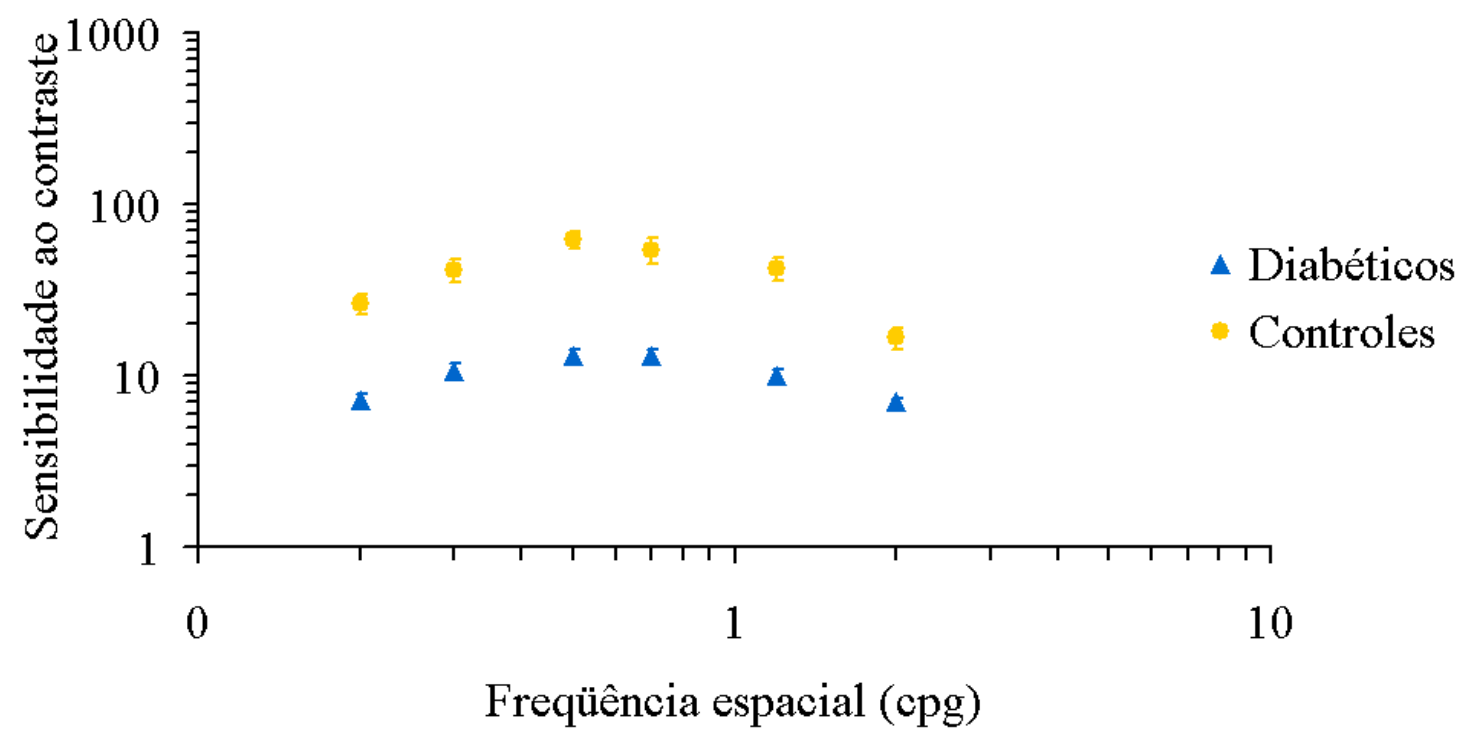

Figura 44: Sensibilidade ao contraste amarelo. Curvas determinadas pelos valores médios de pacientes e controles. As barras verticais representam \pm o erro padrão da média de cada grupo. 
Sensibilidade ao contraste de luminância -

Médias de pacientes e controles

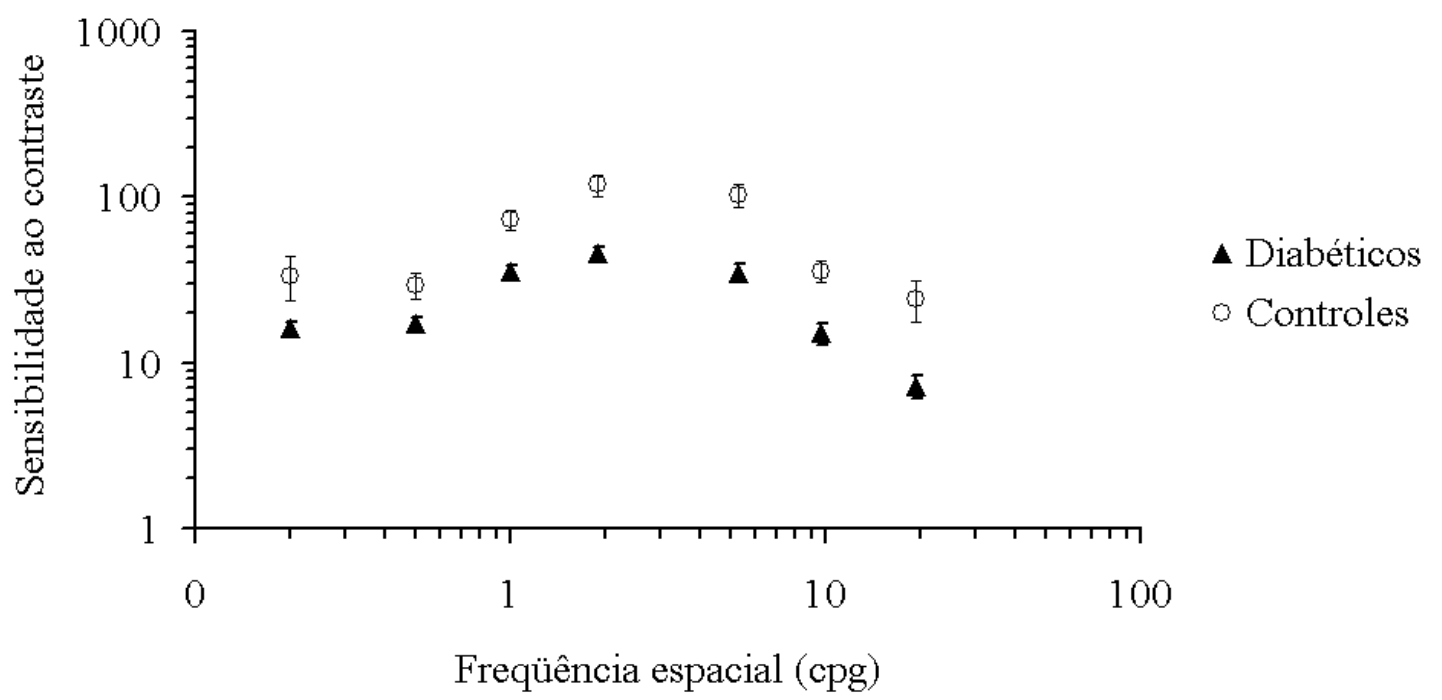

Figura 45: Sensibilidade ao contraste de luminância. Curvas determinadas pelos valores médios de pacientes e controles. As barras verticais representam $\pm \mathbf{0}$ erro padrão da média de cada grupo.

A confrontação dos resultados de CSF cromática dos pacientes com os limites normais mostrou que a quantidade de pacientes fora do normal foi ligeiramente menor nas freqüências espaciais mais baixas com exceção à freqüência de 0,2 cpg. É provável valor para a frequiência de $0,2 \mathrm{cpg}$ esteja superestimado devido a efeitos da luminância que ocorre para estímulos formados por menos que quatro períodos (Mullen, 1985).

Os gráficos das figuras 46 a 48 mostram a dispersão dos resultados individuais dos pacientes para cada série de estímulos e as respectivas faixas de normalidade. 
Sensibilidade ao contraste vermelho/verde -

Dados individuais dos pacientes e limites de normalidade

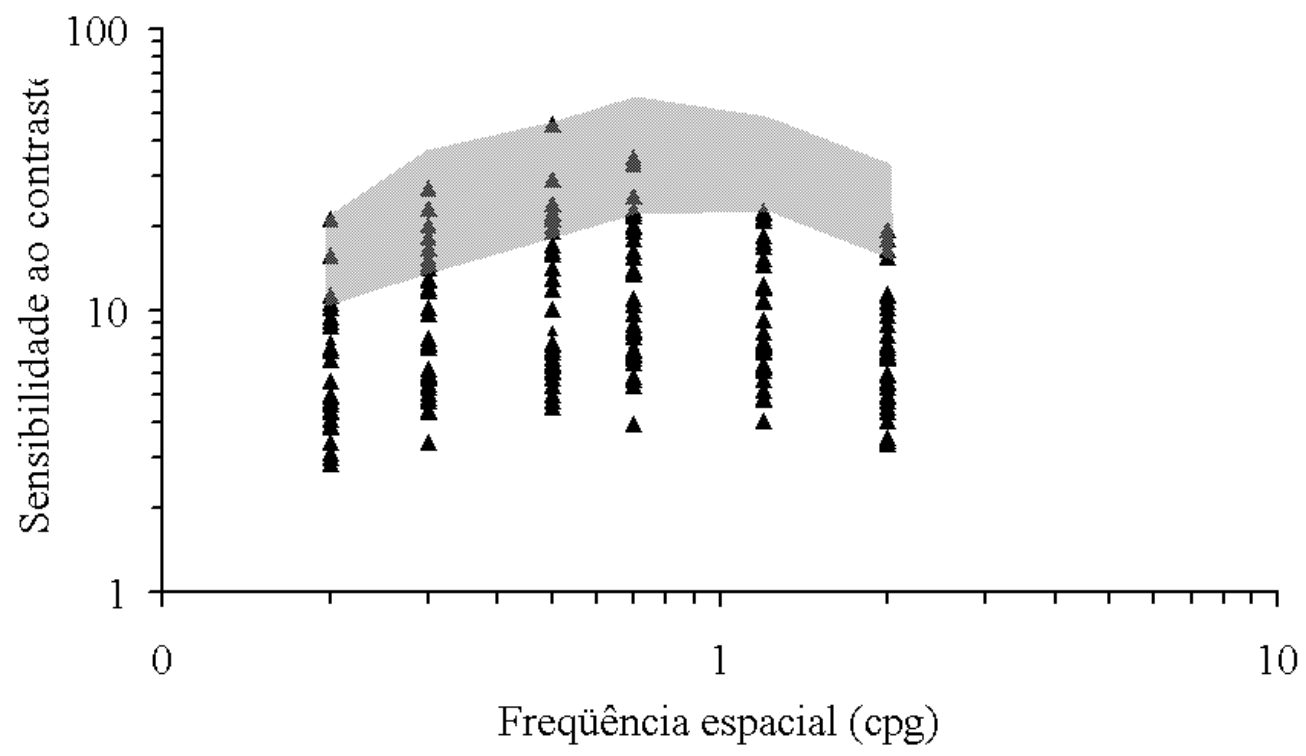

Figura 46: Sensibilidade ao contraste vermelho/verde. Dados individuais do grupo de pacientes. 


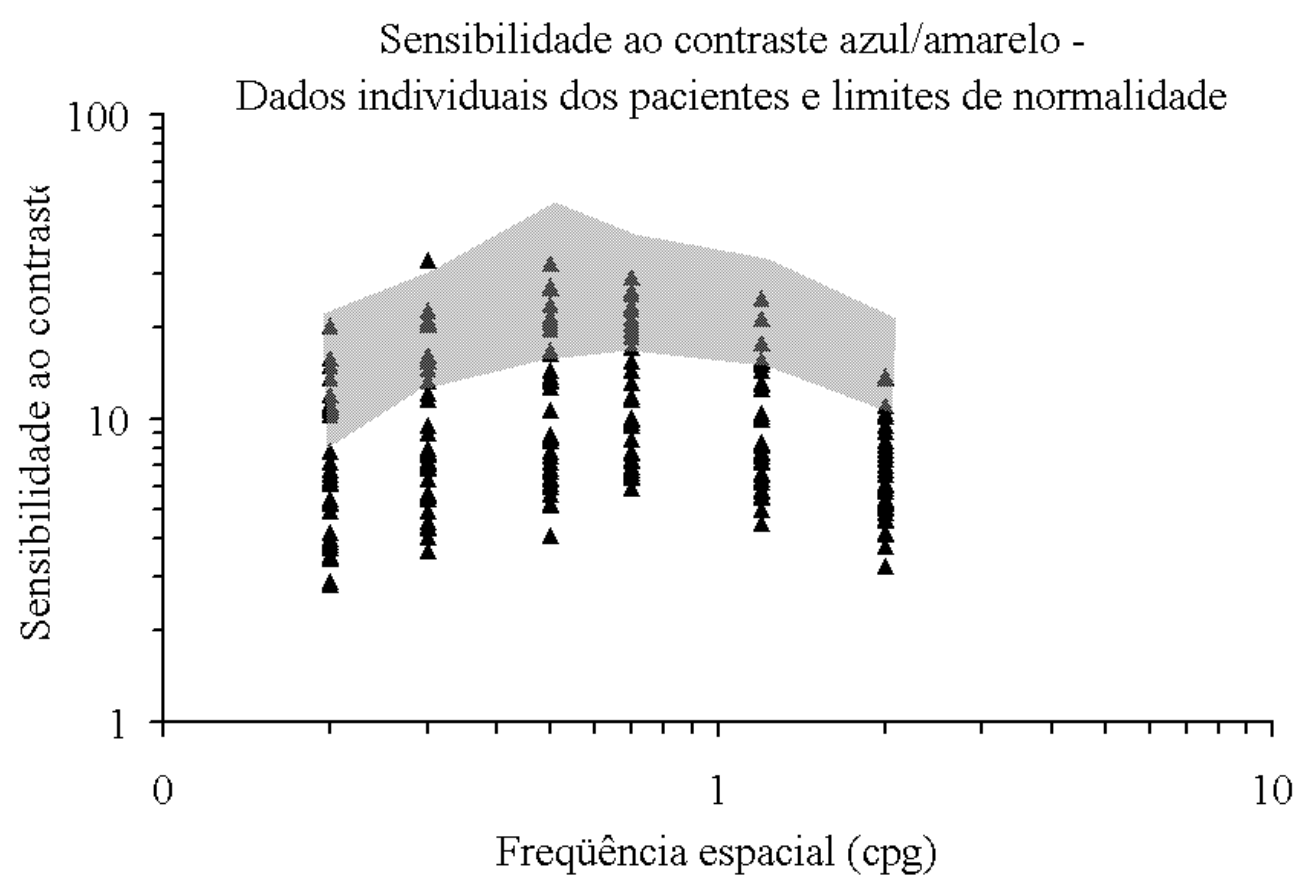

Figura 47: Sensibilidade ao contraste azul/amarelo. Dados individuais do grupo de pacientes. 
Sensibilidade ao contraste de luminância -

Dados individuais dos pacientes e limites de normalidade

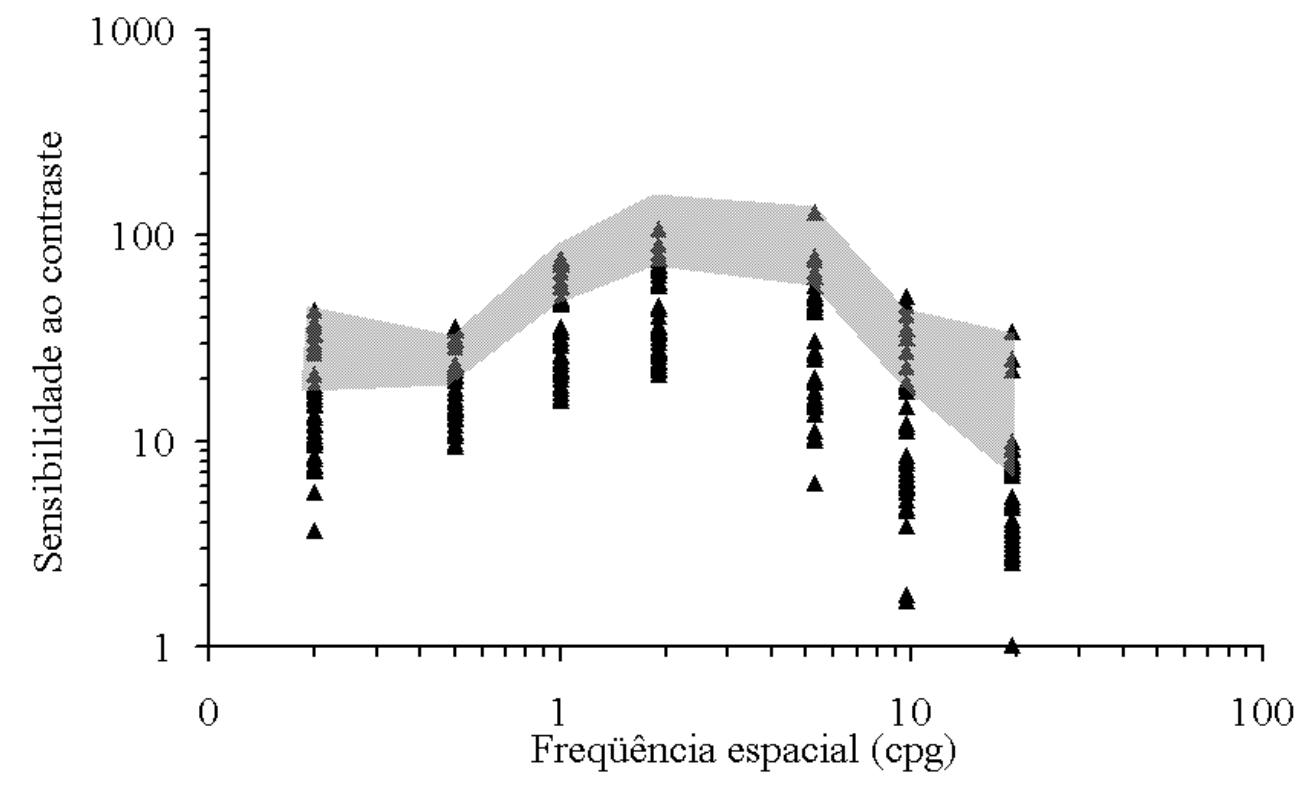

Figura 48: Sensibilidade ao contraste azul/amarelo. Dados individuais do grupo de pacientes.

A diferença entre os resultados dos pacientes e controles pode ser expressa sob a forma de uma razão entre os resultados de cada grupo, de forma que seja possível estabelecer uma relação de grandeza entre os resultados, ou seja, quantas vezes a sensibilidade de um grupo é maior ou menor que a outra. A seguir, são apresentadas as razoes entre os dados de sensibilidade ao contraste para cada série analisada.

Nas funções de sensibilidade a contrastes cromáticos, a diferença foi de aproximadamente $-10 \mathrm{~dB}$, enquanto que na sensibilidade ao contraste de luminância a diferença foi, em média, de -6 dB (figuras 49 a 51). 
Sensibilidade ao contraste vermelho/verde -

Diferença entre pacientes e controles

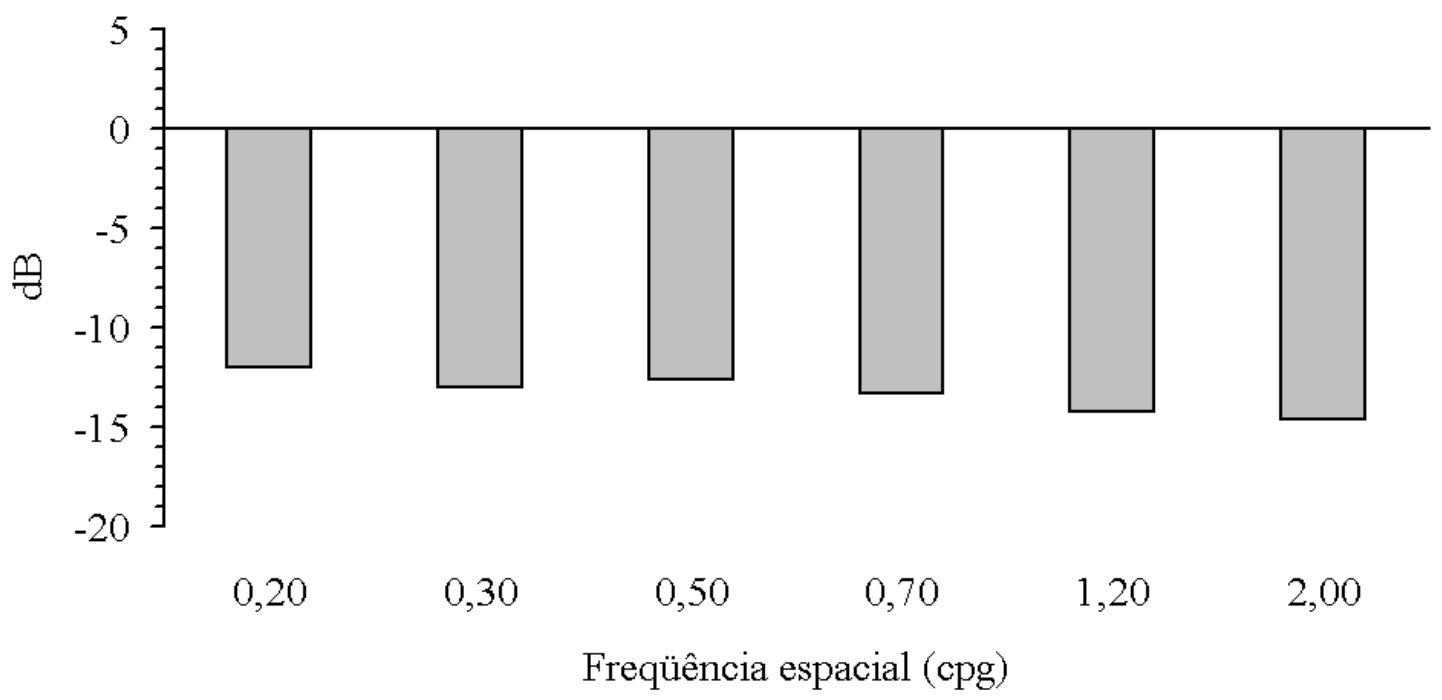

Figura 49: Sensibilidade ao contraste vermelho/verde. Diferença em dB entre as respostas médias de pacientes e controles. 
Sensibilidade ao contraste azul/amarelo -

Diferença entre pacientes e controles

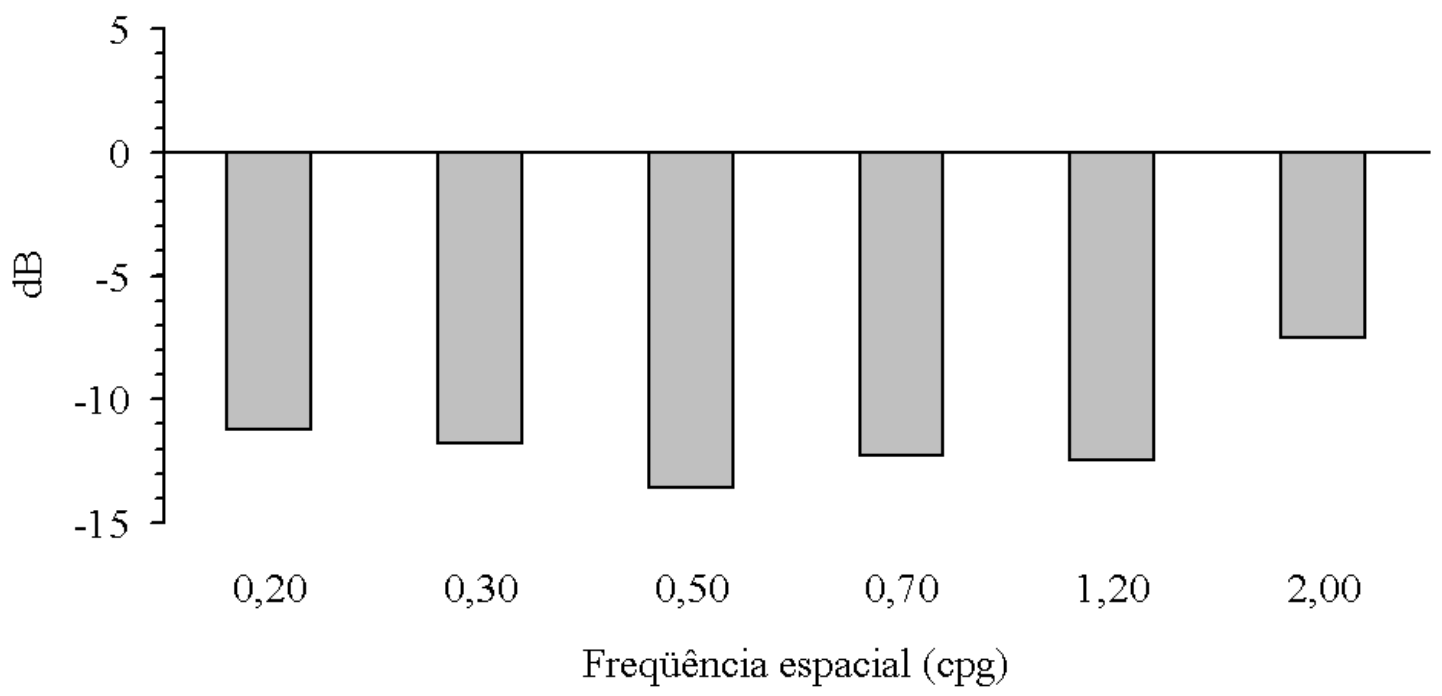

Figura 50: Sensibilidade ao contraste azul/amarelo. Diferença em $\mathrm{dB}$ entre as respostas médias de pacientes e controles. 
Sensibilidade ao contraste de luminância -

Diferença entre pacientes e controles

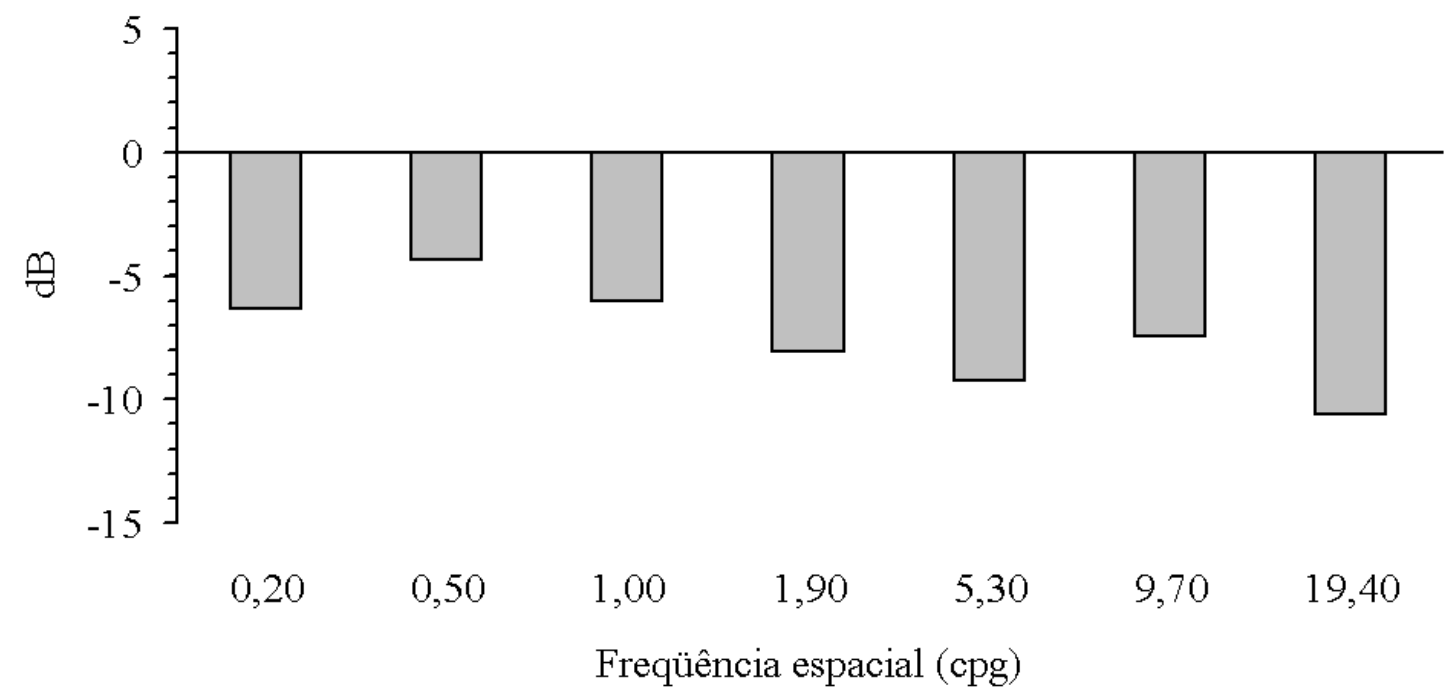

Figura 51: Sensibilidade ao contraste de luminância. Diferença em $\mathrm{dB}$ entre as respostas médias de pacientes e controles.

Em nenhuma série de teste de sensibilidade ao contraste foi encontrada correlação significante com os fatores de glicemia e tempo de diagnóstico. 


\section{DISCUSSÂO}

Déficits funcionais na visão de diabéticos sem alterações morfológicas no fundo de olho vêm sendo discutidos como fatores importantes que devem ser levados em consideração quando da escolha do melhor tratamento para os pacientes (Kurtenbach $e$ cols., 1999).

\subsection{VISÃO DE CORES}

Nossos resultados de visão de cores mostram que os pacientes diabéticos têm déficit da visão de cores em todos os eixos.

A comparação entre nossos grupos experimental e controle mostrou que proporcionalmente as perdas no eixo vermelho/verde são maiores que as perdas no eixo tritan, uma vez que as maiores proporções de resultados alterados são para os limiares protan e deutan do teste trivector e para as elipses 1, 2 e 3 cuja disposição no diagrama CIE favorece a discriminação mediada pelos cones $-\mathrm{M}$ e $-\mathrm{L}$.

Este resultado mostra claramente que as perdas não são devidas ao amarelecimento do cristalino.

O padrão de perda difuso da discriminação cromática com maior acometimento do eixo vermelho/verde que encontramos neste trabalho confirma os dados de alguns autores (Kurtenbach e cols., 1994; Trick e cols., 1988) e.vai contra a maioria dos trabalhos anteriores sobre este assunto. 
Daley e cols., mostraram através de testes com flicker cromático, redução da sensibilidade ao azul mesmo em pacientes adultos jovens e sem retinopatia diabética, (Daley e cols 1987).

Em um trabalho de avaliação histológica post-mortem de retinas humanas doadas por diabéticos e pessoas sem alterações na retina Cho e cols, 2000 estabeleceram densidades para as diferentes classes de cones em regiões centrais da retina $(0,1$ a 1,5mm de excentricidade a partir da fóvea em 360 graus). Seus resultados mostraram que a relação entre a densidade de cones-S contra $\mathrm{M}$ e L foi $21 \%$ menor nas retinas dos doadores diabéticos. A principal conclusão do trabalho é que embora não se conheça como ocorre, pode-se afirmar que realmente há morte seletiva dos cones-S em pessoas diabéticas.

Em 1982 e 1983, Zrenner (apud Kurtenbach e cols., 1994) mostrou que na diabete, a atividade dos canais iônicos de $\mathrm{Na}+$ e $\mathrm{K}+$ dos cones-S pode estar afetada, enquanto a dos outros dois tipos cones não estão.

Independentemente do eixo em que ocorram, os prejuízos na visão de cores podem ter conseqüências na vida prática do diabético, inclusive quanto ao próprio controle da doença. Pacientes diabéticos com deficiências na visão de cores podem ter dificuldade na leitura das faixas coloridas dos testes de glicose no sangue. Isto foi constatado em $50 \%$ dos casos de um estudo em que a avaliação da visão de cores era acompanhada da leitura das faixas coloridas para medida da glicemia (Mantyjarvi 1992). 


\subsection{SENSIBILIDADE AO CONTRASTE}

A sensibilidade a contrastes de nosso grupo experimental mostrou-se reduzida, sobretudo para contrastes cromáticos. Em média, a sensibilidade ao contraste dos pacientes foi cinco vezes menor que a dos controles quando foram usados estímulos cromáticos; e apenas duas vezes menor quando foram usados estímulos acromáticos.

Houve diferença significativa entre os dados de sensibilidade de pacientes e controles independente da freqüência espacial - alta ou baixa - ou do tipo de contraste do estímulo - cromático ou de luminância. A não seletividade para alguma faixa de freqüência espacial pode ter ocorrido porque talvez os estímulos usados no protocolo deste trabalho não sejam suficientemente robustos para isolar funções das diferentes vias de processamento; principalmente porque são estímulos relacionados estritamente ao domínio espacial e neste domínio tem-se mostrado que estímulos cromáticos e acromáticos compartilham mecanismos de resposta semelhantes, pelo menos em estágios de processamento que precedem o processamento cortical (Mullen e Beaudot, 2001).

Di Leo e cols., 1992 usaram metodologia bastante semelhante à do presente trabalho e discutiram a aplicação de testes psicofísicos e eletrofisiológicos para o acesso à função de sensibilidade ao contraste de forma a identificar se o prejuízo ocorre seletivamente nas células ganglionares tipo $\mathrm{P}$, que originam a via parvocelular ou nas células ganglionares do tipo $\mathrm{M}$ cujas fibras seguem para formar a via magnocelular. Nos resultados, a medida psicofísica da sensibilidade a contrastes de luminância não indicou perda acentuada para alguma faixa de freqüência espacial e, portanto, nenhum tipo de 
seletividade nas alterações, enquanto que as medidas eletrofisiológicas indicaram déficits atribuídos às células tipo $\mathrm{M}$.

\subsection{ELETRORRETINOGRAMA}

Com relação ao ERG, nossos resultados mostram que este é um método capaz de detectar alterações funcionais anteriores as alterações visíveis no exame fundoscópico clínico.

Aumento da latência de O1 no registro dos potenciais oscilatórios do ERG de campo total, assim como redução da amplitude e aumento da latência da onda b do ERG escotópico já foram reportados em trabalhos anteriores e têm sido consideradas as mais freqüentes em pacientes diabéticos (Greenstein e cols., 2000; Holopigian e cols., 1997, Scholl e Zrenner, 2000; Shirao e Kawasaki, 1998; Tzekov e Arden, 1999). Estes resultados indicam que as camadas internas da retina podem ser afetadas em maior escala ou mais precocemente, uma vez que a presença dos PO é atribuída principalmente à atividade das células amácrinas (Tzekov e Arden, 1999; Wachtmeister e cols., 1998), assim como o surgimento da onda b é atribuído à atividade das células de Muller e bipolares, na camada nuclear interna da retina (apud Brown, 1969). Tzekov afirma que anormalidades nestas respostas refletem deficiência da função vascular da retina, pois diferente dos fotorreceptores que são nutridos pelo epitélio pigmentado da retina, as camadas internas dependem da rede vascular do tecido.

Contudo, deve-se considerar a possibilidade de que estas alterações nos registros de atividades das camadas internas sejam um reflexo do déficit na função dos receptores. 
A fim de verificar o quanto alterações do ERG podem ser devidas a problemas nos receptores ou nas camadas pós-receptores. Holopigian e cols, em 1997, analisaram detalhadamente dados de latência da onda a que reflete atividade da retina externa, da onda $\mathrm{b}$ e de $\mathrm{O} 1$, em função da intensidade do estímulo; seus resultados mostraram que a maior parte das alterações eletrorretinográficas têm origem nos fotorreceptores, mas ainda assim em aproximadamente $30 \%$ dos pacientes os registros de onda b e PO correspondem a perdas exclusivamente das camadas pós-receptores.

Para se obter explicações acerca dos possíveis mecanismos de acometimento visual em estágios precoces da diabete têm-se buscado relações entre os dados de exames visuais e outros parâmetros como controle glicêmico, idade e tempo de diabete. A análise destes parâmetros tem tido resultados conflitantes.

Nenhuma correlação significativa entre os dados da avaliação visual e tempo de diagnóstico da patologia ou controle da glicemia foi encontrada no presente estudo, tanto para as medidas colhidas no dia do exame, ideais para a detecção de hipoglicemia aguda, quanto para a percentagem de hemoglobina glicosilada, ideal para a detecção de hiperglicemia crônica.

A ausência de correlação entre estes dados tem sido apresentada em diversos trabalhos (Trick e cols., 1988; Hardy e cols., 1992; Kurtenbach e cols., 1994). Em contrapartida, Deschênes e cols., 1998 mostram que esta correlação existe, e que sobretudo os períodos de hipoglicemia aguda se correlacionam com alterações funcionais da visão. Nossas medidas de glicemia no dia de exame foram feitas com a 
intenção de verificar essa relação entre hipoglicemia e acometimento visual, mas nenhum dos pacientes teve taxas de glicemia abaixo do mínimo normal: $70 \mathrm{mg} / \mathrm{dl}$.

\subsection{MECANISMOS ENVOLVIDOS}

A hipoxia do tecido retiniano tem sido apontada como a principal causa de redução de funções visuais em diabéticos inclusive em estágios que precedem alterações da retina detectáveis no exame oftalmológico clinico (Arden, 2001; Dean e cols., 1997; Fristrom, 1998; Harris e cols., 1996; Lovasik e Kergoat, 1993).

Lovasik e Kergoat, 1993 analisaram o ERG de pacientes diabéticos e controles sob condições normais e de inversão da posição corporal ou sucção da esclera como forma de simular alteração da perfusão ocular. O objetivo do trabalho foi saber como o ERG - especificamente os PO - pode ser influenciado pelos mecanismos fisiológicos de auto-regulação do tônus vascular responsáveis por manter constante o fluxo sanguíneo ocular quando a pressão de perfusão é alterada. Segundo os autores, estes mecanismos de regulação vascular da retina estão reconhecidamente prejudicados nos indivíduos diabéticos o que os torna susceptíveis à isquemia quando há alterações da circulação da retina. Em seus resultados, a soma das amplitudes dos PO dos pacientes submetidos ao estresse vascular foi significativamente menor que a amplitude dos controles na mesma situação. Assim, os autores concluíram que nos pacientes diabéticos a compensação de alterações do fluxo sanguíneo da retina não ocorre satisfatoriamente e que os PO são sensíveis a esta descompensação. 
Em um trabalho de 1996, Harris e cols. mostraram haver reversibilidade dos déficits na sensibilidade ao contraste de pacientes sem retinopatia ou com retinopatia leve. Neste trabalho, pacientes com diabete tipo 1 que apresentaram redução significativa da CSF quando examinados em situação normal tiveram sua sensibilidade ao contraste retomada a índices normais após a inspiração de oxigênio a 100\%, enquanto os controles não apresentaram mudanças em sua resposta.

No esquema da figura 52 estão algumas das possíveis vias de acometimento visual por diabete. Uma delas (Arden, 2001) aponta para uma hipótese vascular e a outra (Shirao e Kawasaki, 1998) aponta para uma hipótese neural.

Segundo Arden (2001), ramo à esquerda do diagrama, sob situações de hipoxia células de Müller que se tornam hiperfuncionantes, conseqüentemente há aumento da produção de fator de crescimento endotelial vascular (vascular endothelial growth factor, VEGF) por parte destas células. A produção de VEGF influencia diretamente a função vascular dos microvasos da retina interna onde estão localizados os receptores para o fator de crescimento.

Por outro lado, Shirao e Kawasaki (1998) à direita no esquema, mostram que uma das principais causas para as alterações detectadas em registros de PO do ERG e em medidas da CSF é o aumento da concentração de óxido nítrico na retina sob hipoxia (Goldstein, 1996 apud Shirao e Kawasaki, 1998), o que leva a um metabolismo anormal da dopamina. Como a dopamina é mediadora das sinapses das células amácrinas (Negishi e cols., 1989 apud Shirao e Kawasaki, 1998) esta é também uma provável via pela qual a função das células da retina interna são comprometidas. 
De modo geral, a magnitude das alterações não foi proporcional à duração da diabete, mostrando que talvez as alterações sensoriais e da função eletrofisiológica ocorram em função de algum mecanismo que se estabelece muito precocemente. Esta idéia é compatível com as afirmações de Arden e Shirao (2001) e (1998) cujos mecanismos de comprometimento propostos estão estabelecidos desde estágios iniciais da patologia.

\section{Hipóxia}
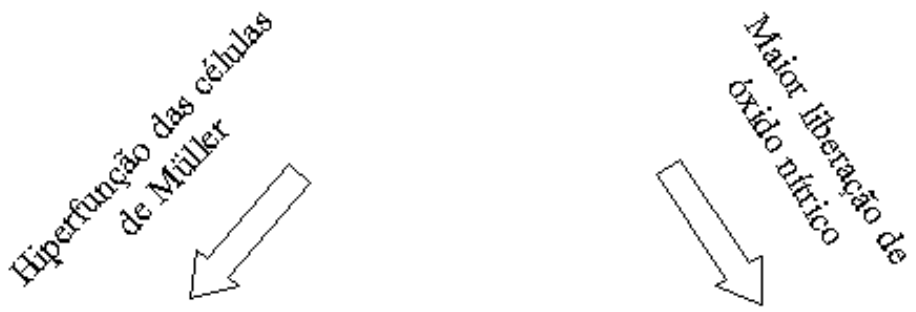

Presença de VEGF nos

Menor liberação de vasos da retina interna dopamina

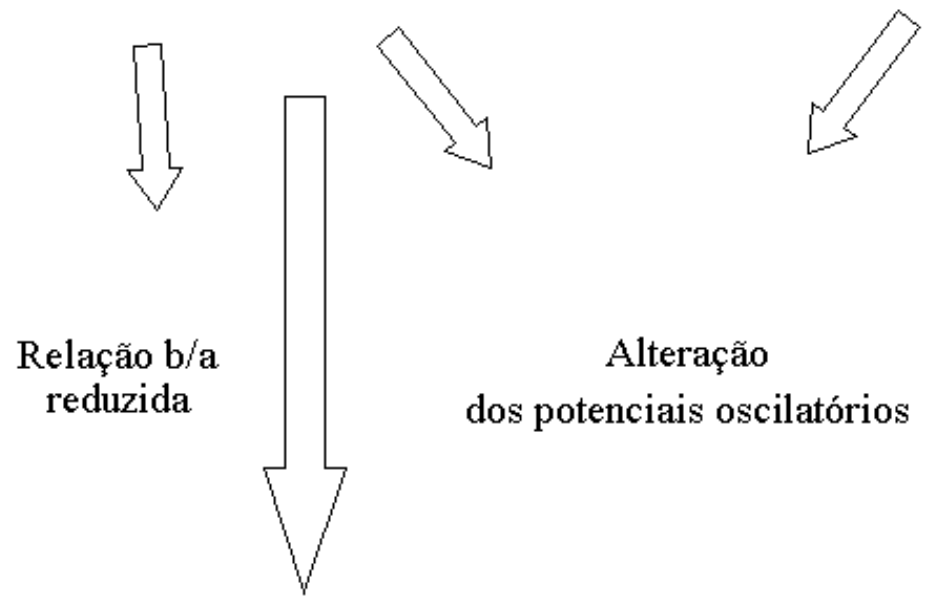

Alterações da visão de cores

$\mathrm{e}$ sensibilidade ao contraste 
Figura 52: Esquema de algumas possíveis vias envolvidas nos déficit funcional e sensorial.

Não é surpreendente notar que este esquema corresponde, de forma simplificada, ao ciclo de eventos relacionados ao desenvolvimento da retinopatia diabética. Este fato reforça a idéia de que os achados relatos no presente trabalho traduzem uma manifestação precoce dos processos patológicos que acabarão por incorrer na retinopatia diabética.

\subsection{SENSIBILIDADE DOS TESTES}

Comparando as maiores proporções de pacientes que tiveram resultados fora dos limites de normalidade em cada teste encontramos que o teste das elipses do CCT foi o parâmetro menos sensível para a detecção de respostas anormais enquanto as séries de CSF cromática foram as mais sensíveis, (figura 53). 
Proporcão de respostas anormais detectadas em cada teste

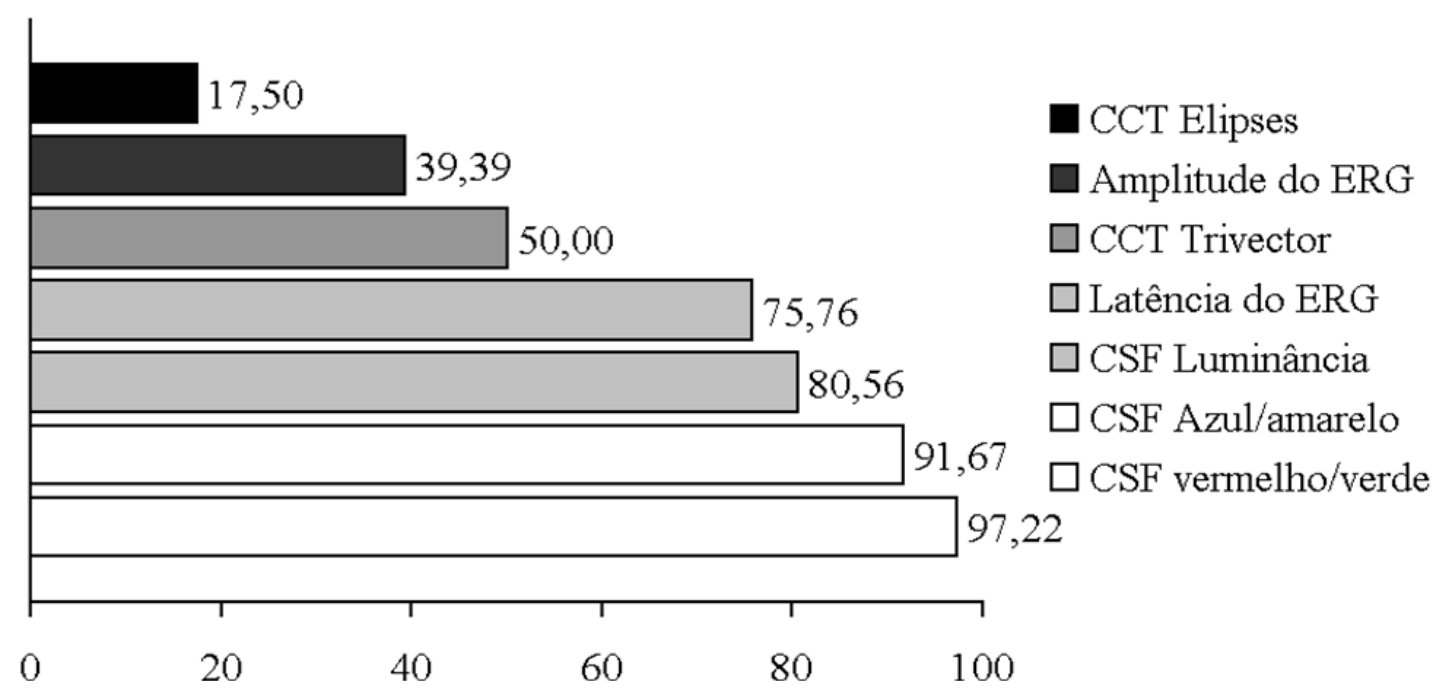

Figura 53: Quantidade de respostas alteradas em cada teste.

Este maior número de respostas anormais detectadas pelos testes de sensibilidade ao contraste não implica necessariamente em inespecificidade dos testes remanescentes, sobretudo do teste de determinação de elipses de discriminação cromática que apresentou uma proporção bem menor de pacientes afetados. Isto porque os parâmetros com os mais altos índices de anormalidade foram os de latência dos PO no ERG e de medida da CSF, justamente aqueles em que foi mostrada a presença de um componente transitório e reversível diretamente dependente dos níveis de $\mathrm{O}_{2}$ ou o status da função circulatória da retina (Dean e cols., 1997; Harris e cols., 1996; Lovasik e Kergoat, 1993). É possível, portanto, que nossos resultados de latência dos PO no ERG e de CSF estejam mostrando a somatória de alterações permanentes e reversíveis com inalação de $\mathrm{O}_{2}$, o que explicaria os altos números de respostas anormais. 
Enfim, os métodos usados neste trabalho indicam que provavelmente, tanto a retina quanto a via visual estão prejudicadas nestes pacientes. Ainda assim, é ideal que se busque e aplique métodos capazes de isolar tanto quanto possível as respostas da retina, distinguindo componentes de diferentes grupos celulares, e da via visual, isolando respostas de vias $\mathrm{M}, \mathrm{P}$ e $\mathrm{K}$ de forma que se possa conhecer em detalhes quais são os circuitos mais precocemente afetados e como isto ocorre em função do desenvolvimento da patologia, o que remete a outro ponto, colocado a seguir.

É importante saber o quanto alterações como as identificadas neste trabalho se relacionam com o agravamento do acometimento visual do paciente que se deflagra no estabelecimento da retinopatia diabética. Para tanto, é necessária a realização de trabalhos de avaliação longitudinal que relacionem alterações sensoriais, eletrofisiológicas funcionais e anatômicas da retina ao longo da evolução da doença. 


\section{CONCLUSÕES}

Pode-se concluir que nos pacientes com diabete tipo 2 sem retinopatia detectável no exame fundoscópico examinados:

- As funções de discriminação cromática, de sensibilidade a contrastes de luminância e a atividade elétrica da retina estavam alteradas;

- A discromatopsia foi difusa e maior no eixo protan que nos demais eixos.

- Houve redução da sensibilidade ao contraste cromático em magnitude maior que a para o contraste acromático, mostrando que os mecanismos de processamento de cores foram mais comprometidos que os de processamento de luminância.

- Houve alteração da função da retina, medida pelo ERG de campo total. Este exame mostrou diminuição da amplitude e aumento da latência da onda b nas respostas de bastonetes e nos potenciais oscilatórios, caracterizando comprometimento na atividade das células das células bipolares e da outros tipos celulares da retina interna. Houve também aumento na amplitude das respostas ao flicker de $30 \mathrm{~Hz}$. 


\section{REFERÊNCIAS BIBLIOGRÁFICAS}

Arden G. B. (2001) The absence of diabetic retinopathy in patients with retinitis pigmentosa: implications for pathophysiolgy and possible treatment. Bristish Journal of Ophthalmology 85 366-370.

Arden G. B., Gunduz K., Perry S. (1988). Colour vision testing with a computergraphics system; preliminary results. Documenta Ophthalmologica 69 167-174.

Banford D., North R. V., Dolben J., Butler G., Owens D.R. (1994). Longitudinal-Study of Visual Functions in Young Insulin- Dependent Diabetics. Ophthalmic and Physiological Optics 14 339-346.

Bangstad H. J., Brinchmann-Hansen O., Hultgren S., Dahl-Jorgensen K., Hanssen K. F. (1994). Impaired contrast sensitivity in adolescents and young Type 1 (insulindependent) diabetic patients with microalbuminuria. Acta Ophthalmologica 72-6 668-673.

Bear M. F., Connors B. W., Paradiso M. A. (2002). Neurociências. Desvendando o sistema nervoso. P. 309. ArtMed. Sào Paulo.

Bowmaker J. K., Dartnall H. J. (1980). Visual pigments of rods and cones in a human retina. Journal of Physiology 298 501-511.

Brown K. T. (1969). The Electroretinogram: its components and their origins. Vision Research 8 633-677. 
Cho N. C., Poulsen G. L., Ver Hoeve J. N., Nork T. M. (2000). Selective loss of Scones in diabetic retinopathy. Archives of Ophthalmology 118(10) 1393-400.

Crognale M. A., Kelly J. P., Weiss A. H., Teller D.Y. (1998). Development of the spatio-chromatic visual evoked potential (VEP): a longitudinal study. Vision Research 38 3283-3292.

Dean F. M., arden G. B., Dornhorst A. (1997). Partial reversal of protan and tritan colour defects with inhaled oxygen in insulin-dependent diabetic subjects. British Journal of Ophthalmology 81 27-30.

DeMarco P., Pokorny J., Smith V. C. (1992). Full spectrum cone sensitivity functions for X-chromosome-linked anomalous trichromats. Journal of the Optical Society of America A,9 1465-1476.

Deschênes M. C., Coupland S. G., Ross A. S., Fick G. H. (1998). Early macular dysfunction detected by focal electroretinographic recording in non-insulindependent diabetics without retinopathy. Documenta Ophthalmologica 94223 237.

DeValois R. L. (1965). Behavioral and electrophysiological studies of primate vision. In: Contributions to sensory physiology volume 1. Neff W. D (editor). Academic Press. New York.

Di Leo M. A. S., Caputo S., Falsini B., Porciatti V., Minnella A., Greco A. V., Ghirlanda G. (1992). Nonselective Loss of Contrast Sensitivity in Visual System Testing in Early Type I Diabetes. Diabetes Care 15-5 620-624.

Dixon W. J., Massey Jr. F. J. (1957). Introduction to statistical analysis. McGraw-Hill. New York. 
Doucet J., Moore N., Gancel A., Courtois H., Schrub J. C. (1991). Diabetic Dyschromatopsia - a Multifactorial Approach in 100 Diabetic-Patients. Diabetes \& Metabolism 17 31-37.

Enroth-Cugell C. (1993). The World of Retinal Ganglion Cells. In: Shapley., R. \& Lam D.M.(editores), Contrast Sensitivity. (pp. 149-179). Massachusetts: MIT Press.

Ewing F. M. E., Deary I. J., Strachan., W. J., Frier B. M. (1998). Seeing Beyond Retinopathy in Diabetes: Electrophysiological and Psychophysical Abnormalities and Alterations in Vision. Endocrine Reviews 19462 - 476.

Fong D. S., Barton F. B., Bresnick G. H. (1999). Impaired color vision associated with diabetic retinopathy: Early treatment diabetic retinopathy study report no. 15. American Journal of Ophthalmology 128 612-617.

Fristrom B. (1998). Peripheral and central colour contrast sensitivity in diabetes. Acta Ophthalmologica Scandinavia 76 541-545.

Greenstein V., Holopigian K., Hood D. C., Seiple W., Carr R. E. (2000). The Nature and Extent of Da retina Dysfunction Associated with Diabetic Macular Edema. Investigative Ophthalmology \& Visual Science 41-11 3643-3654.

Hardy K. J., Liptom J., Scase M. O., Foster D. H., Scarpello J. H. B. (1992). Detection of Color-Vision Abnormalities in Uncomplicated Type-1 Diabetic-Patients with Angiographically Normal Retinas. British Journal of Ophthalmology 76 461464. 
Harris A., Arend O., Danis R. P., Evans D., Wolf S., Martin B. J. (1996). Hyperoxia improves contrast sensitivity in early diabetic retinopathy. British Journal of Ophthalmology 80 209-213.

Holopigian K., Greenstein V. C., Seiple W., Hood D. C., Carr R. E. (1997). Evidence for photoreceptor changes in patients with diabetic retinopathy. Investigative Ophthalmology \& Visual Science 38 2355-2365.

Knapp A.G., Schiller P.H. (1984). The contribution of on-bipolar cells to the electroretinogram of rabbits and monkeys. Vision Research 24 1841-1846.

Knight R., Buck S. L. (2002). Time dependent changes of rod influence on hue perception. Vision Research 42 1651-1662.

Kurtenbach A., Wagner U., Neu A., Schiefer U., Ranke M. B., Zrenner E. (1994). Brightness Matching and Color Discrimination in Young Diabetics without Retinopathy. Vision Research 34 115-122.

Kurtenbach A., Schiefer U., Neu A., Zrenner E. (1999). Development of brightness batching and colour vision deficits in juvenile diabetics. Vision Research 39 1221-1229.

Lawrenson J. G. (2000). Histopathology and patogénesis of diabetic retinopathy. In: Diabetic eye disease: identification and co-management. Rudnicka A. R. e Birch J. (editors). Butterworth-Heinemann. Oxford.

Lieth E., Gardner T. W., Barber A. J. Antonetti D. A. (2000). Retinal neurodegeneration: early pathology in diabetes. Clinical and Experimental Ophthalmology 28 3-8. 
Lee, B. B. (2004). Paths to colour in the retina. Clinical and Experimental Optometry 87.

Lovasik J. V., Kergoat H. (1993). Electroretinographic Results and Ocular Vascular Perfusion in Type-1 Diabetes. Investigative Ophthalmology \& Visual Science 34 1731-1743.

Mac Leod D. I. A., Boynton R. M. (1979). Chromaticity diagram showing cone excitation by stimuli of equal luminance. Journal of the Optical Society of America A, 69 1183-1186.

Mantyjarvi. M. (1992). Screening of Diabetics Who Read Incorrectly Color-Dependent Glucose Test-Strips. Documenta Ophthalmologica 80 (4). 323-328.

Mollon J. D. (1982). The anomalies of the blue mechanism. In: The senses (Cambridge texts in the psychological sciences: 3). Barlow H. B. e Mollon J. D. (editors), Cambridge University Press 176-179.

Mollon J. D., Reffin J. P (1989). A computer-controlled colour vision test that combines the principles of Chibret and Stilling. Journal of Physiology 414 5p.

Mullen K. T. (1985). The contrast sensitivity of human colour vision to red-green and blue-yellow chromatic gratings. Journal of Physiology 359 381-400.

Mullen K. T.; Beaudot W. H. A. (2001). Comparison of color and luminance vision on a global shape discrimination task. Vision Research 42 565-575. 
Nakajima Y., Iwakabe H., Akazawa C. (1993). Molecular characterization of a novel retinal metabotropic glutamate receptor mGluR6 with a high agonist selectivity for L-2-amino-phosphonobutyrate. Journal of Biological Chemistry 268 1186811873.

North R. V., Farrell U., Banford D., Jones C., Gregory J. W., Butler G., Owens D. R (1997). Visual function in young IDDM patients over 8 years of age - A 4-year longitudinal study. Diabetes Care 20 1724-1730.

Papakostopoulos D., Hart J. C. D., Corrall R. J. M., Harney B. (1996). The scotopic electroretinogram to blue flashes and pattern reversal visual evoked potentials in insulin dependent diabetes. International Journal of Psychophysiology 21 33-43.

Paranhos F. R. L., Ávila M. P., Paranhos A. Cialdini A. P. (1997). Estudo estatístico de valores normais do eletrorretinograma. Contribuição à padronização do exame. Arquivos Brasileiros de Oftalmologia 60 280-283.

Pereira J. M., Mendieta L., Sacai P. Y., Salomão S. R., Berezovsky A. (2003). Estudo normativo do eletrorretinograma de campo total em adultos jovens. Arquivos Brasileiros de Oftalmologia 66 137-144.

Pokorny J., Smith V. C., Verriest G., Pinckers A. J. L. G. (1979). Congenital and acquired color vision defects Vol. 66. Grune \& Stratton. New York.

Reitner A., Sharpe L. T., Zrenner E.. (1991). Is colour vision possible with only rods and blue-sensitive cones? Nature 352 798-800.

Rushton W. A. H. (1965). Bleached rhodopsin and visual adaptation. Journal of Physiology 181 645-655. 
Rushton W. A. H. (1972). Visual pigments in man. In: HJA Dartnall (editor). Handbook of Sensory Physiology, volume VII/1: Photochemistry of vision 364-394). New York: Springer Verlag.

Rushton W. A. H., Powell D. S., White K. D. (1973). Exchange thresholds in dichromats. Vision Research 13 1993-2002.

Scholl H. P. N., Zrenner E. (2000). Electrophysiology in the Investigation of Acquired Da retina Disorders. Survey of Ophthalmology 45 29-47.

Schwartz S. H. (2004). Visual perception: a clinical orientation. McGraw-Hill. New York.

Shirao Y., Kawasaki K. (1998). Electrical Response from Diabetic Retina. Progress in Retina and Eye Research 17 59-76.

Smith V. C., Pokorny J., Zaidi Q. (1983). How do sets of Color-Matching Functions differ? In: Colour Vision: Physiology and Psychophysics. Mollon J. D. e Sharpe L. T. (editores), London: Academic Press.

Summers K., Cronin T. W., Kennedy T. (2003). Variation in spectral reflectance among populations of Dendrobates pumilio, the strawberry poison frog, in the Bocas del Toro Archipelago, Panama. Journal of Biogeography 30 35-53.

Swanson W. H. (1989). Color Vision - Assessment and Clinical Relevance. Ophthalmology Clinics of North America 2 391-413.

Tregear S. J., Knowles P. J., Ripley L. G., Casswell A. G. (1997). Chromatic-contrast threshold impairment in diabetes. Eye 11 537-546. 
Trick G. L., Burde R. M., Gordon M. O., Santiago J. V., Kilo C. (1988). The relationship between hue discrimination and contrast sensitivity deficits in patients with diabetes mellitus. Ophthalmology 95-5 693-698.

Tzekov R., Arden G. B. (1999). The Electroretinogram in Diabetic Retinopathy. Survey of Ophthalmology 44 53-60.

Ventura D. F., Zana Y., Souza J. M. De Voe R. D. (2001). Ultraviolet color opponency in the turtle retina. Journal of Experimental Biology 204 2527-2534.

Ventura D. F., Nishi M., Bernicki M., Costa M. F., Bonci D., Gualtieri M., Souza J. M. (2003a). Early vision loss in diabetic patients assessed by the Cambridge Colour Test. In: Normal and Defective Color Vision. Mollon J. D., Pokorny J. e Knoblauch K. (editors). Oxford University Press 395-403.

Ventura D. F., Silveira L. C. L., Rodrigues A. R., Souza J. M.., Gualtieri M., Bonci D., Costa M. F. (2003b). Preliminary norms for the Cambridge Colour Test. In: Normal and Defective Color Vision. Mollon J. D., Pokorny J. e Knoblauch K. (editors). Oxford University Press 331-339.

Ventura D. F., Simões A. L., Tomaz S., Costa M.F., Lago M., Costa M.T.V., CantoPereira L.H.M., de Souza J.M., Faria M.A.M., Silveira L.C.L. (no prelo). Color vision and contrast sensitivity losses of mercury intoxicated industry workers in Brazil. Environmental Toxicology and Pharmacology.

Wachtmeister L. (1998). Oscillatory Potentials in the Retina: What do they Reveal. Progress in Retina and Eye Research 14-4 485-521. 

ANEXOS 


\section{ANEXO A}

Carta confirmando a aprovação do projeto nos Comitês de Ética em Pesquisa do HUUSP e IP-USP 
XEROX 


\begin{abstract}
ANEXO B
Autorização para a convocação de voluntários emitida pelo Conselho Consultivo da Universidade Aberta à Terceira Idade
\end{abstract}


XEROX 


\section{ANEXO C}

Modelo da ficha de anamnese aplicada 


\section{Universidade de São Paulo}

Instituto de Psicologia

Depto. de Psicologia Experimental

Setor de Psicofísica e Eletrofisiologia Visual Clínica

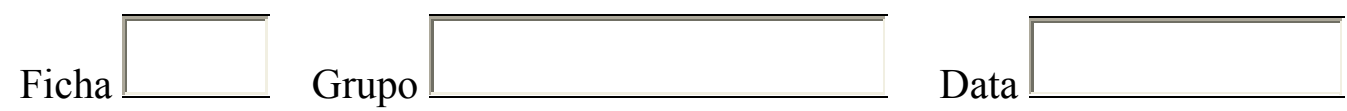

Nome
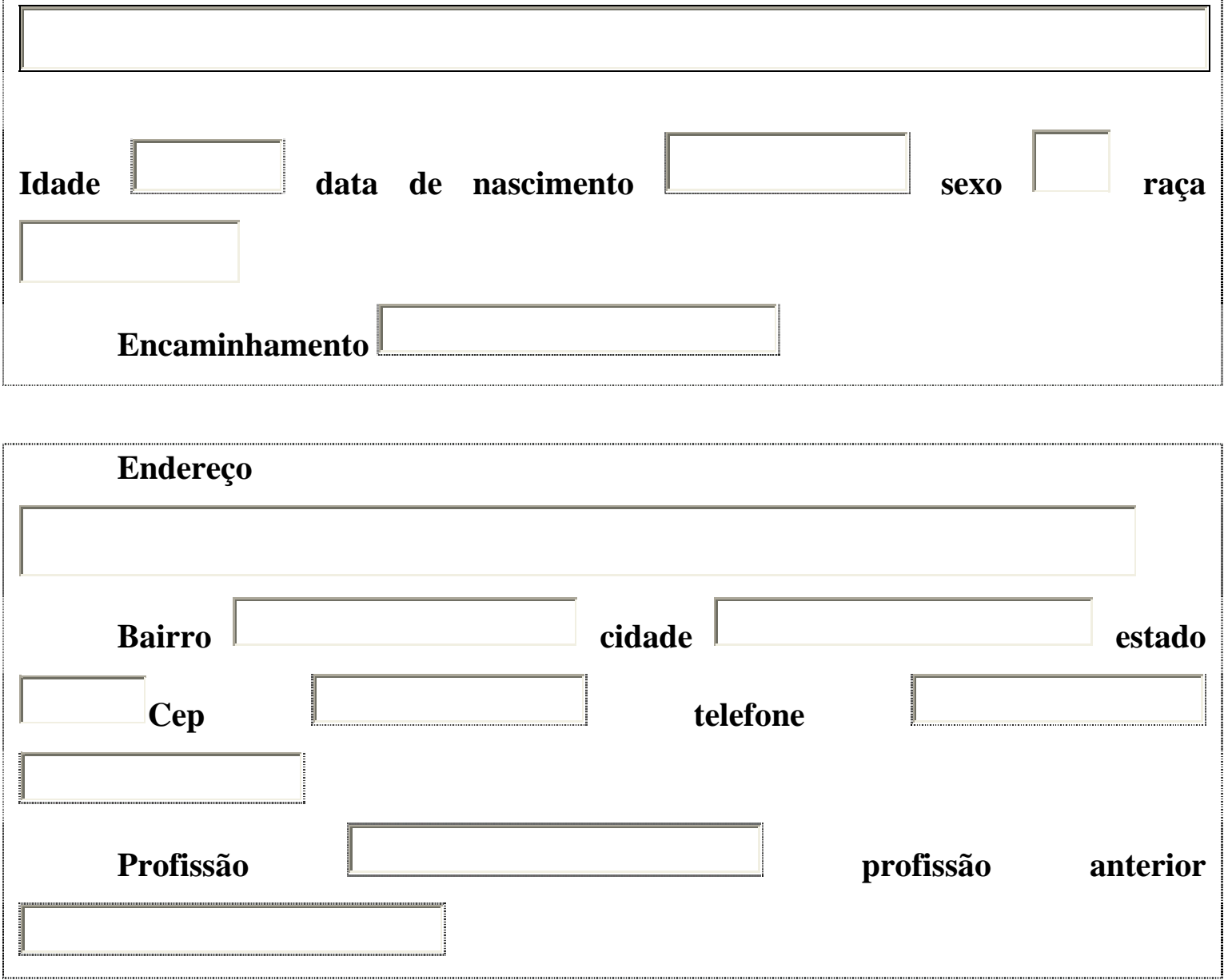

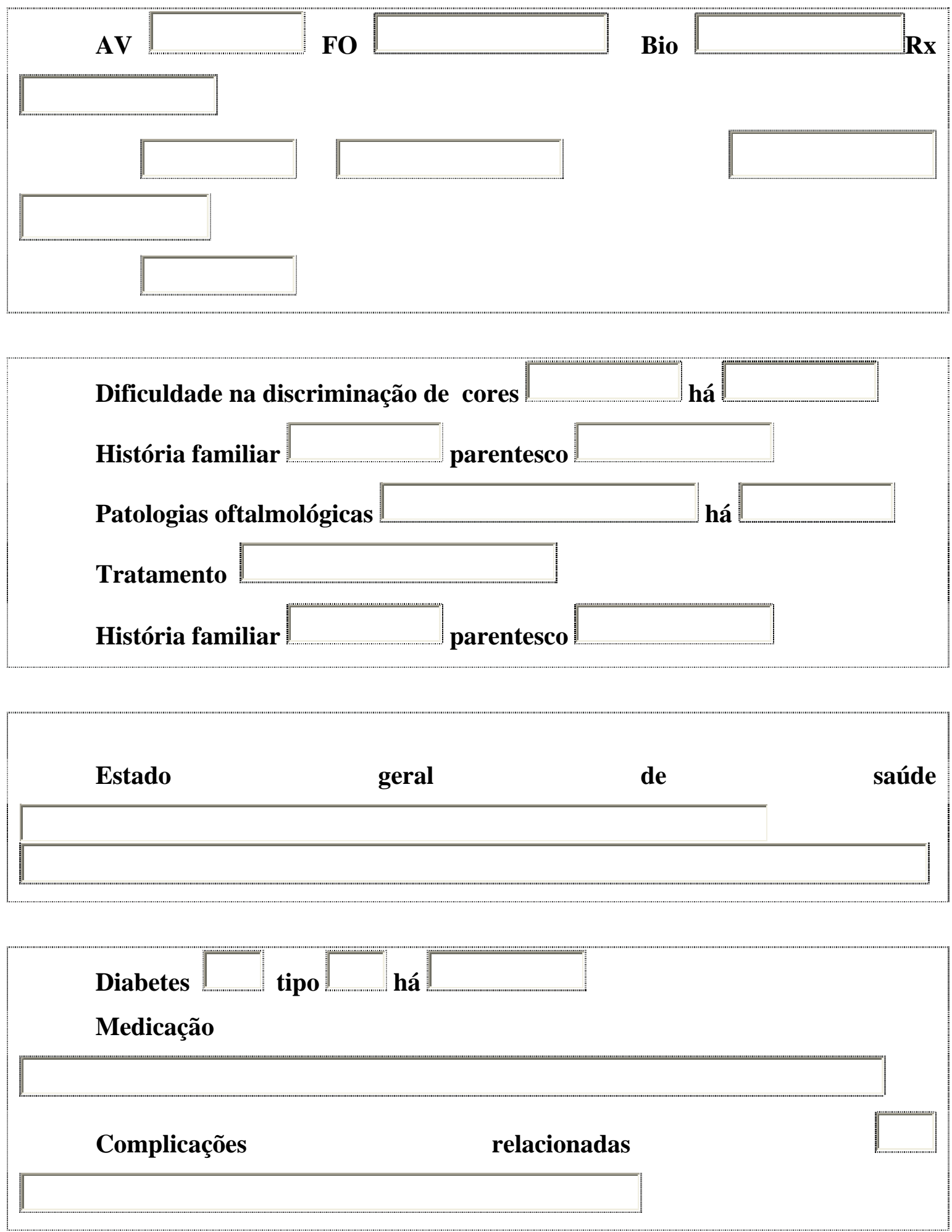


\begin{tabular}{|lll|}
\hline Histórico & familiar \\
\hline &
\end{tabular}
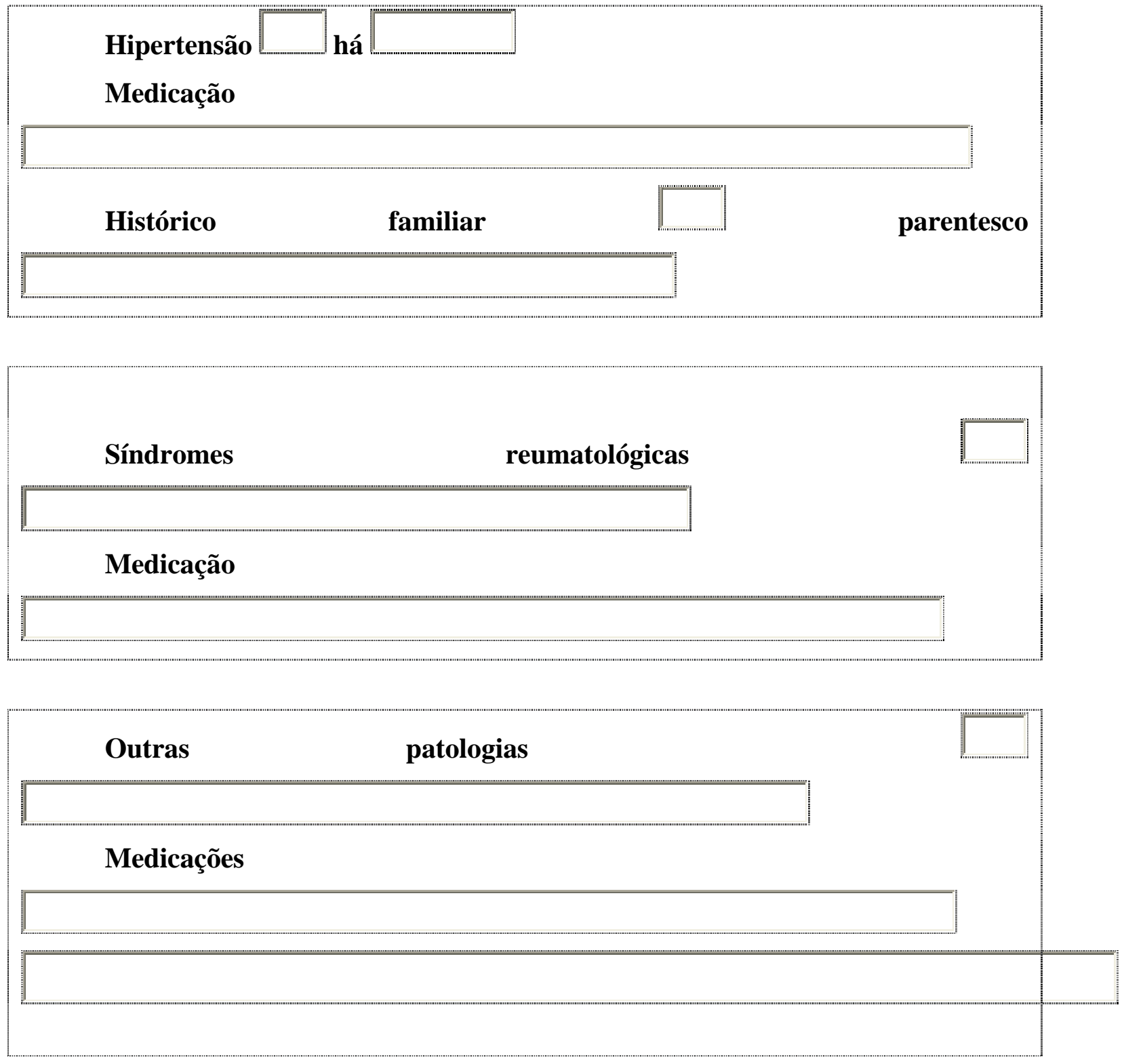

Trauma craniano $\square$ há

Tratamento neurológico $\square$ há 


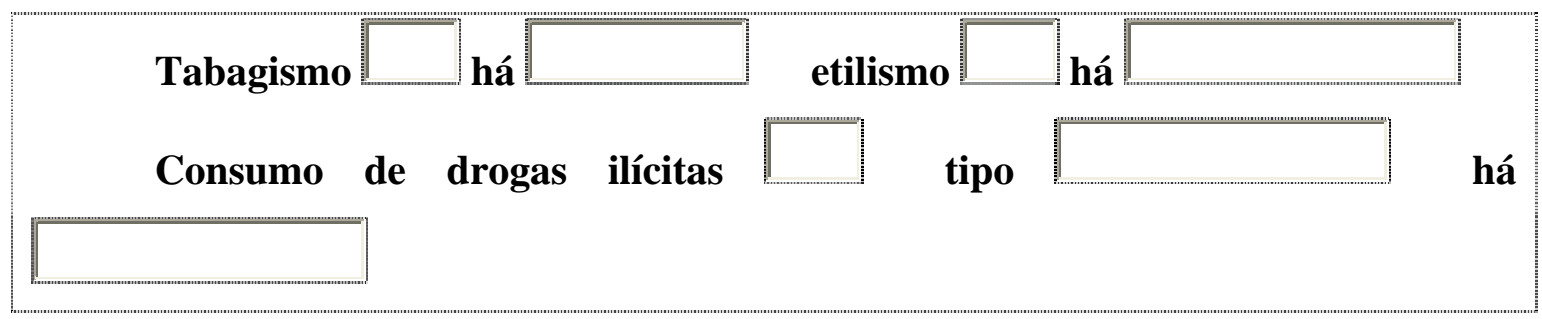

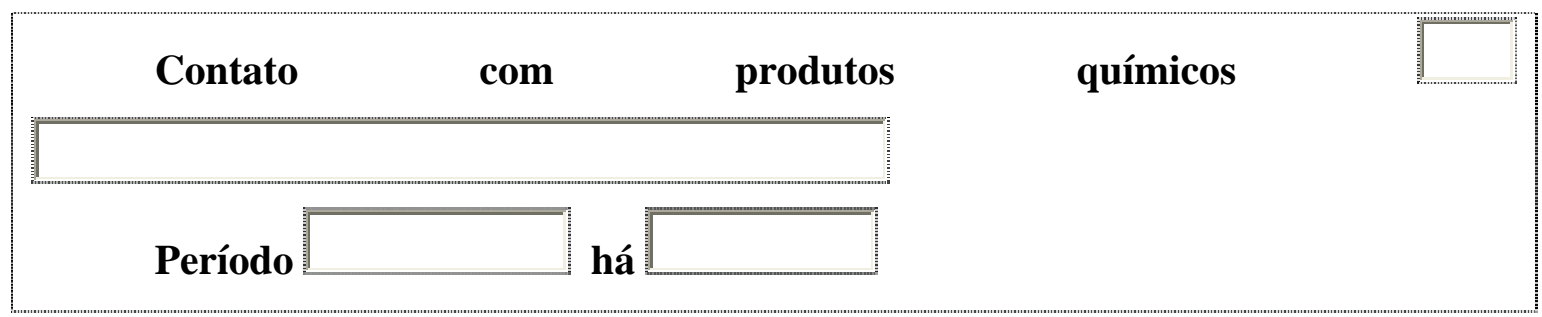

Gravidez no período de doença/exposição

Abortos no período de doença/exposição $\square$

Número de filhos no período de doença/exposição

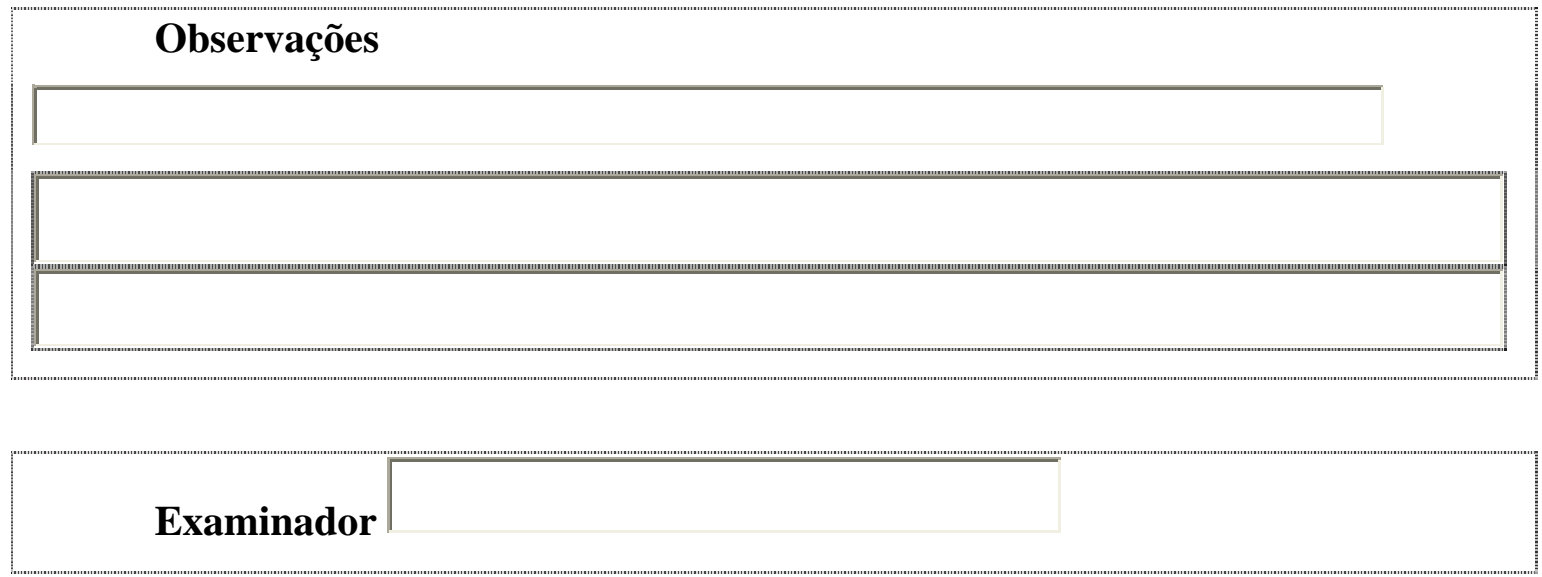




\section{ANEXO D}

Termo de consentimento livre e esclarecido 


\section{Estudo da Visão de Cores em Pacientes Diabéticos}

Pesquisadores: Mirella Gualtieri, Mauro Nishi, Dora Fix Ventura.

Você está sendo convidado(a) a participar de uma pesquisa que estuda a visão de cores em diabéticos. $\mathrm{O}$ estudo é baseado no resultado de dois exames.

$\mathrm{O}$ primeiro exame usa uma tela de computador que apresenta uma letra colorida e um controle para você informar a posição da figura mostrada.

O segundo usa uma cúpula, você estará sentado em frente a ela e serão emitidos flashes de luz. As respostas do seu olho à luz serão captadas por um eletrodo como se fosse uma lente de contato. Para esse exame são necessárias a dilatação das pupilas e a anestesia da córnea com uso de colírios.

Serão examinados os dois olhos separadamente, usando um tampão adesivo antialérgico. Os exames não são invasivos e não oferecem qualquer risco de dano físico.

Será feita também uma medida da taxa de glicose no sangue no dia de sua avaliação. O procedimento é simples. Perfura-se superficialmente um dos dedos da mão, usando material limpo e descartável obtém-se uma gota de sangue.

Os resultados serão sigilosos e seu nome não será divulgado. Apenas os números de dados poderão ser divulgados em publicações científicas.

Sendo sujeito voluntário para este estudo:

- Você fica livre para esclarecer suas dúvidas sobre qualquer aspecto deste estudo e também para retirar sua participação a qualquer momento. A participação no estudo é totalmente voluntária.

- Você poderá tomar conhecimento dos resultados obtidos ao final da pesquisa, se desejar.

Caso seja detectada qualquer alteração da visão de cores ou atividade da retina, será fornecido relatório detalhado e será dada orientação quanto à necessidade de procurar acompanhamento médico. 
Após ter lido as informações acima (ou alguém ter lido para você), estou ciente de que o estudo será útil para a descrição das possíveis alterações da visão de cores causadas pela diabete e autorizo a utilização de meus resultados para pesquisa.

Nome

( ) paciente ( )esponsável/grau

Documento de identidade $\mathrm{N}^{\circ}$

Endereço

$\mathrm{CPF} \mathrm{N}^{\mathrm{o}}$

São Paulo, de

de

Assinatura do paciente/responsável

Assinatura do pesquisador 


\begin{abstract}
ANEXO E
Instrução prévia dada ao sujeito submetido ao Cambridge Colour Test
\end{abstract}




\section{INSTRUÇÃO AO PACIENTE}

"Você pode ver o padrão de pontos na tela? Neste teste você verá figuras um de anel com uma abertura que pode estar no lado de cima, de baixo, direito ou esquerdo. A abertura dela está virada para (lado que estiver). Sua tarefa é apertar na caixa de resposta o botão correspondente à posição da abertura. Neste caso, por exemplo, você deveria apertar o botão (lado que estiver). Conforme o teste avança o computador faz com que o anel fique mais difícil de ver. A cor do anel ficará cada vez mais parecida com a cor do fundo até um ponto em que você não conseguirá mais ver o anelou a sua abertura. Quando isso acontecer não aperte nenhum botão; em pouco tempo aparecerá uma outra figura. Você entendeu o que deve fazer? Então comece apertando o botão que você acha certo para este anel". 


\begin{abstract}
ANEXO F
Instrução prévia dada ao sujeito submetido ao teste de Fotometria por Flicker heterocromático
\end{abstract}




\section{INSTRUÇÃO AO PACIENTE}

"Você pode ver o padrão de listras na tela? Elas estão piscando, percebe? Sua tarefa é olhar com atenção e me dizer quando as listras deixam de piscar. Avise quando tiver certeza de que elas estão paradas. Se você achar que elas não param em nenhum momento, tente perceber qual o ponto em que elas piscam menos e me avise. Assim que você me avisar aparecerá uma outra figura e faremos da mesma forma. Você entendeu o que deve fazer?. 


\section{ANEXO G \\ Instrução prévia dada ao sujeito submetido ao teste de medida da Função de Sensibilidade ao Contraste}




\section{INSTRUÇÃO AO PACIENTE}

"Você pode ver o padrão de listras no centro da tela? Elas agora têm cores fortes, percebe? Com o passar do tempo, as cores das listras ficarão cada vez mais claras até um ponto em que você deixará de vê-las. O centro e as bordas da tela ficarão iguais. Assim que isto acontecer você deve me avisar. A partir daí as cores voltarão a aparecer lentamente, quando você for capaz de perceber as listras novamente (mesmo que as cores ainda estejam muito fracas) você deve me avisar novamente. Esse procedimento será feito várias vezes e você deverá agir da mesma forma. Podemos começar?”. 